\title{
Malaria dynamics with long latent period in hosts
}

\author{
by \\ Kyeongah Nah \\ Supervisor: \\ Gergely Röst, Ph.D.
}

A thesis submitted for the degree of Doctor of Philosophy

\author{
in the \\ Bolyai Institute \\ Doctoral School in Mathematics and Computer Science
}

June 2015 


\section{Acknowledgements}

I would like to express my deep appreciation to my $\mathrm{PhD}$ supervisor, Dr. Gergely Röst, for patient guidance during the past four years. His close supervision and insightful comments were critical in the research presented on the thesis.

I would also like to thank my coauthors for allowing our published work to be in my thesis. I am fortunate to have had the opportunity to work with them.

I am also indebted to Dr. Attila Dénes by translating the summary part to Hungarian. I am also grateful to my MSc advisor, Dr. Yongkuk Kim, for introducing me to the mathematical biology, especially to the modeling of $P$. vivax.

Special thanks to the EPIDELAY reasearch group, members of Bolyai Institute, and neighbors in Eötvös dormitory. Without their kind support I would not have been able to finish the $\mathrm{PhD}$.

I acknowledge the financial support of the International Institute for Applied Systems Analysis (IIASA) and European Research Council Starting Investigator Grant No. 259559. 


\section{Contents}

Acknowledgements $\quad$ i

1 Introduction 1

$2 \quad P$. vivax transmission with long latent period $\quad 6$

2.1 Modeling efforts on the spread of malaria . . . . . . . . . . . . 6

2.2 Study on $P$. vivax models without seasonality . . . . . . . . . . . . . 9

2.2.1 ODE model with exponentially distributed incubation periods . . . 13

2.2.2 DDE model with fixed length of latency . . . . . . . . . . . . . 18

2.2.3 Comparison of ODE and DDE models . . . . . . . . . . . . 23

2.2.4 Global dynamics of DDE model . . . . . . . . . . . . . . . . . . . 27

2.3 Study on $P$. vivax models with seasonality . . . . . . . . . . . . . . . . . . 46

2.4 Implication of the results . . . . . . . . . . . . . 50

3 Latent period as an adaptation strategy to seasonal forcing $\quad \mathbf{5 4}$

3.1 Motivation of the study . . . . . . . . . . . . . . 54

3.2 Introduction to adaptive dynamics . . . . . . . . . . . . . 55

3.3 Classic SLIS model with seasonality . . . . . . . . . . . . . . 58

3.3 .1 Model description . . . . . . . . . . . . . . . . . 58

3.3.2 The basic reproduction number in seasonal environment . . . . . 65

3.4 Evolutionary model with seasonality . . . . . . . . . . . . . 66

3.4.1 Resident-mutant system . . . . . . . . . . . . . . . . 69

3.4.2 Dependence of CSS on the on-season length . . . . . . . . . . 70

3.4.3 The road to frequency dependent selection . . . . . . . . . . . 70

3.4.4 Coexistence and the evolutionary state of dimorphism . . . . . . 72

3.5 Robustness of results . . . . . . . . . . . . . . . . . 76

3.6 Interpretation of the results $\ldots \ldots \ldots \ldots$

4 Study of $\dot{x}(t)=-a(t) x(t)+b(t) x(t-1) \quad \mathbf{7 9}$

4.1 Motivation of the study . . . . . . . . . . . . . . . . . 79

4.2 Stability theorem . . . . . . . . . . . . . . . . 81

4.3 Case of $r$ not being a stability threshold . . . . . . . . . . . . . . . . . . . . . . 84

4.4 Implication of the results $\ldots \ldots \ldots \ldots$. . . . . . . 87

$\begin{array}{llr}5 & \text { Summary } & 89\end{array}$

6 Összefoglalás $\quad 93$ 
Bibliography 


\section{Chapter 1}

\section{Introduction}

Many European countries were endemic of malaria for many centuries. Hungary was one of them until 1963 [67]. Medical reports of János Bolyai (1802-1860) show that he also suffered from malaria. Enormous progress in the understanding of malaria was made in the first half of the 20th century, which led to the successful control in many countries [7]. The cause of malaria, a single-celled parasite named Plasmodium, was discovered in 1889. It was only in 1897 when it was confirmed that the parasites are transmitted by mosquitoes. By this finding, the medical doctor Ronald Ross received the Nobel Prize in Medicine [32].

Ross further translated the parasitological research to preventive action. Constructing deterministic differential equations describing the spread of malaria between human and mosquito populations, he deduced that malaria can be controlled by reducing the mosquito density below a critical level. His work is regarded as introducing the concept of threshold dynamics in disease transmission models [8]. His model also provided the formula of the infected human population at equilibrium, expressed by epidemiological parameters. The human endemicity is observed to increase with respect to the number of mosquitoes, but its change becomes relatively smaller as mosquito population increases. This could be a reason why it was hard to relate malaria to mosquitoes [4].

The analytical framework of Ross is still being applied to understand the epidemiology of vector-borne diseases and target interventions. The threshold widely used in current epidemiological models is the basic reproduction number, denoted by $R_{0}$, which is defined as the average number of secondary infections produced by a single infection in a completely susceptible population. For many deterministic models, $R_{0}$ is the threshold quantity that determines when an infection can invade and persist in a new host population [24]. In those cases, $R_{0}>1$ implies the instability of the disease-free state and the invasion of the host population by the disease, while $R_{0}<1$ implies the stability of 
the disease-free state and hence invasion is not possible. From the magnitude of $R_{0}$ we can determine the amount of effort which is necessary either to prevent an epidemic or to eliminate an infection from a population [16]. The threshold of a critical mosquito population that Ross deduced corresponds to $R_{0}=1$ in present-day terms.

Though the eradication program in the middle of the 20th century was successful in many regions of the world, a hundred of countries or territories are still at risk of malaria [74]. Among four species of Plasmodium recognized to infect humans, Plasmodium falciparum and Plasmodium vivax are the two major species imposing a heavy economic burden on endemic countries. The majority of the studies to date have focused on P. falciparum, which causes severe malaria in tropical and subtropical areas. There are several hundreds of research publications using mathematical models to investigate various aspects, such as immunity, spatiotemporal heterogeneities, and vector control [38]. The other main species, P. vivax, has been overlooked due to severity of P. falciparum [41]. However, recent research suggests that severe and complicated vivax malaria may be more common than previously thought [52]. In addition, it is the most geographically widespread among the four species: endemic in the Middle East, Asia, and the Western Pacific, threatening almost $40 \%$ of the world's population [41, 49]. It was the same species which was responsible for malaria in Europe till the middle of last century. It is believed that the reason why $P$. vivax could be widespread is that it has evolved to adapt to the long winters across the Northern hemisphere [72].

Plasmodium has multiple developmental stages in humans and mosquitoes. While feeding on humans, infected female mosquitoes inject so-called sporozoites into the bloodstream, which infect liver cells. After the latent period in liver cells, merozoites are released back into the bloodstream and blood then becomes infective. Some of the merozoites mature into so-called gametocytes, which, after spreading back to feeding mosquitoes, reproduce sexually and ultimately produce more sporozoites that can again be transmitted to humans $[3,19]$. Symptoms follow shortly after blood becomes infective [73], and in our work we consider the incubation period and the latent period to be same.

Most of malaria models up to date are studied the transmission of $P$. falciparum, which causes relatively short incubation period to hosts. However, the parasite type $P$. vivax, which is common in temperate zones, can remain dormant in liver cells as a so-called hypnozoite, leading to an increased incubation period. Incubation times of $P$. vivax malaria in Republic of Korea are bimodally distributed, with a clear distinction of shortterm and long-term incubations $[43,46]$. It is of our interest to capture this bimodality in a transmission model. 
The model of Ross describes the dynamics of populations divided into susceptible humans, infectious humans, susceptible mosquitoes and infectious mosquitoes, neglecting the incubation period $[3,56]$. He assumed the rate of outflow from each population class to be proportional to the size of the population. This leads to an ordinary differential equations model, describing the time spent in each compartment with exponential distribution. Sharpe and Lotka [63] extended this model incorporating the latent period of humans and mosquitoes with discrete time delays, resulting in delay differential equations. However, they neglected the mortality of mosquitoes during the latent period, and concluded that the delay has no effect on the equilibrium [64]. Later Anderson and May [3] studied the modified model including mortality during latent periods. It is shown that the basic reproduction number is a decreasing function of both time delays, and prolonging the incubation periods reduces the prevalence of infection. Other researchers expressed the incubation period by exponential distribution, letting the population of latent individuals decay exponentially in the absence of new infection, thus formulating the models by systems of ordinary differential equations [11, 45].

To model the observed bimodal distribution of incubation times of $P$. vivax in Korea, Nah et al. [44] added two separated classes of exposed human populations, individuals going through short-term and long-term incubation time. Both short- and long-term incubation periods are expressed by exponential distributions. However, expressing long incubation period with discrete delay term could better describe the clear bimodality of incubation periods, though the resulting delay differential equations address challenge in analyses and numerical studies.

In Chapter 2 of the present thesis, we compare two transmission models for $P$. vivax malaria, where we model the long-term incubation period using ordinary differential equations or delay differential equations. We identify the basic reproduction number $R_{0}$ and show that it is a threshold parameter for the global dynamics of the model. For the DDE model, the global analysis is performed using persistence theory and Lyapunov functionals. We show that, while the qualitative behavior of the two models is similar, the ODE model overestimates the basic reproduction number and also the level of endemicity, compared to the DDE model. Observing the expression of the basic reproduction numbers, we conclude that long incubation time is not beneficial to the parasite in either ODE or DDE setting. We later conclude that the empirically observed presence of long incubation time is connected to the seasonality of endemic regions.

Most of the endemic areas where the incubation period of Plasmodium vivax shows bimodal distribution of short- and long-term incubation periods, are of temperate climate (for example in Korea). The dynamics of the mosquito population in those regions shows strong seasonality, and we extend our model to include a periodic environment. From 
numerical studies we show that the interplay of the time delay and the periodicity results that in some situations the DDE model predicts higher prevalence of malaria. The result is very much in contrast with the autonomous case when we neglected seasonal changes.

Strains of $P$. vivax from different geographical areas exhibit various latent periods. In general it seems that $P$. vivax of the temperate zone has a longer incubation time than its tropical counterpart. Battle et al. [6] conducted an analysis on the reports of $P$. vivax relapse and latency from various geographic regions. The result showed the high relapse frequency in tropical regions and prolonged latent periods in temperate areas, indicating that parasites have evolved to exploit seasonal changes in vector survival and therefore optimize transmission [6]. However, there is no convincing explanation for the regulation of incubation time has been presented to date [26]. The conditions that allow for adaptive diversification can be difficult to identify experimentally, but they can often be elucidated through the use of mathematical models [14].

Adaptive dynamics is a study on the evolutionary process by means of demographic models. In reality, demographic and evolutionary dynamics are entangled in a feedback loop. Adaptive traits influence the dynamics of population abundances, causing environmental change, and subsequent selective pressure would influence the trait evolution. Adaptive dynamics takes into account the feedback loop of evolutionary and demographic changes [13]. Assuming each individual is characterized by the adaptive traits, evolution of the traits can be studied by a resident-mutant model, describing the competition between the resident and mutant populations. The investigation of demographic resident-mutant dynamics identifies the conditions under which a resident trait is replaced by an invading mutation. The invasion success of a mutation is measured by the so-called invasion fitness, which value identifies whether the mutation gives some advantage or disadvantage to its bearers. For autonomous models, it is defined as the initial exponential growth rate of a rare mutant population appeared in an environment set by the resident population [20]. However, we need careful formulation of the invasion fitness in a seasonal environment.

In Chapter 3, using the tools of adaptive dynamics, we study the evolution of latency in a seasonal environment, assuming pathogens are capable of mutations that modify the latent period in the infected host. This is the first theoretical work for predicting the evolution of latent periods of parasites in hosts in seasonal environment, and it is expected to provide an important step toward understanding the documented bimodality in $P$. vivax incubation time.

We start with investigating the role of latency on the classic SEIS disease transmission model with periodic seasonal parameters. From numerical solutions, we observe the impact of latency on the disease dynamics in seasonal environment. Applying a recently 
developed approach, we calculate the basic reproduction number numerically. We show that the basic reproduction number depends non-monotonically on the average latent period in seasonal environment, in sharp contrast with the non-seasonal case.

Assuming that infected host individuals are characterized by the latent period as their adaptive trait, we study the evolution of latency by a resident-mutant model. We develop a numerical algorithm to calculate the invasion fitness and produce a pairwise invasibility plot (PIP), which visualizes the course of trait evolution. We identify evolutionary convergence and stable strategies on PIPs with various mosquito season lengths, and conclude that the short season length leads to longer latency. We further show that coexistence of two different traits is possible in seasonal environment. To investigate the long-term evolutionary result of the coexistence, we calculate the invasion fitness of mutants when the resident population is settled with two different traits.

In Chapter 2, we performed global analysis on the addressed delay differential equation model in a constant environment, but the mathematical analysis of the model with periodic coefficients is rather challenging. Periodic delay differential equations arise in several mathematical models, such as neural networks, transmission dynamics of vector-borne diseases and population growth models with seasonality [9, 10, 35, 77]. Linearization of such models often leads to the scalar periodic equation

$$
\dot{x}(t)=-a(t) x(t)+b(t) x(t-1),
$$

where $a, b$ are assumed to be periodic continuous real functions with $a(t) \geq 0$ and $b(t) \geq 0$.

This equation has been studied in many papers, however, there is no complete answer to the stability of the zero solution. It is known that if the delay is an integer multiple of the period, the stability threshold is $r=0$ [57], where

$$
r:=\int_{0}^{P}(b(s)-a(s)) \mathrm{d} s .
$$

In Chapter 4, we generalize this principle to situations when the delay and the period are not related. We prove that if $b(s+1)-a(s)$ does not change sign, $r$ is the stability threshold. We also construct a class of equations showing that $r=0$ does not work as a stability threshold in general. 


\section{Chapter 2}

\section{P. vivax transmission with long latent period}

\subsection{Modeling efforts on the spread of malaria}

Malaria is one of the serious and widespread infectious diseases. According to recent research, 104 countries or territories are at risk of malaria [74]. In addition to its health toll, malaria imposes a heavy economic burden on endemic countries [55]. Mathematical models have long been used for the understanding of malaria epidemiology and targeting interventions, through analytical representations of the underlying biology [40].

Most epidemics can be described by compartmental models, which divides hosts population into a number of compartments depending on the disease status. A typical SIR model consists of three compartments, susceptibles (S) who might become infected if exposed, infectious hosts (I) who can transmit the infection to susceptibles, and removed individuals $(\mathrm{R})$ who are immune to the infection and do not affect the transmission dynamics [18].

The classical mathematical models for the dynamics of malaria transmission are based on SIS-SI compartmental model for hosts and vectors (i.e. humans and mosquitoes), using differential equations [3, 56], following the works of Ross and Macdonald. The basic models of Ross and Macdonald used ordinary differential equations to understand the dynamics of malaria transmission $[37,56]$. The incubation period was incorporated first by Sharpe and Lotka [63] as a discrete time delay. The delayed Ross-Macdonald model was later modified and analyzed in $[3,37,60]$. It was concluded that prolonging the incubation periods reduces the prevalence of the disease. Other researchers expressed the incubation period by exponential distribution, letting the latent compartment decay 


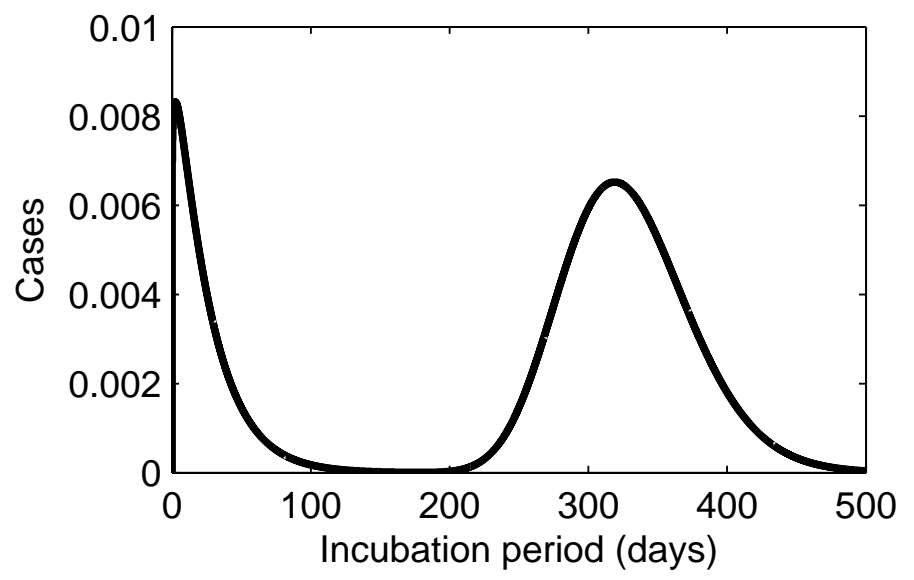

FIgure 2.1: Estimation of the probability density function of $\boldsymbol{P}$. vivax incubation time in Korea [43, 68].

exponentially in the absence of inflow from the infectious compartment [11, 45], thus formulating the models by systems of ordinary differential equations.

Xiao and Zou [76] considered a general probability function $P(t)$ describing the latency distribution, in order to reflect the fact that the latency period varies from individual to individual. They show that when the basic reproduction number is less than one, the disease will eventually die out. When the basic reproduction number is greater than one, they consider two specific forms for $P(t)$ : (i) $P(t)$ is an exponential function; (ii) $P(t)$ is a step function. In both cases, when the basic reproduction number is greater than one, they show that the disease will persist. Moreover, under additional conditions, all admissible positive solutions converge to the unique endemic equilibrium. They have generalized the conclusion of Ruan et al. [60] that longer incubation periods lead to lower prevalence of the infection, regardless of the specific form of the distributions.

One of the most common types of malaria is caused by Plasmodium vivax. The parasite $P$. vivax can remain dormant in liver cells in a form called hypnozoite, leading to an increased incubation period. P. vivax strains from different regions of the world have different length of incubation time [12]. Recent analyses of the incubation period of $P$. vivax malaria in Korea have confirmed that the incubation times have a bimodal distribution, with a clear distinction of short-term and long-term incubations [46].

Based on empirical observation of the bimodality of the incubation times of $P$. vivax in Korea, Nah et al. [44] separated the exposed class in their model into short-term and long-term exposed classes. They describe $P(t)$ as a weighted sum of two exponential functions. However, based on the empirical estimations of $P$. vivax incubation time in Korea $[43,46]$, it is natural to use discrete delay for the long-term incubation period, as 


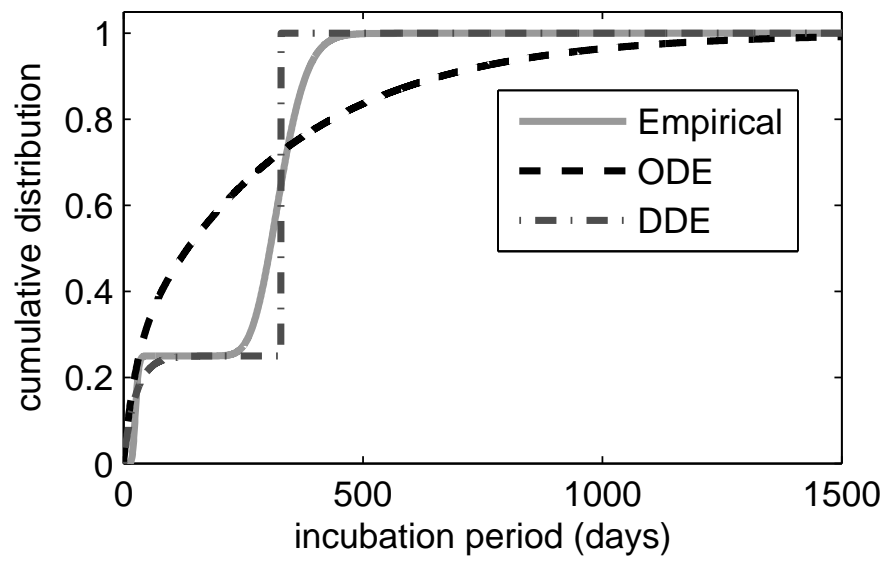

Figure 2.2: Cumulative distribution functions of incubation time. The Kantorovich distance between the distributions of the incubation time using DDE model and Empirical observation was 31.4, being much smaller than the distance between ODE model and empirical observation, which is 154.8 .

a much better approximation of the empirical observation (see Figure 2.1) than the exponential distribution assumption. The cumulative distribution functions are depicted in Figure 2.2, and one can see that assuming fixed length for the long-term incubation period gives a distribution that is much closer to the empirical distribution in the most common probability metrics (such as the Kantorovich metric or the Lévy metric), than the exponentially distributed long-term incubation period. If $F_{X}$ and $F_{Y}$ are the distribution functions of random variables $X$ and $Y$, the Kantorovich distance is defined by

$$
d_{\mathrm{K}}(X, Y):=\int_{-\infty}^{\infty}\left|F_{X}(x)-F_{Y}(x)\right| \mathrm{d} x
$$

and the Lévy distance is

$$
d_{\mathrm{L}}(X, Y):=\inf \left\{\epsilon: F_{Y}(x-\epsilon)-\epsilon \leq F_{X}(x) \leq F_{Y}(x+\epsilon)+\epsilon\right\}
$$

[21]. In this sense, it is more realistic to describe $P(t)$ as a weighted sum of an exponential function and a step function, as it provides a better approximation of the observed phenomenon.

In Chapter 2.2, we study P. vivax models without seasonality. In Chapter 2.2.1 and Chapter 2.2.2, we introduce two models for $P$. vivax transmission dynamics where both short and long incubation times are present. In both cases, we separate the exposed individuals into two distinct compartments, depending on the length of their incubation period (short-term or long-term). In the first model, we assume exponential distribution for the long-term incubation period, thus resulting a system of ordinary differential equations (ODE). In the second model, we assume fixed length for the long-term incubation period, obtaining a system of delay differential equations (DDE). In Chapter 
2.2.3 we compare the two models by means of mathematical analysis, to investigate the qualitative and quantitative differences between the two models, and to discuss the implications of these two approaches. In Chapter 2.2.4, we investigate global behavior of the solutions of DDE model. It is shown that the basic reproduction number is a threshold parameter determining the extinction or the persistence of the disease. Further, in the special case of lifelong immunity, we prove the global stability of endemic equilibrium when the basic reproduction number is greater than one.

Since the vector population and their contact rate with hosts has strong seasonality in temperate regions where $P$. vivax is endemic, we also study the disease dynamics given by those two models in a periodic environment in Chapter 2.3 .

\subsection{Study on $P$. vivax models without seasonality}

In this section, we introduce two models for $P$. vivax transmission dynamics where both short and long incubation times are present. In both cases, we separate the exposed individuals into two distinct compartments, depending on the length of their incubation period (short-term or long-term). In the first model, we assume exponential distribution for the long-term incubation period, thus resulting a system of ordinary differential equations (ODE). In the second model, we assume fixed length for the long-term incubation period, obtaining a system of delay differential equations (DDE). Our goal is to compare the two models by means of mathematical analysis, to investigate the qualitative and quantitative differences between the two models, and to discuss the implications of these two approaches. Since the disease dynamics show strong seasonality in temperate endemic regions, we also study the disease dynamics given by those two models in a periodic environment.

To describe the transmission of $P$. vivax malaria, we assume SEIRS disease dynamics for the human and SI for the mosquito population. If a susceptible human $\left(S_{H}\right)$ is successfully infected by a mosquito $\left(I_{M}\right)$, then this individual goes through incubation period $\left(E_{H}\right)$, then becomes infectious $\left(I_{H}\right)$ after this incubation time and be able to infect susceptible mosquitoes $\left(S_{M}\right)$. Recovered humans are in the class $R_{H}$, and return to $S_{H}$ after their immunity wanes. A susceptible mosquito $\left(S_{M}\right)$ moves to infectious class $\left(I_{M}\right)$ when successfully infected by an infectious host, and it remains to be infectious for a lifetime. It is further assumed that all newborns are susceptible to infection and there is no vertical transmission. 
The cross-infection between mosquitoes and humans is described by the terms $a b I_{M} \frac{S_{H}}{H}$ and $a c S_{M} \frac{I_{H}}{H}$, where $a$ is the per capita biting rate of mosquitoes with $b, c$ transmission efficiency, and $H$ is the constant human population size.

Denoting by $\xi$ the mortality rate of the human population, the exposed human population at time $t$ is given by

$$
E_{H}(t)=\int_{0}^{\infty} a b \frac{S_{H}(t-u)}{H} I_{M}(t-u) P(u) e^{-\xi u} \mathrm{~d} u,
$$

where $P: \mathbb{R}_{+} \rightarrow[0,1]$ and $P(u)$ denotes the probability that an individual is still being in the exposed class $u$ units of time after entering the exposed class, provided that this individual survived this period, which has probability $e^{-\xi u}$. Taking into account the two distinctive type of incubation periods, we separate the exposed individuals into two distinct classes, $E_{H}^{s}(t)$ and $E_{H}^{l}(t)$, the exposed human population with shortterm incubation period and with long-term incubation period at time $t$, respectively. Denoting by $p \in(0,1)$ the probability that an exposed individual experiences short-term incubation period upon a successful contact with an infected mosquito, each population at time $t$ is described by

$$
\begin{aligned}
& E_{H}^{s}(t)=\int_{0}^{\infty} p a b \frac{S_{H}(t-u)}{H} I_{M}(t-u) P_{s}(u) e^{-\xi u} \mathrm{~d} u, \\
& E_{H}^{l}(t)=\int_{0}^{\infty}(1-p) a b \frac{S_{H}(t-u)}{H} I_{M}(t-u) P_{l}(u) e^{-\xi u} \mathrm{~d} u,
\end{aligned}
$$

where each term $P_{s}(u)$ and $P_{l}(u)$ denotes the probability that an individual is still being in the exposed class $E_{H}^{s}(u)$ and $E_{H}^{l}(u)$, respectively, $u$ units of time after entering each classes, provided that this individual survived this period. We can specify $P(u)$ as

$$
P(u)=p P_{s}(u)+(1-p) P_{l}(u),
$$

and it holds that

$$
E_{H}(t)=E_{H}^{s}(t)+E_{H}^{l}(t)
$$




\begin{tabular}{cl}
\hline PARAMETER & DESCRIPTION \\
\hline \hline$a$ & contact rate of a mosquito with humans \\
$b$ & transmission efficacy of contact \\
& between an infected mosquito and a human individual \\
$m$ & proportion of mosquito population to human population \\
$c$ & transmission efficacy of contact \\
& between an infected human and a mosquito \\
$p$ & probability of an exposed human \\
& to experience short-term incubation period after infection \\
$\xi$ & long-term incubation period of humans \\
$\mu$ & mortality rate of humans \\
$d_{s}\left(d_{l}\right)$ & mortality rate of mosquitoes \\
& to of progression from the short-term (long-term) exposed state \\
$r$ & recovery rate of humans \\
$\omega$ & rate of loss of immunity for humans
\end{tabular}

TABLE 2.1: Description of parameters

By considering the infectious and recovered class of humans, $I_{H}(t)$ and $R_{H}(t)$, and the mosquito population dynamics, we arrive to the following model in population level,

$$
\begin{aligned}
\frac{d S_{H}(t)}{d t} & =\xi H-a b \frac{S_{H}(t)}{H} I_{M}(t)-\xi S_{H}(t)+\omega R_{H}(t), \\
E_{H}^{s}(t) & =\int_{0}^{\infty} p a b \frac{S_{H}(t-u)}{H} I_{M}(t-u) P_{s}(u) e^{-\xi u} \mathrm{~d} u, \\
E_{H}^{l}(t) & =\int_{0}^{\infty}(1-p) a b \frac{S_{H}(t-u)}{H} I_{M}(t-u) P_{l}(u) e^{-\xi u} \mathrm{~d} u, \\
I_{H}(t) & =H-S_{H}(t)-E_{H}^{s}(t)-E_{H}^{l}(t)-R_{H}(t), \\
\frac{d R_{H}(t)}{d t} & =r I_{H}(t)-(\omega+\xi) R_{H}(t), \\
\frac{d S_{M}(t)}{d t} & =\mu M-a c S_{M}(t) \frac{I_{H}(t)}{H}-\mu S_{M}(t), \\
I_{M}(t) & =M-S_{M}(t),
\end{aligned}
$$

referring to Table 2.1 for the description of the parameters. In this section, we assume the mosquito population to be constant, having the same birth and mortality rate $\mu$. System (2.1) can be rescaled by introducing the new variables

$$
\begin{gathered}
s_{H}=\frac{S_{H}}{H}, \quad e_{H}^{s}=\frac{E_{H}^{s}}{H}, \quad e_{H}^{l}=\frac{E_{H}^{l}}{H}, \quad i_{H}=\frac{I_{H}}{H}, \quad r_{H}=\frac{R_{H}}{H}, \\
s_{M}=\frac{S_{M}}{M}, \quad i_{M}=\frac{I_{M}}{M} \quad \text { and } \quad m=\frac{M}{H} .
\end{gathered}
$$


Population dynamics of the susceptible human population would be rescaled to

$$
\begin{aligned}
\frac{d s_{H}(t)}{d t} & =\frac{1}{H} \frac{d S_{H}(t)}{d t} \\
& =\frac{1}{H}\left(\xi H-a b \frac{S_{H}(t)}{H} I_{M}(t)-\xi S_{H}(t)+\omega R_{H}(t)\right) \\
& =\xi-a b m s_{H}(t) i_{M}(t)-\xi s_{H}(t)+\omega r_{H}(t)
\end{aligned}
$$

and the dynamics of susceptible mosquito population would be rescaled to

$$
\begin{aligned}
\frac{d s_{M}(t)}{d t} & =\frac{1}{M} \frac{d S_{M}(t)}{d t} \\
& =\frac{1}{M}\left(\mu M-a c S_{M}(t) \frac{I_{H}(t)}{H}-\mu S_{M}(t)\right) \\
& =\mu-a c s_{M}(t) i_{H}(t)-\mu s_{M}(t) .
\end{aligned}
$$

Note that the cross-infection terms become

$$
a b m i_{M} s_{H} \text { and } a c s_{M} i_{H} .
$$

By similar calculation, we obtain the rescaled equations

$$
\begin{aligned}
\frac{d s_{H}(t)}{d t} & =\xi-\alpha s_{H}(t) i_{M}(t)-\xi s_{H}(t)+\omega r_{H}(t) \\
e_{H}^{s}(t) & =\int_{0}^{\infty} p \alpha s_{H}(t-u) i_{M}(t-u) P_{s}(u) e^{-\xi u} \mathrm{~d} u \\
e_{H}^{l}(t) & =\int_{0}^{\infty}(1-p) \alpha s_{H}(t-u) i_{M}(t-u) P_{l}(u) e^{-\xi u} \mathrm{~d} u \\
i_{H}(t) & =1-s_{H}(t)-e_{H}^{s}(t)-e_{H}^{l}(t)-r_{H}(t) \\
\frac{d r_{H}(t)}{d t} & =r i_{H}(t)-(\omega+\xi) r_{H}(t) \\
\frac{d s_{M}(t)}{d t} & =\mu-\beta s_{M}(t) i_{H}(t)-\mu s_{M}(t) \\
i_{M}(t) & =1-s_{M}(t)
\end{aligned}
$$

where $\alpha:=a b m$ and $\beta:=a c$.

See Figure 2.3 for the disease transmission diagram and Tables 2.1 and 2.2 for the description of the parameters and the variables.

In the following two sections, we consider two models: the short-term incubation time has an exponential distribution in both models, but the distributions of long-term incubation time are different. The first model assumes exponential distribution for long incubation time, as in previous research. In the second model, individuals going through long-term incubation time have the same length of incubation time, i.e. long-term incubation time has Dirac-delta distribution. The second model better describes the observed 


\begin{tabular}{cl}
\hline VARIABLE & DESCRIPTION \\
\hline \hline$s_{H}$ & susceptible human proportion \\
$e_{H}$ & exposed human proportion \\
$e_{H}^{s}$ & exposed human proportion having a short-term incubation period \\
$e_{H}^{l}$ & exposed human proportion having a long-term incubation period \\
$i_{H}$ & infectious human proportion \\
$r_{H}$ & recovered human proportion \\
$s_{M}$ & susceptible mosquito proportion \\
$i_{M}$ & infectious mosquito proportion \\
\hline
\end{tabular}

TABLE 2.2: Description of the dynamical variables. Each variable denotes a fraction of the population so that $s_{H}+\left(e_{H}^{s}+e_{H}^{l}\right)+i_{H}+r_{H}=1$ and $s_{M}+i_{M}=1$ hold.

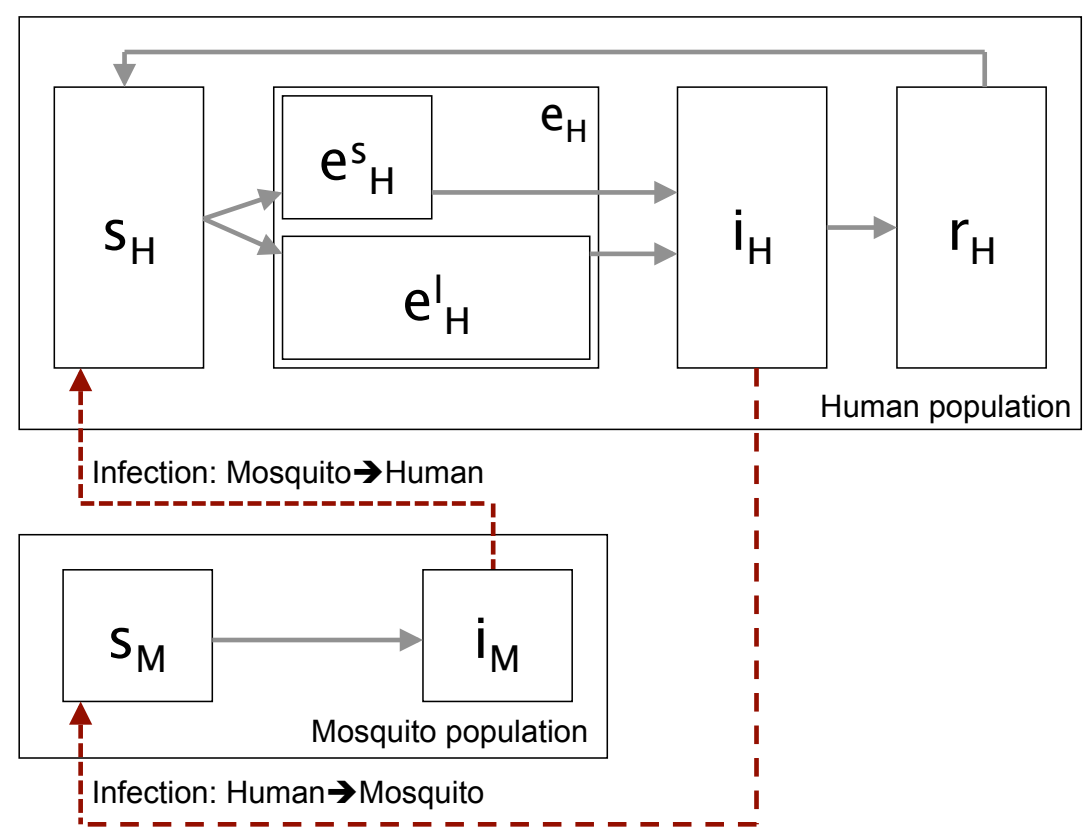

Figure 2.3: Diagram for the disease transmission. The exposed class of humans is separated into two distinct classes according to the length of incubation period.

distribution of long-term incubation time than the first one (see Figures 2.1 and 2.2), however, the second model is more difficult to analyze mathematically.

\subsubsection{ODE model with exponentially distributed incubation periods}

For the ODE model, we assume exponential distribution for both the short and the long incubation period, with mean $1 / d_{s}$ and $1 / d_{l}$, resp. In specific, with the following probability distribution

$$
P_{s}(u):=e^{-d_{s} u}, \quad P_{l}(u):=e^{-d_{l} u}
$$


And we obtain

$$
\begin{aligned}
e_{H}^{s}(t) & =\int_{0}^{\infty} p \alpha s_{H}(t-u) i_{M}(t-u) P_{s}(u) e^{-\xi u} \mathrm{~d} u \\
& =\int_{0}^{\infty} p \alpha s_{H}(t-u) i_{M}(t-u) e^{-\left(d_{s}+\xi\right) u} \mathrm{~d} u, \\
e_{H}^{l}(t) & =\int_{0}^{\infty}(1-p) \alpha s_{H}(t-u) i_{M}(t-u) P_{l}(u) e^{-\xi u} \mathrm{~d} u \\
& =\int_{0}^{\infty}(1-p) \alpha s_{H}(t-u) i_{M}(t-u) e^{-\left(d_{l}+\xi\right) u} \mathrm{~d} u .
\end{aligned}
$$

One can differentiate both sides with respect to $t$ to get the ordinary differential equations

$$
\begin{aligned}
& \frac{d e_{H}^{s}(t)}{d t}=p \alpha s_{H}(t) i_{M}(t)-\left(d_{s}+\xi\right) e_{H}^{s}(t) \\
& \frac{d e_{H}^{l}(t)}{d t}=(1-p) \alpha s_{H}(t) i_{M}(t)-\left(d_{l}+\xi\right) e_{H}^{l}(t) .
\end{aligned}
$$

The fraction of human population progressing to the infectious class per unit of time at time $t$, after experiencing either the short- or long-term incubation period, is given by

$$
d_{s} e_{H}^{s}(t)+d_{l} e_{H}^{l}(t)
$$

Thus, the dynamics of the fraction of the infective human population is captured by the following differential equation:

$$
\frac{d i_{H}}{d t}=d_{s} e_{H}^{s}+d_{l} e_{H}^{l}-r i_{H}-\xi i_{H}
$$

Consequently, we obtain the ODE system

$$
\begin{aligned}
\frac{d s_{H}}{d t} & =\xi-\alpha s_{H} i_{M}+\omega r_{H}-\xi s_{H}, \\
\frac{d e_{H}^{s}}{d t} & =p \alpha s_{H} i_{M}-d_{s} e_{H}^{s}-\xi e_{H}^{s}, \\
\frac{d e_{H}^{l}}{d t} & =(1-p) \alpha s_{H} i_{M}-d_{l} e_{H}^{l}-\xi e_{H}^{l}, \\
\frac{d i_{H}}{d t} & =d_{s} e_{H}^{s}+d_{l} e_{H}^{l}-r i_{H}-\xi i_{H}, \\
\frac{d r_{H}}{d t} & =r i_{H}-\omega r_{H}-\xi r_{H}, \\
\frac{d s_{M}}{d t} & =\mu-\beta s_{M} i_{H}-\mu s_{M}, \\
\frac{d i_{M}}{d t} & =\beta s_{M} i_{H}-\mu i_{M} .
\end{aligned}
$$


Model (2.2) is modified from the model of Nah et al. [44], and assumes that individuals leave the exposed compartments at constant rate. The feasible domain

$$
\left\{\left(s_{H}, e_{H}^{s}, e_{H}^{l}, i_{H}, r_{H}, s_{H}, i_{M}\right) \in \mathbb{R}_{+}^{7} \mid s_{H}+e_{H}^{s}+e_{H}^{l}+i_{H}+r_{H}=1, s_{M}+i_{M}=1\right\}
$$

is clearly invariant.

The basic reproduction number is defined as the expected number of secondary cases produced by a single infection in a completely susceptible population. For many deterministic models, $R_{0}$ is the threshold quantity that determines when an infection can invade and persist in a new host population [24]. More precisely, $R_{0}>1$ implies the instability of the disease-free state and the invasion of the host population by the disease, while $R_{0}<1$ implies the stability of the disease-free state and hence invasion is not possible.

We define the basic reproduction number $R_{o}$ for the ODE model by

$$
R_{o}=\sqrt{\frac{\alpha \beta}{(r+\xi) \mu}\left(p \frac{d_{s}}{d_{s}+\xi}+(1-p) \frac{d_{l}}{d_{l}+\xi}\right)},
$$

where we adapted the convention of taking the square root as reproduction requires two epidemiological generations. The term $\alpha$ describes the successful contacts infectious mosquitoes have with humans per unit time, $\frac{1}{\mu}$ is the length of the infectious period of mosquitoes. Since $p \frac{d_{s}}{d_{s}+\xi}+(1-p) \frac{d_{l}}{d_{l}+\xi}$ is the probability that an infected human survives the exposed state and becomes infectious, $\beta$ is the number of valid contacts infectious humans have with mosquitoes per unit time and $\frac{1}{r+\xi}$ is the length of the infectious period of a human; We show that $R_{o}$ works as a threshold for the existence and stability of equilibria of system (2.2).

Lemma 2.1. The disease-free equilibrium (DFE) $(1,0,0,0,0,1,0)$ of system (2.2) always exists. An endemic equilibrium (EE) exists if and only if $R_{O}>1$ and it is given by the following relations:

$$
\begin{gathered}
i_{H}^{*}=\frac{R_{o}^{2}-1}{\frac{\beta}{\mu}+K_{o} R_{o}^{2}}, \quad e_{H}^{s *}=\frac{\frac{p}{d_{s}+\xi}(r+\xi)}{p \frac{d_{s}}{d_{s}+\xi}+(1-p) \frac{d_{l}}{d_{l}+\xi}} i_{H}^{*}, \quad e_{H}^{l *}=\frac{1-p}{d_{l}+\xi} \frac{d_{s}+\xi}{p} e_{H}^{s *}, \\
r_{H}^{*}=\frac{r}{\omega+\xi} i_{H}^{*}, \quad i_{M}^{*}=\frac{\frac{\beta}{\mu} i_{H}^{*}}{1+\frac{\beta}{\mu} i_{H}^{*}}, \quad s_{H}^{*}=1-e_{H}^{s *}-e_{H}^{l *}-i_{H}^{*}-r_{H}^{*}
\end{gathered}
$$

and $\quad s_{M}^{*}=1-i_{M}^{*}, \quad$ where $\quad K_{o}=\frac{\frac{p}{d_{s}+\xi}+\frac{1-p}{d_{l}+\xi}}{p_{\frac{d}{d_{s}+\xi}+(1-p) \frac{d_{l}}{d_{l}+\xi}}}(r+\xi)+1+\frac{r}{\omega+\xi}$. 
Proof. To find equilibria, we set the left-hand side of system (2.2) to zero, and obtain

$$
\begin{aligned}
& 0=p \alpha s_{H}^{*} i_{M}^{*}-\left(d_{s}+\xi\right) e_{H}^{s *}, \\
& 0=(1-p) \alpha s_{H}^{*} i_{M}^{*}-\left(d_{l}+\xi\right) e_{H}^{l *}, \\
& 0=d_{s} e_{H}^{s *}+d_{l} e_{H}^{l *}-(r+\xi) i_{H}^{*}, \\
& 0=r i_{H}^{*}-\omega r_{H}^{*}-\xi r_{H}^{*}, \\
& 0=\beta s_{M}^{*} i_{H}^{*}-\mu i_{M}^{*} .
\end{aligned}
$$

If either $i_{H}^{*}=0$ or $i_{M}^{*}=0$, we have a DFE, $\left(s_{H}^{*}, e_{H}^{s *}, e_{H}^{l *}, i_{H}^{*}, r_{H}^{*}, s_{M}^{*}, i_{M}^{*}\right)=(1,0,0,0,0,1,0)$. Consider the case $i_{H}^{*}>0$ and $i_{M}^{*}>0$. Adding three equations, (2.5) multiplied by $\frac{d_{s}}{\xi+d_{s}}$, (2.6) multiplied by $\frac{d_{l}}{\xi+d_{l}}$, and (2.7),

$$
\alpha\left(p \frac{d_{s}}{\xi+d_{s}}+(1-p) \frac{d_{l}}{\xi+d_{l}}\right) s_{H}^{*} i_{M}^{*}=(r+\xi) i_{H}^{*} .
$$

By (2.9),

$$
\beta s_{M}^{*} i_{H}^{*}=\mu i_{M}^{*}
$$

Multiplying each side of (2.10) and (2.11), and dividing by $(r+\xi) \mu i_{H}^{*} i_{M}^{*}$,

$$
R_{0}^{2} s_{H}^{*} s_{M}^{*}=1 .
$$

Multiplying $\frac{\beta}{(r+\xi) \mu}$ to (2.10) gives

$$
R_{o}^{2} s_{H}^{*}\left(1-s_{M}^{*}\right)=\frac{\beta}{\mu} i_{H}^{*} .
$$

By (2.12) and (2.13), we get

$$
s_{H}^{*}=\frac{1}{R_{o}^{2}}+\frac{\beta}{R_{o}^{2} \mu} i_{H}^{*} .
$$

Comparing (2.5) and (2.10), we have

$$
e_{H}^{s *}=\alpha s_{H}^{*} i_{M}^{*} \frac{p}{d_{s}+\xi}=\frac{\frac{p}{\xi+d_{s}}(r+\xi)}{p \frac{d_{s}}{\xi+d_{s}}+(1-p) \frac{d_{l}}{\xi+d_{l}}} i_{H}^{*} .
$$

Comparing (2.6) and (2.10), we have

$$
e_{H}^{l *}=\alpha s_{H}^{*} i_{M}^{*} \frac{1-p}{d_{l}+\xi}=\frac{\frac{1-p}{\xi+d_{l}}(r+\xi)}{p \frac{d_{s}}{\xi+d_{s}}+(1-p) \frac{d_{l}}{\xi+d_{l}}} i_{H}^{*} .
$$

By (2.8),

$$
r_{H}^{*}=\frac{r}{\omega+\xi} i_{H}^{*}
$$


By (2.15), (2.16) and (2.17),

$$
\begin{aligned}
s_{H}^{*} & =1-e_{H}^{s *}-e_{H}^{l *}-i_{H}^{*}-r_{H}^{*} \\
& =1-\frac{\left(\frac{p}{\xi+d_{s}}+\frac{1-p}{\xi+d_{l}}\right)(r+\xi)}{p_{\frac{d_{s}}{\xi+d_{s}}}+(1-p) \frac{d_{l}}{\xi+d_{l}}} i_{H}^{*}-i_{H}^{*}-\frac{r}{\omega+\xi} i_{H}^{*} \\
& =1-K_{o} i_{H}^{*} .
\end{aligned}
$$

By (2.14) and (2.18), we get $i_{H}^{*}=\frac{R_{o}^{2}-1}{\frac{\beta}{\mu}+K_{o} R_{o}^{2}}$, which exists when $R_{O}>1$.

Theorem 2.2. The DFE of system (2.2) is locally asymptotically stable if $R_{o}<1$ and is unstable if $R_{o}>1$.

Proof. Consider the linearized system of (2.2) at an equilibrium:

$$
\begin{aligned}
\frac{d e_{H}^{s}}{d t} & =p \alpha s_{H}^{*} i_{M}-p \alpha i_{M}^{*}\left(e_{H}^{s}+e_{H}^{l}+i_{H}+r_{H}\right)-\left(d_{s}+\xi\right) e_{H}^{s}, \\
\frac{d e_{H}^{l}}{d t} & =(1-p) \alpha s_{H}^{*} i_{M}-(1-p) \alpha i_{M}^{*}\left(e_{H}^{s}+e_{H}^{l}+i_{H}+r_{H}\right)-\left(d_{l}+\xi\right) e_{H}^{l}, \\
\frac{d i_{H}}{d t} & =d_{s} e_{H}^{s}+d_{l} e_{H}^{l}-(r+\xi) i_{H}, \\
\frac{d r_{H}}{d t} & =r i_{H}-(\omega+\xi) r_{H}, \\
\frac{d i_{M}}{d t} & =\beta s_{M}^{*} i_{H}-\beta i_{H}^{*} i_{M}-\mu i_{M} .
\end{aligned}
$$

The characteristic function $F(\lambda)$ is

$$
\left|\begin{array}{ccccc}
\lambda+d_{s}+\xi+A & A & A & A & -p \alpha s_{H}^{*} \\
B & \lambda+d_{l}+\xi+B & B & B & -(1-p) \alpha s_{H}^{*} \\
-d_{s} & -d_{l} & \lambda+r+\xi & 0 & 0 \\
0 & 0 & -r & \lambda+\omega+\xi & 0 \\
0 & 0 & -\beta s_{M}^{*} & 0 & \lambda+\mu+\beta i_{H}^{*}
\end{array}\right|
$$

where $A=p \alpha i_{M}^{*}, B=(1-p) \alpha i_{M}^{*}$. After simplification,

$$
\begin{aligned}
F(\lambda)= & (\lambda+r+\xi)(\lambda+\omega+\xi)\left(\lambda+\mu+\beta i_{H}^{*}\right)\left[\left(\lambda+d_{s}+\xi\right)\left(\lambda+d_{l}+\xi\right)\right. \\
& \left.+\alpha i_{M}^{*}\left\{(1-p)\left(\lambda+d_{s}+\xi\right)+p\left(\lambda+d_{l}+\xi\right)\right\}\right]+\alpha i_{M}^{*}\left(\lambda+\mu+\beta i_{H}^{*}\right) \\
& \times\{(\lambda+\omega+\xi)+r\}\left\{(1-p) d_{l}\left(\lambda+d_{s}+\xi\right)+p d_{s}\left(\lambda+d_{l}+\xi\right)\right\} \\
& -\alpha \beta s_{H}^{*} s_{M}^{*}(\lambda+\omega+\xi)\left\{(1-p) d_{l}\left(\lambda+d_{s}+\xi\right)+p d_{s}\left(\lambda+d_{l}+\xi\right)\right\} .
\end{aligned}
$$


At the DFE, it reduces to

$$
\begin{aligned}
F(\lambda)= & (\lambda+\omega+\xi)\left\{\left(\lambda+d_{s}+\xi\right)\left(\lambda+d_{l}+\xi\right)(\lambda+r+\xi)(\lambda+\mu)\right. \\
& \left.-(1-p) d_{l} \alpha \beta\left(\lambda+d_{s}+\xi\right)-p d_{s} \alpha \beta\left(\lambda+d_{l}+\xi\right)\right\}
\end{aligned}
$$

Now assume $R_{o}<1$. Suppose there exists a root of $F(\lambda)=0$ with non-negative real part. Then,

$$
\begin{aligned}
& \left|\frac{\lambda}{d_{s}+\xi}+1\right|\left|\frac{\lambda}{d_{l}+\xi}+1\right|\left|\frac{\lambda}{r+\xi}+1\right|\left|\frac{\lambda}{\mu}+1\right| \\
\leq & \frac{\alpha \beta}{(r+\xi) \mu}\left((1-p) \frac{d_{l}}{d_{l}+\xi}\left|\frac{\lambda}{d_{s}+\xi}+1\right|+p \frac{d_{s}}{d_{s}+\xi}\left|\frac{\lambda}{d_{l}+\xi}+1\right|\right) \\
\leq & \left|\frac{\lambda}{d_{s}+\xi}+1\right|\left|\frac{\lambda}{d_{l}+\xi}+1\right| R_{o}^{2},
\end{aligned}
$$

which contradicts to $R_{o}<1$. Therefore, the roots of $F(\lambda)=0$ have negative real part, implying that the DFE is locally asymptotically stable if $R_{o}<1$. Now, assume $R_{o}>1$. Note that $F(\lambda)=0$ has at least one real root. Since $F(\lambda) \rightarrow \infty$ for real $\lambda \rightarrow \infty$ and

$$
F(0)=(\omega+\xi)\left(d_{s}+\xi\right)\left(d_{l}+\xi\right)(r+\xi) \mu\left(1-R_{o}^{2}\right)<0,
$$

$F(\lambda)=0$ has a positive real root. Therefore, the DFE is unstable.

\subsubsection{DDE model with fixed length of latency}

For the ODE model in section 2.2.1, exponential distribution was assumed for the long incubation period, with mean $1 / d_{l}$. In this section, we introduce a DDE model assuming the long incubation period has a fixed length, $\tau$. Then we have

$$
P_{s}(u):=e^{-d_{s} u}, \quad P_{l}(u):= \begin{cases}1, & u \in[0, \tau], \\ 0, & u \in(\tau, \infty),\end{cases}
$$

and we obtain

$$
\begin{aligned}
e_{H}^{s}(t) & =\int_{0}^{\infty} p \alpha s_{H}(t-u) i_{M}(t-u) P_{s}(u) e^{-\xi u} d u \\
& =\int_{0}^{\infty} p \alpha s_{H}(t-u) i_{M}(t-u) e^{-\left(d_{s}+\xi\right) u} d u, \\
e_{H}^{l}(t) & =\int_{0}^{\infty}(1-p) \alpha s_{H}(t-u) i_{M}(t-u) P_{l}(u) e^{-\xi u} d u \\
& =\int_{0}^{\tau}(1-p) \alpha s_{H}(t-u) i_{M}(t-u) e^{-\xi u} d u .
\end{aligned}
$$


By differentiating both sides of (2.19) with respect to $t$, one can obtain

$$
\frac{d e_{H}^{l}(t)}{d t}=(1-p) \alpha s_{H}(t) i_{M}(t)-(1-p) \alpha s_{H}(t-\tau) i_{M}(t-\tau) e^{-\xi \tau}-\xi e_{H}^{l}(t) .
$$

The fraction of human population progressing to the infectious class per unit of time at time $t$, after experiencing either the short- or long-term incubation period, is given by $d_{s} e_{H}^{s}(t)+(1-p) \alpha s_{H}(t-\tau) i_{M}(t-\tau) e^{-\xi \tau}$. The following differential equation captures the dynamics of the fraction of the infective human population $i_{H}(t)$ :

$$
\frac{d i_{H}(t)}{d t}=d_{s} e_{H}^{s}(t)+(1-p) \alpha s_{H}(t-\tau) i_{M}(t-\tau) e^{-\xi \tau}-(r+\xi) i_{H}(t) .
$$

By considering

$$
e_{H}^{l}=1-s_{H}-e_{H}^{s}-i_{H}-r_{H},
$$

we arrive to the DDE model

$$
\begin{aligned}
\frac{d s_{H}}{d t} & =\xi-\alpha s_{H} i_{M}+\omega r_{H}-\xi s_{H} \\
\frac{d e_{H}^{s}}{d t} & =p \alpha s_{H} i_{M}-d_{s} e_{H}^{s}-\xi e_{H}^{s} \\
\frac{d e_{H}^{l}}{d t} & =(1-p) \alpha s_{H} i_{M}-(1-p) \alpha s_{H}(t-\tau) i_{M}(t-\tau) e^{-\xi \tau}-\xi e_{H}^{l}, \\
\frac{d i_{H}}{d t} & =d_{s} e_{H}^{s}+(1-p) \alpha s_{H}(t-\tau) i_{M}(t-\tau) e^{-\xi \tau}-r i_{H}-\xi i_{H} \\
\frac{d r_{H}}{d t} & =r i_{H}-\omega r_{H}-\xi r_{H} \\
\frac{d s_{M}}{d t} & =\mu-\beta s_{M} i_{H}-\mu s_{M} \\
\frac{d i_{M}}{d t} & =\beta s_{M} i_{H}-\mu i_{M} .
\end{aligned}
$$

To guarantee that solutions remain in the feasible domain, compared to the ODE model here we need the additional condition that the initial functions satisfy

$$
e_{H}^{l}(0) \geq(1-p) \alpha \int_{-\tau}^{0} s_{H}(u) i_{M}(u) e^{-\xi u} d u
$$

The basic reproduction number $R_{d}$ of the DDE model is given by

$$
R_{d}=\sqrt{\frac{\alpha \beta}{\mu(r+\xi)}\left((1-p) e^{-\xi \tau}+p \frac{d_{s}}{d_{s}+\xi}\right)}
$$

being defined in the same manner as $R_{o}$. Comparing with Eq. (2.4), the term

$$
(1-p) e^{-\xi \tau}+p \frac{d_{s}}{d_{s}+\xi}
$$


is the only different part, which is the probability that a human will survive the exposed state to become infectious. $R_{d}$ is a stability threshold of system (2.21).

Lemma 2.3. The disease-free equilibrium (DFE) $(1,0,0,0,0,1,0)$ of system (2.21) always exists. An endemic equilibrium (EE) exists if and only if $R_{d}>1$ and it is given by the following relations:

$$
\begin{aligned}
& i_{H}^{*}=\frac{R_{d}^{2}-1}{\frac{\beta}{\mu}+K_{d} R_{d}^{2}}, \quad e_{H}^{s *}=\frac{p \xi}{(1-p)\left(d_{s}+\xi\right) e^{-\xi \tau}+p d_{s}} \frac{r+\xi}{\xi} i_{H}^{*}, \\
& e_{H}^{l *}=\frac{(1-p)\left(d_{s}+\xi\right)\left(1-e^{-\xi \tau}\right)}{p \xi} e_{H}^{s *}, \quad r_{H}^{*}=\frac{r}{\omega+\xi} i_{H}^{*}, \quad i_{M}^{*}=\frac{\frac{\beta}{\mu} i_{H}^{*}}{1+\frac{\beta}{\mu} i_{H}^{*}}, \\
& s_{H}^{*}=1-e_{H}^{s *}-e_{H}^{l *}-i_{H}^{*}-r_{H}^{*} \quad \text { and } s_{M}^{*}=1-i_{M}^{*} \text {, where } \\
& K_{d}=\frac{\frac{p}{d_{s}+\xi}+(1-p) \frac{1-e^{-\xi \tau}}{\xi}}{p \frac{d_{s}}{d_{s}+\xi}+(1-p) e^{-\xi \tau}}(r+\xi)+1+\frac{r}{\omega+\xi} .
\end{aligned}
$$

Proof. We put LHS of the system (2.21) to be zero and obtain the following equations

$$
\begin{aligned}
& 0=p \alpha s_{H}^{*} i_{M}^{*}-\left(d_{s}+\xi\right) e_{H}^{s *}, \\
& 0=(1-p) \alpha s_{H}^{*} i_{M}^{*}-(1-p) \alpha s_{H}^{*} i_{M}^{*} e^{-\xi \tau}-\xi e_{H}^{l *}, \\
& 0=d_{s} e_{H}^{s *}+(1-p) \alpha s_{H}^{*} i_{M}^{*} e^{-\xi \tau}-(r+\xi) i_{H}^{*}, \\
& 0=r i_{H}^{*}-(\omega+\xi) r_{H}^{*} \\
& 0=a c s_{M}^{*} i_{H}^{*}-\mu i_{M}^{*}
\end{aligned}
$$

If either $i_{H}^{*}=0$ or $i_{M}^{*}=0$, we have a DFE

$$
\left(s_{H}^{*}, e_{H}^{s *}, e_{H}^{l *}, i_{H}^{*}, r_{H}^{*}, s_{M}^{*}, i_{M}^{*}\right)=(1,0,0,0,0,1,0)
$$

Consider the case $i_{H}^{*}>0$ and $i_{M}^{*}>0$. Adding two equations, (2.23) multiplied by $\frac{d_{s}}{\xi+d_{s}}$, and (2.25), one has

$$
\left((1-p) e^{-\xi \tau}+p \frac{d_{s}}{\xi+d_{s}}\right) \alpha s_{H}^{*} i_{M}^{*}=(r+\xi) i_{H}^{*}
$$

By $(2.27)$,

$$
\beta s_{M}^{*} i_{H}^{*}=\mu i_{M}^{*}
$$

Multiplying both sides of (2.28) and (2.29), and dividing by $(r+\xi) \mu i_{H}^{*} i_{M}^{*}$,

$$
R_{d}^{2} s_{H}^{*} s_{M}^{*}=1
$$


Meanwhile, multiplying $\frac{\beta}{(r+\xi) \mu}$ to $(2.28)$,

$$
R_{d}^{2} s_{H}^{*}\left(1-s_{M}^{*}\right)=\frac{\beta}{\mu} i_{H}^{*} .
$$

By (2.30) and (2.31), we get

$$
s_{H}^{*}=\frac{1}{R_{d}^{2}}+\frac{\beta}{R_{d}^{2} \mu} i_{H}^{*} .
$$

Comparing (2.23) and (2.28), we have

$$
e_{H}^{s *}=\alpha s_{H}^{*} i_{M}^{*} \frac{p}{d_{s}+\xi}=\frac{\frac{p}{\xi+d_{s}}(r+\xi)}{(1-p) e^{-\xi \tau}+p_{\frac{d_{s}}{\xi+d_{s}}}^{-}} i_{H}^{*} .
$$

Comparing (2.24) and (2.28), we have

$$
e_{H}^{l *}=\alpha s_{H}^{*} i_{M}^{*} \frac{(1-p)\left(1-e^{-\xi \tau}\right)}{\xi}=\frac{\frac{(1-p)\left(1-e^{-\xi \tau}\right)}{\xi}(r+\xi)}{(1-p) e^{-\xi \tau}+p \frac{d_{s}}{\xi+d_{s}}} i_{H}^{*} .
$$

By $(2.26)$,

$$
r_{H}^{*}=\frac{r}{\omega+\xi} i_{H}^{*}
$$

By (2.33), (2.34) and (2.35),

$$
\begin{aligned}
s_{H}^{*} & =1-e_{H}^{s *}-e_{H}^{l *}-i_{H}^{*}-r_{H}^{*} \\
& =1-\frac{\frac{p}{\xi+d_{s}}+(1-p) \frac{1-e^{-\xi \tau}}{\xi}}{(1-p) e^{-\xi \tau}+p \frac{d_{s}}{\xi+d_{s}}}(r+\xi) i_{H}^{*}-i_{H}^{*}-\frac{r}{\omega+\xi} i_{H}^{*} \\
& =1-K_{d} i_{H}^{*} .
\end{aligned}
$$

By (2.32) and (2.36), we get $i_{H}^{*}=\frac{R_{d}^{2}-1}{\frac{\beta}{\mu}+K_{d} R_{d}^{2}}$, which exists when $R_{d}>1$.

Theorem 2.4. The DFE of system (2.21) is locally asymptotically stable if $R_{d}<1$ and is unstable if $R_{d}>1$. 
Proof. Consider the linearized system of (2.21) at an equilibrium:

$$
\begin{aligned}
\frac{d e_{H}^{s}}{d t}= & -p \alpha i_{M}^{*}\left(e_{H}^{s}(t)+e_{H}^{l}(t)+i_{H}(t)+r_{H}(t)\right)+p \alpha s_{H}^{*} i_{M}(t)-\left(d_{s}+\xi\right) e_{H}^{s}(t), \\
\frac{d e_{H}^{l}}{d t}= & -(1-p) \alpha i_{M}^{*}\left(e_{H}^{s}(t)+e_{H}^{l}(t)+i_{H}(t)+r_{H}(t)\right)+(1-p) \alpha s_{H}^{*} i_{M}(t) \\
& +(1-p) \alpha i_{M}^{*}\left(e_{H}^{s}(t-\tau)+e_{H}^{l}(t-\tau)+i_{H}(t-\tau)+r_{H}(t-\tau)\right) e^{-\xi \tau} \\
& -(1-p) \alpha s_{H}^{*} i_{M}(t-\tau) e^{-\xi \tau}-\xi e_{H}^{l}(t) \\
\frac{d i_{H}}{d t}= & -(1-p) \alpha i_{M}^{*}\left(e_{H}^{s}(t-\tau)+e_{H}^{l}(t-\tau)+i_{H}(t-\tau)+r_{H}(t-\tau)\right) e^{-\xi \tau} \\
& +d_{s} e_{H}^{s}(t)+(1-p) \alpha s_{H}^{*} i_{M}(t-\tau) e^{-\xi \tau}-r i_{H}(t)-\xi i_{H}(t) \\
\frac{d r_{H}}{d t}= & r i_{H}(t)-\omega r_{H}(t)-\xi r_{H}(t) \\
\frac{d i_{M}}{d t}= & \beta s_{M}^{*} i_{H}(t)-\beta i_{H}^{*} i_{M}(t)-\mu i_{M}(t)
\end{aligned}
$$

The characteristic function $F(\lambda)$ is the determinant of the matrix

$$
\lambda I+\left(\begin{array}{ccccc}
d_{s}+\xi+A & A & A & A & -p \alpha s_{H}^{*} \\
B & \xi+B & B & B & -(1-p) \alpha s_{H}^{*}\left(1-e^{-\xi \tau-\lambda \tau}\right) \\
-d_{s}+C & C & r+\xi+C & C & -(1-p) \alpha s_{H}^{*} e^{-\xi \tau-\lambda \tau} \\
0 & 0 & -r & \omega+\xi & 0 \\
0 & 0 & -\beta s_{M}^{*} & 0 & \mu+\beta i_{H}^{*}
\end{array}\right)
$$

where $A=p \alpha i_{M}^{*}, B=(1-p) \alpha i_{M}^{*}\left(1-e^{-\xi \tau-\lambda \tau}\right)$, and $C=(1-p) \alpha i_{M}^{*} e^{-\xi \tau-\lambda \tau}$. After simplification,

$$
\begin{aligned}
F(\lambda)= & \left(\lambda+\mu+\beta i_{H}^{*}\right)(\lambda+\omega+\xi)\left(\lambda+\xi+\alpha i_{M}^{*}\right)\left(\lambda+d_{s}+\xi\right)(\lambda+r+\xi) \\
& -\omega r \alpha i_{M}^{*}\left\{p d_{s}+(1-p) e^{-\xi \tau-\lambda \tau}\left(\lambda+d_{s}+\xi\right)\right\}\left(\lambda+\mu+\beta i_{H}^{*}\right) \\
& -\alpha \beta s_{H}^{*} s_{M}^{*}\left\{p d_{s}+(1-p) e^{-\xi \tau-\lambda \tau}\left(\lambda+d_{s}+\xi\right)\right\}(\lambda+\omega+\xi)(\lambda+\xi) .
\end{aligned}
$$

At the DFE, it reduces to

$$
\begin{aligned}
F(\lambda)= & (\lambda+\omega+\xi)(\lambda+\xi)\left\{\left(\lambda+d_{s}+\xi\right)(\lambda+r+\xi)(\lambda+\mu)\right. \\
& \left.-\left(\lambda+d_{s}+\xi\right)(1-p) \alpha \beta e^{-\xi \tau-\lambda \tau}-p \alpha \beta d_{s}\right\} .
\end{aligned}
$$

Assume that $R_{d}<1$. Suppose there exists a root for $F(\lambda)=0$ with non-negative real part. Then,

$$
\left|\left(\lambda+d_{s}+\xi\right)(\lambda+\mu)(\lambda+r+\xi)\right|=\left|\left(\lambda+d_{s}+\xi\right)(1-p) \alpha \beta e^{-\xi \tau-\lambda \tau}+p \alpha \beta d_{s}\right| .
$$


Dividing both sides by $\left(d_{s}+\xi\right) \mu(r+\xi)$ gives

$$
\begin{aligned}
& \left|\frac{\lambda}{d_{s}+\xi}+1\right|\left|\frac{\lambda}{\mu}+1\right|\left|\frac{\lambda}{r+\xi}+1\right| \\
= & \frac{\alpha \beta}{\mu(r+\xi)}\left|\left(\frac{\lambda}{d_{s}+\xi}+1\right)(1-p) e^{-\xi \tau-\lambda \tau}+p \frac{d_{s}}{d_{s}+\xi}\right| \\
\leq & \left|\frac{\lambda}{d_{s}+\xi}+1\right| R_{d}^{2},
\end{aligned}
$$

which contradicts to $R_{d}<1$. Therefore, every root of $F(\lambda)=0$ has negative real part, implying the DFE is locally asymptotically stable if $R_{d}<1$.

Now assume $R_{d}>1$. Note that $F(\lambda)=0$ has at least one real root. Since $F(\lambda) \rightarrow \infty$ for real $\lambda \rightarrow \infty$ and

$$
F(0)=\left(d_{s}+\xi\right) \mu(r+\xi)\left(1-R_{d}^{2}\right)<0,
$$

$F(\lambda)=0$ has a positive real root. Therefore the DFE is unstable.

\subsubsection{Comparison of ODE and DDE models}

In Section 2.2.1 and 2.2.2, we have shown that for both ODE and DDE models there exists a threshold value determining the existence and stability of equilibria. Now we compare these threshold values and also the endemic equilibria of the two models.

Proposition 2.5. When all parameters are fixed, the basic reproduction number $R_{o}$ of the ODE model is greater than the basic reproduction number $R_{d}$ of the DDE model. Moreover, when $R_{d}>1, i_{H}^{*}$ of the ODE model (denoted by $i_{o}$ ) is greater than $i_{H}^{*}$ of the DDE model (denoted by $i_{d}$ ).

Proof. Comparing (2.4) and (2.22), we obtain

$$
\begin{aligned}
R_{o} & =\sqrt{\frac{\alpha \beta}{(r+\xi) \mu}\left(p \frac{d_{s}}{d_{s}+\xi}+(1-p) \frac{1}{1+\xi \tau}\right)} \\
& >\sqrt{\frac{\alpha \beta}{(r+\xi) \mu}\left(p \frac{d_{s}}{d_{s}+\xi}+(1-p) \frac{1}{e^{\xi \tau}}\right)} \\
& =R_{d}
\end{aligned}
$$




\begin{tabular}{lll}
\hline PARAMETER & VALUE & REFERENCE \\
\hline$\xi$ & 0.00004 & human life span \\
$\mu$ & $0.2[0.1,0.24]$ & {$[53]$} \\
$b$ & 0.5 & {$[60]$} \\
$c$ & 0.5 & {$[60]$} \\
$a$ & $0.3[0.25,0.5]$ & {$[29]$} \\
$d_{s}$ & 0.04 & {$[43,46]$} \\
$d_{l}$ & 0.003 & {$[43,46]$} \\
$r$ & $0.07[0.005,0.5]$ & {$[29,33,39]$} \\
$p$ & 0.25 & {$[68]$} \\
$\omega$ & $1 / 365$ & \\
\hline
\end{tabular}

TABLE 2.3: Baseline parameter values for simulations

because $e^{\xi \tau}>1+\xi \tau$. To compare the equilibria, consider

$$
\begin{aligned}
i_{o}-i_{d} & =\frac{\left(R_{o}^{2}-1\right)\left(\frac{\beta}{\mu}+K_{d} R_{d}^{2}\right)-\left(R_{d}^{2}-1\right)\left(\frac{\beta}{\mu}+K_{o} R_{o}^{2}\right)}{\left(\frac{\beta}{\mu}+K_{o} R_{o}^{2}\right)\left(\frac{\beta}{\mu}+K_{d} R_{d}^{2}\right)} \\
& =\frac{\frac{\beta}{\mu}\left(R_{o}^{2}-R_{d}^{2}\right)+\left(K_{d}-K_{o}\right) R_{o}^{2} R_{d}^{2}}{\left(\frac{\beta}{\mu}+K_{o} R_{o}^{2}\right)\left(\frac{\beta}{\mu}+K_{d} R_{d}^{2}\right)} .
\end{aligned}
$$

Since $R_{o}>R_{d}$, it is sufficient to show $K_{d}>K_{o}$ in order to conclude $i_{o}>i_{d}$. Since $e^{\xi \tau}>1+\xi \tau, e^{-\xi \tau}<\frac{1}{1+\xi \tau}$. Recall that $\tau=1 / d_{l}$, hence

$$
e^{-\xi \tau}<\frac{d_{l}}{d_{l}+\xi}
$$

Thus, $1-e^{-\xi \tau}>1-\frac{1}{1+\xi \tau}=\frac{\xi}{d_{l}+\xi}$, implying

$$
\frac{1-e^{-\xi \tau}}{\xi}>\frac{1}{d_{l}+\xi}
$$

By (2.37) and (2.38), we find

$$
\frac{\frac{p}{d_{s}+\xi}+(1-p) \frac{1-e^{-\xi \tau}}{\xi}}{p \frac{d_{s}}{d_{s}+\xi}+(1-p) e^{-\xi \tau}}>\frac{\frac{p}{d_{s}+\xi}+\frac{1-p}{d_{l}+\xi}}{p \frac{d_{s}}{d_{s}+\xi}+(1-p) \frac{d_{l}}{d_{l}+\xi}}
$$

which is equivalent to $K_{d}>K_{o}$.

In conclusion, the ODE model gives a larger basic reproduction number than the DDE model, because of the higher probability of surviving the incubation period. Figure 2.4 and Figure 2.5 show numerical solutions. Figure 2.4 shows the case $R_{o}>1$ and $R_{d}>1$, when $i_{H}(t)$ converges to the endemic equilibrium for both models. Figure 2.5 shows a particular case when $R_{o}>1$ but $R_{d}<1$. Despite that all parameters are the same, here 


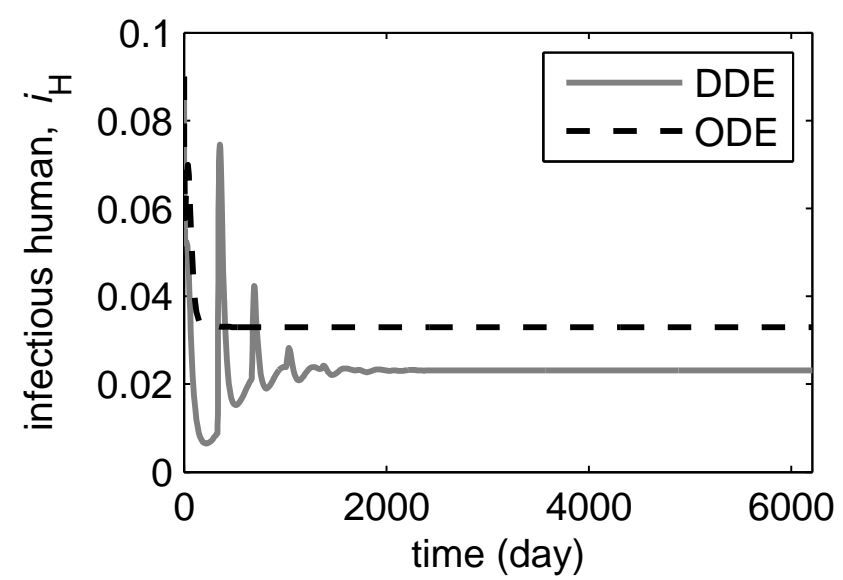

Figure 2.4: $\boldsymbol{R}_{\boldsymbol{o}}>\mathbf{1}$ and $\boldsymbol{R}_{\boldsymbol{d}}>\mathbf{1}$. For both models, $i_{H}(t)$ converges to endemic equilibrium with $i_{o}>i_{d}$. To clearly show the difference of $i_{o}$ and $i_{d}$, we set $\xi=0.004$ and $m=10$. Other parameter values are as indicated in Table 2.3. Initial condition for ODE model is $\left(s_{H}, e_{H}^{s}, e_{H}^{l}, i_{H}, r_{H}, s_{M}, i_{M}\right)(0)=(0.91,0,0,0.09,0,0,0.01)$. For sake of convenience, initial condition of DDE model is set to be $s_{H}(t)=1$ and $s_{M}(t)=1$ for $t<0$, introducing infectious mosquito at $t=0,\left(s_{H}, e_{H}^{s}, e_{H}^{l}, i_{H}, r_{H}, s_{M}, i_{M}\right)(0)=$ $(0.91,0,0,0.09,0,0,0.01)$.

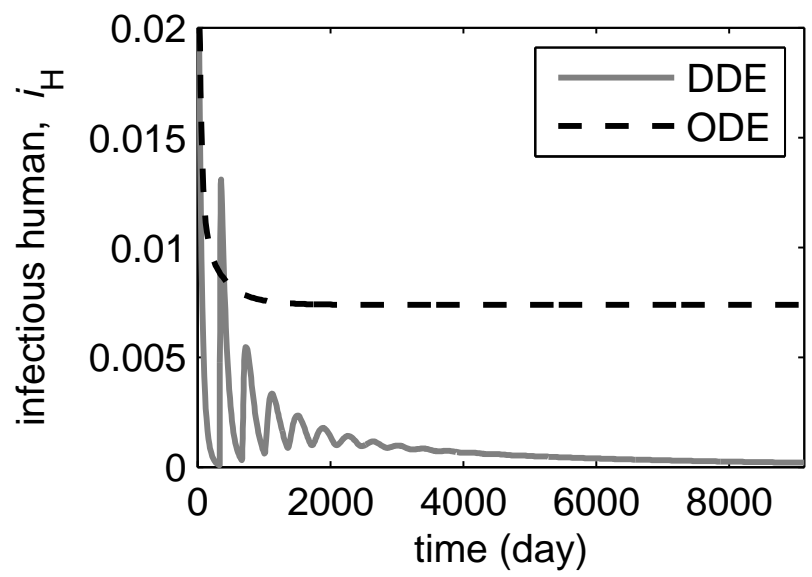

Figure 2.5: $\boldsymbol{R}_{\boldsymbol{o}}>\mathbf{1}$ and $\boldsymbol{R}_{\boldsymbol{d}}<\mathbf{1}$. For the ODE model, $i_{H}(t)$ converges to EE, while it converges to DFE for the DDE model. To compare with Figure 2.4, we used parameter value $m=1.5$. Other parameter values and initial condition are same as the one in Figure 2.4.

$i_{H}(t)$ of ODE model converges to the endemic equilibrium, and $i_{H}(t)$ of DDE model converges to the disease-free equilibrium, thus the two models provide very different predictions.

To investigate the robustness of the basic reproduction number with respect to the long-term incubation time, in Figure 2.6 we compared

$$
\frac{\partial R_{o}}{\partial \tau}=\frac{-1}{2 R_{o}} \frac{\alpha \beta}{\mu(r+\xi)} \frac{(1-p) \xi}{(1+\xi \tau)^{2}}
$$




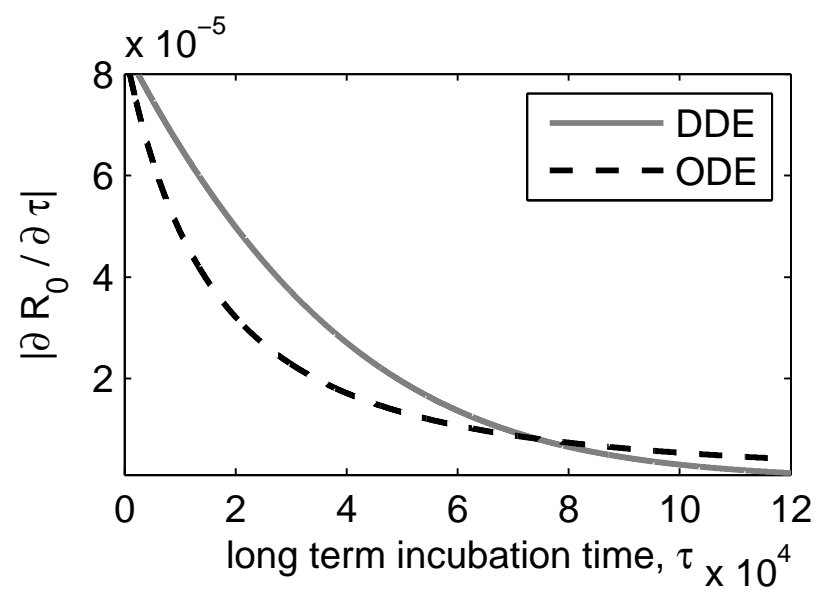

FIGURE 2.6: Sensitivity of the basic reproduction number to the long-term incubation time. For $\tau$ being in reasonable range, $\left|\frac{\partial R_{o}}{\partial \tau}\right|<\left|\frac{\partial R_{d}}{\partial \tau}\right|$. Parameter values are as in Table 2.3 with $m=20$.

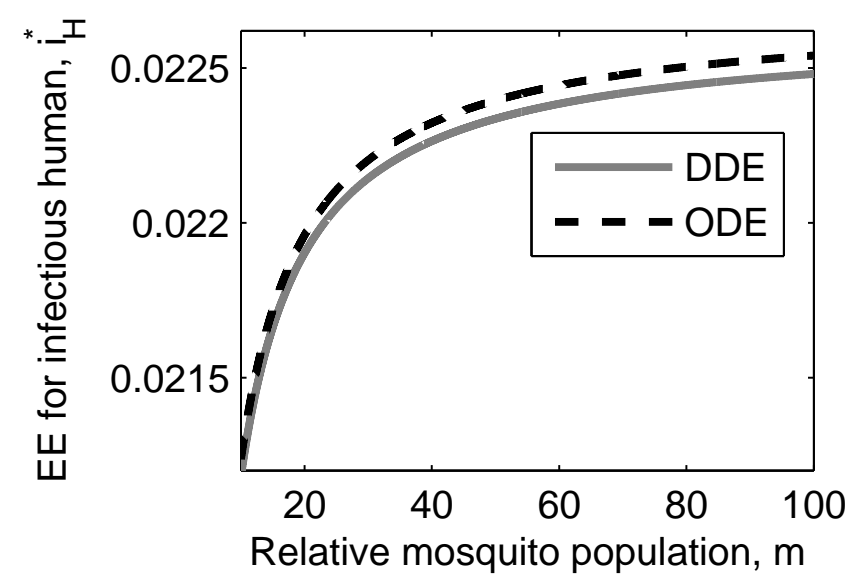

Figure 2.7: Relation of $\boldsymbol{m}$ and $\boldsymbol{i}_{H}^{*}$. Change of $i_{H}^{*}$ is more drastic at smaller mosquito population. Parameter values are as in Table 2.3.

and

$$
\frac{\partial R_{d}}{\partial \tau}=\frac{-1}{2 R_{d}} \frac{\alpha \beta}{\mu(r+\xi)}(1-p) \xi e^{-\xi \tau} .
$$

The magnitude of $\frac{\partial R_{o}}{\partial \tau}$ is smaller than $\frac{\partial R_{d}}{\partial \tau}$ when $\tau$ is in the reasonable range, so the basic reproduction number is more sensitive to the long-term incubation time in the DDE model.

In Figure 2.7, the infectious human component of the endemic equilibrium is plotted for various mosquito populations. As expected from Proposition 2.5, the infectious human equilibrium for the ODE model is greater than for the DDE model. Moreover, we can see that a small change in the mosquito population affects the level of endemicity more significantly when the mosquito population is relatively small. 


\subsubsection{Global dynamics of DDE model}

In this section, we study the global dynamics of the DDE model presented in Section 2.2.2. Note that $e_{H}^{l}(t)$ does not appear in the right-hand side of the system (2.21) and it can reduced to the system

$$
\begin{aligned}
& \frac{d s_{H}(t)}{d t}=\xi-\alpha s_{H}(t) i_{M}(t)-\xi s_{H}(t)+\omega r_{H}(t), \\
& \frac{d e_{H}^{s}(t)}{d t}=p \alpha s_{H}(t) i_{M}(t)-\left(d_{s}+\xi\right) e_{H}^{s}(t), \\
& \frac{d i_{H}(t)}{d t}=d_{s} e_{H}^{s}(t)+(1-p) \alpha s_{H}(t-\tau) i_{M}(t-\tau) e^{-\xi \tau}-(r+\xi) i_{H}(t), \\
& \frac{d r_{H}(t)}{d t}=r i_{H}(t)-(\omega+\xi) r_{H}(t), \\
& \frac{d s_{M}(t)}{d t}=\mu-\beta s_{M}(t) i_{H}(t)-\mu s_{M}(t), \\
& \frac{d i_{M}(t)}{d t}=\beta s_{M}(t) i_{H}(t)-\mu i_{M}(t) .
\end{aligned}
$$

Let $C([-\tau, 0], \mathbb{R})$ be the space of real valued continuous functions on the interval $[-\tau, 0]$, and consider

$$
\Omega:=C([-\tau, 0], \mathbb{R}) \times \mathbb{R}^{4} \times C([-\tau, 0], \mathbb{R}) .
$$

Assuming that the solution exists in $\Omega$, it is convenient to introduce a standard notation from the theory of functional differential equations, see e.g. [23, 65]:

$$
x_{t}:=\left(s_{H t}, e_{H}^{s}(t), i_{H}(t), r_{H}(t), s_{M}(t), i_{M t}\right) \in \Omega,
$$

where $s_{H t} \in C([-\tau, 0], \mathbb{R})$ and $i_{M t} \in C([-\tau, 0], \mathbb{R})$ are defined by the relations

$$
s_{H t}(\theta)=s_{H}(t+\theta), \quad i_{M t}(\theta)=i_{M}(t+\theta) \quad \text { for } \quad \theta \in[-\tau, 0] .
$$

In what follows, we write $\hat{y}$ for the element of $C([-\tau, 0], \mathbb{R})$ satisfying $\hat{y}(\theta)=y$ for all $\theta \in[-\tau, 0]$. Let

$$
\Omega_{+}:=C\left([-\tau, 0], \mathbb{R}_{+}\right) \times \mathbb{R}_{+}^{4} \times C\left([-\tau, 0], \mathbb{R}_{+}\right) .
$$

Following the biological interpretation of our system, we prescribe the initial condition as

$$
x_{0}=\phi_{0} \in \Omega_{+} .
$$

Then system (2.39) can be written in the abstract form

$$
\frac{d x(t)}{d t}=\mathcal{F}\left(x_{t}\right),
$$


where $\mathcal{F}: \Omega \rightarrow \mathbb{R}^{6}$, with initial condition (2.40). We consider $\mathbb{R}^{6}$ equipped with the $L^{\infty}$ norm and $C([-\tau, 0], \mathbb{R})$ equipped with the usual supremum norm denoted by $\|\cdot\|$. Now $\Omega$ is a Banach space with the norm

$$
|\phi|_{\Omega}:=\max \left\{\|f\|,\left|q_{2}\right|,\left|q_{3}\right|,\left|q_{4}\right|,\left|q_{5}\right|,\|g\|\right\}
$$

for

$$
\phi=\left(f, q_{2}, q_{3}, q_{4}, q_{5}, g\right) \in \Omega .
$$

Then it is easy to show that $\mathcal{F}$ satisfies the local Lipschitz condition on each bounded subset of $\Omega$, from which the local existence of solutions of (2.39) follows, see also Theorem 3.7 in Chapter 3 in [65]. Furthermore, it is straightforward to show that $x_{t} \in \Omega_{+}$for sufficiently small $t$ and it is easy to give an a priori bound for $\left|x_{t}\right|_{\Omega}$. Thus the solution $x_{t}$ is continuable on $\mathbb{R}_{+}$. Consequently, (2.39) with (2.40) induces a continuous semiflow

$$
\Phi:=\mathbb{R}_{+} \times \Omega_{+} \rightarrow \Omega_{+},
$$

defined by

$$
\Phi\left(t, \phi_{0}\right)=x_{t}\left(\phi_{0}\right)
$$

Let

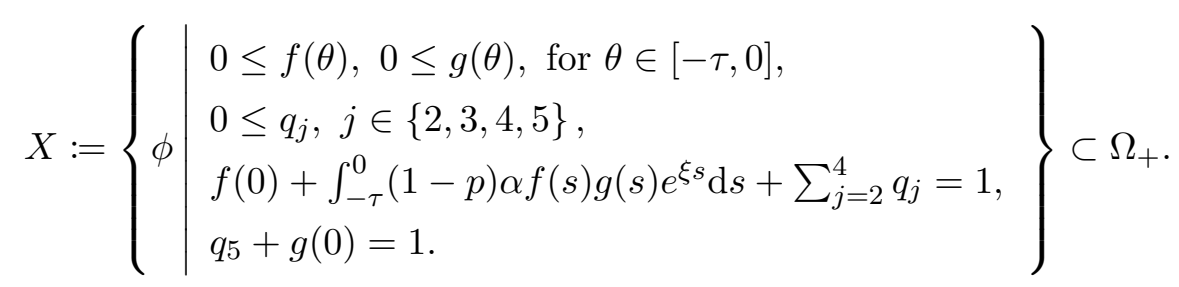

Proposition 2.6. The set $X$ is forward invariant under $\Phi$, i.e.

$$
\Phi(t, X) \subset X, \quad t \in \mathbb{R}_{+} .
$$

Proof. Let $\phi_{0} \in X$. By Theorem 3.4 in [65], one can show that each component of $x_{t}\left(\phi_{0}\right)$ is nonnegative for all $t \geq 0$. Adding (2.39e) and (2.39f), we have $s_{M}^{\prime}+i_{M}^{\prime}=0$, thus $s_{M}(t)+i_{M}(t)$ is a constant function. Since $s_{M}(0)+i_{M}(0)=1$, we have $s_{M}(t)+i_{M}(t)=1$ for all $t \geq 0$. Let

$$
n(t):=s_{H}(t)+e_{H}^{s}(t)+i_{H}(t)+r_{H}(t)+\int_{0}^{\tau}(1-p) \alpha s_{H}(t-a) i_{M}(t-a) e^{-\xi a} \mathrm{~d} a .
$$


Note that from (2.19) and (2.20) we have

$$
\begin{aligned}
& \frac{d}{d t} \int_{0}^{\tau}(1-p) \alpha s_{H}(t-a) i_{M}(t-a) e^{-\xi a} \mathrm{~d} a \\
= & \frac{d}{d t} e_{H}^{l}(t) \\
= & (1-p) \alpha s_{H}(t) i_{M}(t)-(1-p) \alpha s_{H}(t-\tau) i_{M}(t-\tau) e^{-\xi \tau} \\
& -\xi \int_{0}^{\tau}(1-p) \alpha s_{H}(t-a) i_{M}(t-a) e^{-\xi a} \mathrm{~d} a .
\end{aligned}
$$

Adding (2.39a)-(2.39d) and (2.20), one obtains

$$
\frac{d n(t)}{d t}=\xi-\xi n(t)
$$

with $n(0)=1$. Thus $n(t)=1$ for all $t \geq 0$, and the conclusion follows.

The variables in (2.39) represent fractions of either the human population or the mosquito population. Thus, in $X$, the fractions of the human population sum up to 1 , with all human compartments $\left(s_{H}, e_{H}^{s}, e_{H}^{l}, i_{H}, r_{H}\right)$ being nonnegative; and the fractions of mosquito population sum up to 1 , with all mosquito compartments $\left(s_{M}, i_{M}\right)$ being nonnegative. Therefore $X$ is exactly the biologically meaningful state space. In Sections 2 and 3 we consider the dynamics of system (2.39) in $X$.

The result on the existence of equilibria follows from the previous Chapter 2.2.2. Recall (2.22) for the definition of $R_{d}$.

Proposition 2.7. If $R_{d} \leq 1$, then system (2.39) has a unique equilibrium ( $\left.\hat{1}, 0,0,0,1, \hat{0}\right)$ in $X$, the DFE. If $R_{d}>1$, there exist exactly two equilibria in $X$, the DFE and the EE, where each component is positive.

Theorem 2.8. The DFE of system (2.39) is locally asymptotically stable if $R_{d}<1$ and unstable if $R_{d}>1$. The EE is locally asymptotically stable whenever exists, i.e. if $R_{d}>1$.

Proof. The result on the DFE is in the previous section 2.2.2. Assume $R_{d}>1$. Then, the characteristic equation $F(\lambda)=0$ from (2.37) has at least one real root. Since $F(\lambda) \rightarrow \infty$ for real $\lambda \rightarrow \infty$ and

$$
F(0)=\left(d_{s}+\xi\right) \mu(r+\xi)\left(1-R_{d}^{2}\right)<0,
$$

$F(\lambda)=0$ has a positive real root. Therefore the DFE is unstable. 
Suppose that the EE is not locally asymptotically stable. Then there exists a characteristic root $\lambda$ with nonnegative real part. For the EE,

$$
s_{H}^{*} s_{M}^{*}=1 / R_{d}^{2}
$$

holds and the characteristic equation can be re-written as

$$
\begin{aligned}
& \mu(r+\xi) \frac{p d_{s}+(1-p) e^{-\xi \tau-\lambda \tau}\left(\lambda+d_{s}+\xi\right)}{(1-p) e^{-\xi \tau}+p \frac{d_{s}}{d_{s}+\xi}}(\lambda+\omega+\xi)(\lambda+\xi) \\
= & \left(\lambda+\mu+\beta i_{H}^{*}\right)(\lambda+\omega+\xi)\left(\lambda+\xi+\alpha i_{M}^{*}\right)\left(\lambda+d_{s}+\xi\right)(\lambda+r+\xi) \\
& -\omega r \alpha i_{M}^{*}\left\{p d_{s}+(1-p) e^{-\xi \tau-\lambda \tau}\left(\lambda+d_{s}+\xi\right)\right\}\left(\lambda+\mu+\beta i_{H}^{*}\right) .
\end{aligned}
$$

Dividing both sides by

$$
\mu(r+\xi)\left(d_{s}+\xi\right)(\omega+\xi) \xi
$$

gives

$$
\begin{aligned}
& \frac{p \frac{d_{s}}{d_{s}+\xi}+(1-p) e^{-\xi \tau-\lambda \tau}\left(\frac{\lambda}{d_{s}+\xi}+1\right)}{(1-p) e^{-\xi \tau}+p \frac{d_{s}}{d_{s}+\xi}}\left(\frac{\lambda}{\omega+\xi}+1\right)\left(\frac{\lambda}{\xi}+1\right) \\
= & \left(\frac{\lambda}{\mu}+1+\frac{\beta i_{H}^{*}}{\mu}\right)\left[\left(\frac{\lambda}{\omega+\xi}+1\right)\left(\frac{\lambda}{\xi}+1+\frac{\alpha i_{M}^{*}}{\xi}\right)\left(\frac{\lambda}{d_{s}+\xi}+1\right)\left(\frac{\lambda}{r+\xi}+1\right)\right. \\
& \left.-\frac{\omega}{\omega+\xi} \frac{r}{r+\xi} \frac{\alpha i_{M}^{*}}{\xi}\left\{p \frac{d_{s}}{d_{s}+\xi}+(1-p) e^{-\xi \tau-\lambda \tau}\left(\frac{\lambda}{d_{s}+\xi}+1\right)\right\}\right] .
\end{aligned}
$$

Then,

$$
\begin{aligned}
& \left|\frac{\lambda}{\mu}+1+\frac{\beta i_{H}^{*}}{\mu}\right|\left|\frac{\lambda}{\omega+\xi}+1\right|\left|\frac{\lambda}{\xi}+1+\frac{\alpha i_{M}^{*}}{\xi}\right|\left|\frac{\lambda}{d_{s}+\xi}+1\right|\left|\frac{\lambda}{r+\xi}+1\right| \\
= & \mid \frac{p \frac{d_{s}}{d_{s}+\xi}+(1-p) e^{-\xi \tau-\lambda \tau}\left(\frac{\lambda}{d_{s}+\xi}+1\right)}{(1-p) e^{-\xi \tau}+p \frac{d_{s}}{d_{s}+\xi}}\left(\frac{\lambda}{\omega+\xi}+1\right)\left(\frac{\lambda}{\xi}+1\right) \\
& +\frac{\omega}{\omega+\xi} \frac{r}{r+\xi} \frac{\alpha i_{M}^{*}}{\xi}\left\{p \frac{d_{s}}{d_{s}+\xi}+(1-p) e^{-\xi \tau-\lambda \tau}\left(\frac{\lambda}{d_{s}+\xi}+1\right)\right\}\left(\frac{\lambda}{\mu}+1+\frac{\beta i_{H}^{*}}{\mu}\right) \mid \\
= & \left|\frac{p \frac{d_{s}}{d_{s}+\xi}+(1-p) e^{-\xi \tau-\lambda \tau}\left(\frac{\lambda}{d_{s}+\xi}+1\right)}{(1-p) e^{-\xi \tau}+p \frac{d_{s}}{d_{s}+\xi}}\right| \mid\left(\frac{\lambda}{\omega+\xi}+1\right)\left(\frac{\lambda}{\xi}+1\right) \\
& +\frac{\omega}{\omega+\xi} \frac{r}{r+\xi} \frac{\alpha i_{M}^{*}}{\xi}\left\{(1-p) e^{-\xi \tau}+p \frac{d_{s}}{d_{s}+\xi}\right\}\left(\frac{\lambda}{\mu}+1+\frac{\beta i_{H}^{*}}{\mu}\right) \mid \\
\leq & \left|\frac{\lambda}{d_{s}+\xi}+1\right| \mid\left(\frac{\lambda}{\omega+\xi}+1\right)\left(\frac{\lambda}{\xi}+1\right) \\
& +\frac{\omega}{\omega+\xi} \frac{r}{r+\xi} \frac{\alpha i_{M}^{*}}{\xi}\left\{(1-p) e^{-\xi \tau}+p \frac{d_{s}}{d_{s}+\xi}\right\}\left(\frac{\lambda}{\mu}+1+\frac{\beta i_{H}^{*}}{\mu}\right) \mid \\
\leq & \left|\frac{\lambda}{d_{s}+\xi}+1\right|\left(\left|\frac{\lambda}{\omega+\xi}+1\right|\left|\frac{\lambda}{\xi}+1\right|+\frac{\alpha i_{M}^{*}}{\xi}\left|\frac{\lambda}{\mu}+1+\frac{\beta i_{H}^{*}}{\mu}\right|\right) \\
< & \left|\frac{\lambda}{d_{s}+\xi}+1\right|\left|\frac{\lambda}{\omega+\xi}+1\right|\left|\frac{\lambda}{\xi}+1\right|\left|\frac{\lambda}{\mu}+1+\frac{\beta i_{H}^{*}}{\mu}\right|\left(1+\frac{\alpha i_{M}^{*}}{\xi}\right)
\end{aligned}
$$


which is a contradiction, hence the EE is locally asymptotically stable.

First we prove the global attractivity of the disease-free equilibrium for $R_{0} \leq 1$. Let us define a subset of $X$ by

$$
G:=\left\{\phi \in X \mid f(0)>0, q_{5}>0\right\}
$$

It is easy to see that

$$
\Phi(t, X) \subset G, \quad t>0 .
$$

To prove the global attractivity, we construct a Lyapunov functional, for what we use, as a building block, the function

$$
h(x):=x-1-\ln x \quad \text { for } \quad x \in \mathbb{R}_{+} \backslash\{0\} .
$$

Note that $h(x) \geq 0$ for $x \in \mathbb{R}_{+} \backslash\{0\}$ and that $h(x)=0$ if and only if $x=1$.

Theorem 2.9. If $R_{d} \leq 1$, then the disease-free equilibrium is globally attractive in $X$. Furthermore, if $R_{d}<1$ holds, then it is globally asymptotically stable in $X$.

Proof. Consider the following functional $V: G \rightarrow \mathbb{R}_{+}$:

$$
V(\phi):=c_{1} h(f(0))+c_{2} q_{2}+q_{3}+c_{3} h\left(q_{5}\right)+c_{3} g(0)+c_{4} \int_{-\tau}^{0} f(s) g(s) \mathrm{d} s,
$$

where

$$
c_{1}:=\frac{\mu(r+\xi)}{\alpha \beta}, \quad c_{2}:=\frac{d_{s}}{d_{s}+\xi}, \quad c_{3}:=\frac{r+\xi}{\beta}, \quad c_{4}:=(1-p) \alpha e^{-\xi \tau} .
$$

We differentiate $V$ with respect to $t$ along solutions of (2.39):

$$
\begin{aligned}
\frac{d}{d t} V\left(x_{t}\right)= & c_{1}\left(\xi-\alpha s_{H}(t) i_{M}(t)+\omega r_{H}(t)-\xi s_{H}(t)\right) \\
& +c_{1}\left(-\frac{\xi}{s_{H}(t)}+\alpha i_{M}(t)-\omega \frac{r_{H}(t)}{s_{H}(t)}+\xi\right) \\
& +c_{2}\left(p \alpha s_{H}(t) i_{M}(t)-\left(d_{s}+\xi\right) e_{H}^{s}(t)\right) \\
& +d_{s} e_{H}^{s}(t)+(1-p) \alpha s_{H}(t-\tau) i_{M}(t-\tau) e^{-\xi \tau}-(r+\xi) i_{H}(t) \\
& +c_{3}\left(\mu-\beta s_{M}(t) i_{H}(t)-\mu s_{M}(t)\right)+c_{3}\left(-\frac{\mu}{s_{M}(t)}+\beta i_{H}(t)+\mu\right) \\
& +c_{3}\left(\beta s_{M}(t) i_{H}(t)-\mu i_{M}(t)\right) \\
& +c_{4}\left(s_{H}(t) i_{M}(t)-s_{H}(t-\tau) i_{M}(t-\tau)\right) \\
= & c_{1} \xi\left(2-s_{H}(t)-\frac{1}{s_{H}(t)}\right)+c_{3} \mu\left(2-s_{M}(t)-\frac{1}{s_{M}(t)}\right)
\end{aligned}
$$




$$
\begin{aligned}
& +c_{1} \omega r_{H}(t)\left(1-\frac{1}{s_{H}(t)}\right)+\left(c_{2} p \alpha+c_{4}-c_{1} \alpha\right) s_{H}(t) i_{M}(t) \\
& +\left(d_{s}-c_{2}\left(d_{s}+\xi\right)\right) e_{H}^{s}(t)+\left(c_{1} \alpha-c_{3} \mu\right) i_{M}(t)+\left(c_{3} \beta-(r+\xi)\right) i_{H}(t) \\
& +\left((1-p) \alpha e^{-\xi \tau}-c_{4}\right) s_{H}(t-\tau) i_{M}(t-\tau) \\
= & c_{1} \xi\left(2-s_{H}(t)-\frac{1}{s_{H}(t)}\right)+c_{3} \mu\left(2-s_{M}(t)-\frac{1}{s_{M}(t)}\right) \\
& +c_{1} \omega r_{H}(t)\left(1-\frac{1}{s_{H}(t)}\right)+\left(c_{2} p \alpha+c_{4}-c_{1} \alpha\right) s_{H}(t) i_{M}(t) .
\end{aligned}
$$

Since $R_{d} \leq 1$ is assumed, one can get

$$
c_{2} p \alpha+c_{4}-c_{1} \alpha=\frac{\mu(r+\xi)}{\beta}\left(R_{d}^{2}-1\right) \leq 0 .
$$

Therefore we have $\frac{d}{d t} V\left(x_{t}\right) \leq 0$. For a given solution, we define a set

$$
\bar{G}:=\left\{\varphi \in G \mid V(\varphi) \leq V\left(x_{t_{0}}\right)\right\},
$$

for some $t_{0}>0$. One can see that $\bar{G}$ is closed and positively invariant. Thus the closure of $\bar{G}$ is itself and $\bar{G}$ contains $x_{t}$ for all $t \geq t_{0}>0$. Since $V$ is continuous on $\bar{G}, V$ is a Lyapunov functional on $G$, see Chapter 5.3 in [23]. We define the set

$$
E:=\left\{\varphi \in \bar{G} \mid \dot{V}_{(2.39)}(\varphi)=0\right\}
$$

and one finds that

$$
E=\left\{\phi \in \bar{G} \mid f(0)=1, q_{5}=1\right\} .
$$

Let $M$ be the largest subset in $E$ that is invariant with respect to (2.39). By LaSalle's invariance principle, the solution tends to $M$, see Theorem 3.2, Chapter 5.3 in [23]. We show that $M$ consists of only the disease-free equilibrium. From the invariance of $M$, for $\phi \in M$ one has

$$
x_{t}(\phi) \in M \subset E \text { for } t>0 .
$$

Then $s_{M}(t)=1$ and $i_{H}(t)=0$ follow. From (2.39f), we obtain $\lim _{t \rightarrow \infty} i_{M}(t)=0$. Then one can see that

$$
\lim _{t \rightarrow \infty}\left(e_{H}^{s}(t), i_{H}(t), i_{M}(t)\right)=(0,0,0)
$$

and $\lim _{t \rightarrow \infty} s_{H}(t)=1$. Thus, $M$ consists of only the disease-free equilibrium. Hence, every solution converges to the disease-free equilibrium. The local asymptotic stability of the disease-free equilibrium can be demonstrated by standard linearization: one can compute the characteristic equation (see $[23,66]$ ), and show that if $R_{0}<1$, then all roots of the characteristic equation have negative real parts. Here we omit the calculations. Thus the disease-free equilibrium is globally asymptotically stable for $R_{0}<1$. 
Next we prove the persistence of the disease for $R_{0}>1$. Let us define

$$
\rho:=\sum_{i=1}^{4} \rho_{i},
$$

where $\rho_{i}: X \rightarrow \mathbb{R}_{+}$for $i \in\{1,2,3,4\}$ are given by

$$
\begin{array}{ll}
\rho_{1}(\phi)=q_{2}, & \rho_{2}(\phi)=(1-p) \alpha \int_{-\tau}^{0} f(s) g(s) e^{\xi s} d s \\
\rho_{3}(\phi)=q_{3}, & \rho_{4}(\phi)=g(0) .
\end{array}
$$

Let

$$
\begin{aligned}
\tilde{X} & :=\{\phi \in X \mid \rho(\phi)>0\}, \\
X_{0} & :=\{\phi \in X \mid \rho(\phi)=0\}=X \backslash \tilde{X},
\end{aligned}
$$

where $X_{0}$ is called the extinction space corresponding to $\rho$, for obvious reasons: $X_{0}$ is the collection of states where the disease is not present.

Proposition 2.10. The following assertions hold.

1. The set $\tilde{X}$ is forward invariant under $\Phi$. Moreover, for each $i \in\{1,2,3,4\}$ it holds that

$$
\rho_{i}(\Phi(t, \phi))>0 \quad \text { for } \phi \in \tilde{X} \text { and } t>\tau \text {. }
$$

2. The extinction space $X_{0}$ is forward invariant under $\Phi$.

Proof. One can prove the first part by a comparison method and a contradiction argument, thus here we only prove the second part. Let $\phi \in X_{0}$. For $t \in[0, \tau]$ one can see that

$$
(1-p) \alpha s_{H}(t-\tau) i_{M}(t-\tau) e^{-\xi \tau}=(1-p) \alpha f(t-\tau) g(t-\tau) e^{-\xi \tau}=0 .
$$

Therefore, for $t \in[0, \tau],(2.39 \mathrm{~b}),(2.39 \mathrm{c})$ and $(2.39 \mathrm{~d})$ are respectively reduce to

$$
\begin{aligned}
& \frac{d e_{H}^{s}(t)}{d t}=p \alpha s_{H}(t) i_{M}(t)-\left(d_{s}+\xi\right) e_{H}^{s}(t), \\
& \frac{d i_{H}(t)}{d t}=d_{s} e_{H}^{s}(t)-(r+\xi) i_{H}(t), \\
& \frac{d i_{M}(t)}{d t}=\beta s_{M}(t) i_{H}(t)-\mu i_{M}(t)
\end{aligned}
$$

with $e_{H}^{s}(0)=i_{H}(0)=i_{M}(0)=0$. Since $\left(e_{H}^{s}, i_{H}, i_{M}\right)=(0,0,0)$ is an equilibrium of (2.46), we get that

$$
e_{H}^{s}(t)=i_{H}(t)=i_{M}(t)=0, \quad t \in[0, \tau]
$$


therefore

$$
\begin{aligned}
\int_{-\tau}^{0} s_{H t}(s) i_{M t}(s) e^{\xi s} \mathrm{~d} s & =\int_{t-\tau}^{t} s_{H}(s) i_{M}(s) e^{-\xi(t-s)} \mathrm{d} s \\
& =\int_{t-\tau}^{0} f(s) g(s) e^{-\xi(t-s)} \mathrm{d} s+\int_{0}^{t} s_{H}(s) i_{M}(s) e^{-\xi(t-s)} \mathrm{d} s \\
& =0, \quad t \in[0, \tau] .
\end{aligned}
$$

Hence we obtain $\rho(\Phi(t, \phi))=0$ for $t \in[0, \tau]$. By the method of steps, we arrive to the conclusion that $\rho(\Phi(t, \phi))=0$ holds for all $t \in \mathbb{R}_{+}$, i.e. $\rho\left(\Phi(t, \phi) \in X_{0}\right.$ for all $t \in \mathbb{R}_{+}$.

We now introduce some terminology of persistence theory from Chapters 3.1 and 8.3 in [66].

Definition 2.11. Let $X$ be a nonempty set and $\rho: X \rightarrow \mathbb{R}_{+}$.

1. A semiflow $\Phi: \mathbb{R}_{+} \times X \rightarrow X$ is called uniformly weakly $\rho$-persistent, if there exists some $\epsilon>0$ such that

$$
\limsup _{t \rightarrow \infty} \rho(\Phi(t, x))>\epsilon \quad \forall x \in X, \rho(x)>0 .
$$

2. A semiflow $\Phi$ is called uniformly (strongly) $\rho$-persistent, if there exists some $\epsilon>0$ such that

$$
\liminf _{t \rightarrow \infty} \rho(\Phi(t, x))>\epsilon \quad \forall x \in X, \rho(x)>0 .
$$

3. A set $M \subset X$ is called weakly $\rho$-repelling if there is no $x \in X$ such that $\rho(x)>0$ and $\Phi(t, x) \rightarrow M$ as $t \rightarrow \infty$.

Theorem 2.12. If $R_{d}>1$, then the semiflow $\Phi$ is uniformly $\rho$-persistent.

Proof. We apply Theorem 4.5 and Theorem 8.17 in [66]. First, we show that $(\hat{1}, 0,0,0,1, \hat{0})$ is weakly $\rho$-repelling. Suppose that there exists $\psi_{0} \in X$ such that $\rho\left(\psi_{0}\right)>0$ with

$$
\lim _{t \rightarrow \infty} \Phi\left(t, \psi_{0}\right)=(\hat{1}, 0,0,0,1, \hat{0})
$$

We denote by

$$
\left(s_{H_{t}}, e_{H}^{s}(t), i_{H}(t), r_{H}(t), s_{M}(t), i_{M_{t}}\right)
$$

the solution at time $t$ with initial state $\psi_{0}$. Since we have (2.47), there exists $T>0$ such that

$$
s_{H}(t)>\frac{1}{R_{d}} \quad \text { and } \quad s_{M}(t)>\frac{1}{R_{d}}
$$


for all $t>T$. Let us define

$$
U(t):=\frac{d_{s}}{d_{s}+\xi} e_{H}^{s}(t)+(1-p) \alpha e^{-\xi \tau} \int_{-\tau}^{0} s_{H_{t}}(s) i_{M_{t}}(s) \mathrm{d} s+i_{H}(t)+R_{d} \frac{r+\xi}{\beta} i_{M_{t}}(0) .
$$

Since $\rho\left(\psi_{0}\right)>0$, by Proposition 2.10.1, $U(T)>0$. We compute

$$
\begin{aligned}
U^{\prime}(t)= & \frac{d_{s}}{d_{s}+\xi}\left(p \alpha s_{H}(t) i_{M}(t)-\left(d_{s}+\xi\right) e_{H}^{s}(t)\right) \\
& +(1-p) \alpha e^{-\xi \tau}\left(s_{H}(t) i_{M}(t)-s_{H}(t-\tau) i_{M}(t-\tau)\right) \\
& +d_{s} e_{H}^{s}(t)+(1-p) \alpha e^{-\xi \tau} s_{H}(t-\tau) i_{M}(t-\tau)-(r+\xi) i_{H}(t) \\
& +R_{d} \frac{r+\xi}{\beta}\left(\beta s_{M}(t) i_{H}(t)-\mu i_{M}(t)\right) \\
= & \left(p \alpha \frac{d_{s}}{d_{s}+\xi}+(1-p) \alpha e^{-\xi \tau}\right) s_{H}(t) i_{M}(t) \\
& -(r+\xi) i_{H}(t)-R_{d} \frac{(r+\xi) \mu}{\beta} i_{M}(t)+R_{d}(r+\xi) s_{M}(t) i_{H}(t) \\
= & R_{d} \frac{(r+\xi) \mu}{\beta} i_{M}(t)\left(R_{0} s_{H}(t)-1\right)+(r+\xi) i_{H}(t)\left(R_{d} s_{M}(t)-1\right) \\
\geq & 0
\end{aligned}
$$

for $t>T$. Since $U$ is increasing for $t>T$ and $U(T)>0, U(t)$ does not converge to zero as $t \rightarrow \infty$. Thus, there is no $\psi_{0} \in X$ such that $\rho\left(\psi_{0}\right)>0$ and (2.47) holds. Therefore, $(\hat{1}, 0,0,0,1, \hat{0})$ is weakly $\rho$-repelling.

By Proposition 2.10.1, together with the obvious statement

$$
\cup_{\phi \in X_{0}} \omega(\phi)=(\hat{1}, 0,0,0,1, \hat{0})
$$

one can see that $\Phi$ is uniformly weakly $\rho$-persistent using Theorem 8.17 in [66]. Since $\Phi$ has a compact global attractor on $X$, we can apply Theorem 4.5 in [66] to conclude that $\Phi$ is uniformly $\rho$-persistent.

For a function $f: \mathbb{R} \rightarrow \mathbb{R}$, we use the notation

$$
f^{\infty}=\limsup _{t \rightarrow \infty} f(t) \text { and } f_{\infty}=\liminf _{t \rightarrow \infty} f(t) .
$$

Theorem 2.13. If $R_{d}>1$, then $\Phi$ is uniformly $\rho_{4}$-persistent.

Proof. Let $\psi \in X$ with $\rho_{4}(\psi)>0$. Since $\rho(\psi) \geq \rho_{4}(\psi)>0$, by Theorem 2.12, there exists $\epsilon>0$ such that $\liminf _{t \rightarrow \infty} \rho(\Phi(t, \psi))>\epsilon$. Thus, one has

$$
\limsup _{t \rightarrow \infty} \rho_{i}(\Phi(t, \psi))>\epsilon
$$


for some $i \in\{1,2,3,4\}$.

First, assume that $e_{H}^{s \infty}>\epsilon$. By the Fluctuation method [65], we can take a sequence $\left\{t_{j}\right\}_{j=1}^{\infty}$ such that

$$
e_{H}^{s \prime}\left(t_{j}\right) \rightarrow 0, \quad e_{H}^{s}\left(t_{j}\right) \rightarrow e_{H}^{s \infty} \quad \text { as } j \rightarrow \infty .
$$

From (2.39b), we get

$$
\lim _{j \rightarrow \infty} s_{H}\left(t_{j}\right) i_{M}\left(t_{j}\right)=\lim _{j \rightarrow \infty}\left(\frac{1}{p \alpha} e_{H}^{s \prime}\left(t_{j}\right)+\frac{d_{s}+\xi}{p \alpha} e_{H}^{s}\left(t_{j}\right)\right)
$$

and then

$$
i_{M}^{\infty} \geq \lim _{j \rightarrow \infty} s_{H}\left(t_{j}\right) i_{M}\left(t_{j}\right)=\frac{d_{s}+\xi}{p \alpha} e_{H}^{s \infty}>\frac{\left(d_{s}+\xi\right) \epsilon}{p \alpha},
$$

thus we obtain the conclusion. Next we assume that $e_{H}^{l \infty}>\epsilon$. Then we have a sequence $\left\{t_{m}\right\}_{m=1}^{\infty}$ satisfying

$$
e_{H}^{l \prime}\left(t_{m}\right) \rightarrow 0, \quad e_{H}^{l}\left(t_{m}\right) \rightarrow e_{H}^{l \infty} \quad \text { as } m \rightarrow \infty .
$$

From (2.20), we have

$$
\begin{aligned}
& \lim _{m \rightarrow \infty}\left(s_{H}\left(t_{m}\right) i_{M}\left(t_{m}\right)-s_{H}\left(t_{m}-\tau\right) i_{M}\left(t_{m}-\tau\right) e^{-\xi \tau}\right) \\
= & \lim _{m \rightarrow \infty}\left(\frac{1}{(1-p) \alpha} e_{H}^{l \prime}\left(t_{m}\right)+\frac{\xi}{(1-p) \alpha} e_{H}^{l}\left(t_{m}\right)\right) .
\end{aligned}
$$

Then we deduce that

$$
\begin{aligned}
i_{M}^{\infty} & \geq \limsup _{m \rightarrow \infty} s_{H}\left(t_{m}\right) i_{M}\left(t_{m}\right)-\liminf _{m \rightarrow \infty} s_{H}\left(t_{m}-\tau\right) i_{M}\left(t_{m}-\tau\right) e^{-\xi \tau} \\
& \geq \limsup _{m \rightarrow \infty}\left(s_{H}\left(t_{m}\right) i_{M}\left(t_{m}\right)-s_{H}\left(t_{m}-\tau\right) i_{M}\left(t_{m}-\tau\right) e^{-\xi \tau}\right) \\
& =\frac{\xi}{(1-p) \alpha} e_{H}^{l \infty} \\
& >\frac{\xi \epsilon}{(1-p) \alpha}
\end{aligned}
$$

Finally we assume that $i_{H}^{\infty}>\epsilon$. Then there is a sequence $\left\{t_{l}\right\}_{l=1}^{\infty}$ such that

$$
i_{H}^{\prime}\left(t_{l}\right) \rightarrow 0, \quad i_{H}\left(t_{l}\right) \rightarrow i_{H}^{\infty} \quad \text { as } l \rightarrow \infty
$$


From $(2.39 \mathrm{c})$, one has

$$
\begin{aligned}
& \lim _{l \rightarrow \infty}\left(\frac{d_{s}}{\alpha} e_{H}^{s}\left(t_{l}\right)+(1-p) s_{H}\left(t_{l}-\tau\right) i_{M}\left(t_{l}-\tau\right) e^{-\xi \tau}\right) \\
= & \lim _{l \rightarrow \infty}\left(\frac{1}{\alpha} i_{H}^{\prime}\left(t_{l}\right)+\frac{r+\xi}{\alpha} i_{H}\left(t_{l}\right)\right) .
\end{aligned}
$$

Moreover,

$$
i_{M}^{\infty} \geq p i_{M}^{\infty}+(1-p) e^{-\xi \tau} i_{M}^{\infty} .
$$

Since inequality (2.48) implies

$$
i_{M}^{\infty} \geq \frac{d_{s}+\xi}{p \alpha} e_{H}^{s \infty}
$$

by $(2.51)$,

$$
\begin{aligned}
i_{M}^{\infty} & \geq \frac{d_{s}+\xi}{\alpha} e_{H}^{s \infty}+(1-p) e^{-\xi \tau} \limsup _{l \rightarrow \infty} s_{H}\left(t_{l}-\tau\right) i_{M}\left(t_{l}-\tau\right) \\
& \geq \frac{d_{s}}{\alpha} e_{H}^{s \infty}+(1-p) e^{-\xi \tau} \limsup _{l \rightarrow \infty} s_{H}\left(t_{l}-\tau\right) i_{M}\left(t_{l}-\tau\right) \\
& \geq \lim _{l \rightarrow \infty}\left(\frac{d_{s}}{\alpha} e_{H}^{s}\left(t_{l}\right)+(1-p) s_{H}\left(t_{l}-\tau\right) i_{M}\left(t_{l}-\tau\right) e^{-\xi \tau}\right) .
\end{aligned}
$$

By (2.50), we get

$$
i_{M}^{\infty} \geq \frac{r+\xi}{\alpha} i_{H}^{\infty}>\frac{r+\xi}{\alpha} \epsilon
$$

Therefore, $\Phi$ is uniformly weakly $\rho_{4}$-persistent. From the uniformly weak persistence, the uniform persistence follows by Theorem 4.5 in [66].

Theorem 2.14. If $R_{d}>1$, then $\Phi$ is uniformly $\rho_{3}$-persistent.

Proof. Let $\psi \in X$ with $\rho_{3}(\psi)>0$. Since $\rho(\psi) \geq \rho_{3}(\psi)>0$, by Theorem 2.12, there exists $\epsilon>0$ such that $\liminf _{t \rightarrow \infty} \rho(\Phi(t, \psi))>\epsilon$. Then,

$$
\limsup _{t \rightarrow \infty} \rho_{i}(\Phi(t, \psi))>\epsilon \quad \text { for some } i \in\{1,2,3,4\}
$$

Assume that $i_{M}^{\infty}>\epsilon$. By $(2.39 f)$, with a sequence $\left\{t_{k}\right\}_{k=1}^{\infty}$ such that

$$
i_{M}^{\prime}\left(t_{k}\right) \rightarrow 0, \quad i_{M}\left(t_{k}\right) \rightarrow i_{M}^{\infty} \quad \text { as } k \rightarrow \infty
$$

we have

$$
\lim _{k \rightarrow \infty} s_{M}\left(t_{k}\right) i_{H}\left(t_{k}\right)=\lim _{k \rightarrow \infty}\left(\frac{1}{\beta} i_{M}^{\prime}\left(t_{k}\right)+\frac{\mu}{\beta} i_{M}\left(t_{k}\right)\right) .
$$


This implies

$$
i_{H}^{\infty} \geq \lim _{k \rightarrow \infty} s_{M}\left(t_{k}\right) i_{H}\left(t_{k}\right)=\frac{\mu}{\beta} i_{M}^{\infty}>\frac{\mu}{\beta} \epsilon .
$$

Next we assume that $e_{H}^{s \infty}>\epsilon$. Similar as in (2.48), we get

$$
i_{M}^{\infty} \geq \frac{d_{s}+\xi}{p \alpha} e_{H}^{s \infty} .
$$

By (2.52) and (2.53), we find

$$
i_{H}^{\infty} \geq \frac{\mu}{\beta} i_{M}^{\infty} \geq \frac{\mu}{\beta} \frac{d_{s}+\xi}{p \alpha} e_{H}^{s \infty}>\frac{\mu}{\beta} \frac{d_{s}+\xi}{p \alpha} \epsilon .
$$

Next we assume that $e_{H}^{l \infty}>\epsilon$. Similar as in (2.49), we get

$$
i_{M}^{\infty} \geq \frac{\xi}{(1-p) \alpha} e_{H}^{l \infty}
$$

By (2.52) and (2.54), one has

$$
i_{H}^{\infty} \geq \frac{\mu}{\beta} i_{M}^{\infty} \geq \frac{\mu}{\beta} \frac{\xi}{(1-p) \alpha} e_{H}^{l \infty}>\frac{\mu}{\beta} \frac{\xi}{(1-p) \alpha} \epsilon .
$$

From uniformly weak persistence, the uniform persistence follows by Theorem 4.5 in [66].

Lemma 2.15. There exists $T>0$ such that

$$
s_{H}(t)>\frac{1}{2} \frac{\xi}{\alpha+\xi} \quad \text { for all } t \geq T
$$

Proof. From the first equation of (2.39), we have

$$
s_{H}^{\prime}=\xi-\alpha s_{H} i_{M}+\omega r_{H}-\xi s_{H} \geq \xi-\alpha s_{H}-\xi s_{H}
$$

and thus $s_{H \infty} \geq \frac{\xi}{\alpha+\xi}>0$.

Theorem 2.16. If $R_{d}>1$, then $\Phi$ is uniformly $\rho_{2}$-persistent.

Proof. Let $\psi \in X$ with $\rho_{2}(\psi)>0$. By Proposition 2.10.1, there exists $t^{*}>\tau$ such that $\rho_{4}\left(x_{t^{*}}(\psi)\right)>0$.

Then, by Theorem 2.13, there exists $\epsilon>0$ such that

$$
\liminf _{t \rightarrow \infty} \rho_{4}(\Phi(t, \psi))=\liminf _{t \rightarrow \infty} \rho_{4}\left(\Phi\left(t, x_{t^{*}}(\psi)\right)\right)>\epsilon
$$


From now on, we denote by $\left(s_{H_{t}}, e_{H}^{s}(t), i_{H}(t), r_{H}(t), s_{M}(t), i_{M_{t}}\right)$ the solution with initial state $\psi$. There exists $T_{1}>0$ such that

$$
i_{M_{t}}(0)>\frac{1}{2} \epsilon \text { for all } t \geq T_{1} .
$$

Take $T_{2}>0$ such that

$$
s_{H_{t}}(0)>\frac{1}{2} \frac{\xi}{\alpha+\xi} \quad \text { for all } t \geq T_{2}
$$

Then,

$$
\int_{-\tau}^{0} s_{H_{t}}(s) i_{M_{t}}(s) e^{\xi s} \mathrm{~d} s>\frac{1}{4} \frac{\xi}{\alpha+\xi} \epsilon \int_{-\tau}^{0} e^{\xi s} \mathrm{~d} s
$$

for all $t>\max \left\{T_{1}, T_{2}\right\}+\tau$. Therefore,

$$
\liminf _{t \rightarrow \infty}(1-p) \alpha \int_{-\tau}^{0} s_{H_{t}}(s) i_{M_{t}}(s) e^{\xi s} \mathrm{~d} s \geq \frac{1}{4}(1-p) \alpha \frac{\xi}{\alpha+\xi} \epsilon \int_{-\tau}^{0} e^{\xi s} \mathrm{~d} s>0
$$

Theorem 2.17. If $R_{0}>1$, then $\Phi$ is uniformly $\rho_{1}$-persistent.

Proof. Let $\psi \in X$ with $\rho_{1}(\psi)>0$. By Proposition 2.10.1, there exists $t^{*}>\tau$ such that $\rho_{4}\left(x_{t^{*}}(\psi)\right)>0$. Then, by Theorem 2.13 , there exists $\epsilon>0$ such that

$$
\liminf _{t \rightarrow \infty} \rho_{4}(\Phi(t, \psi))=\liminf _{t \rightarrow \infty} \rho_{4}\left(\Phi\left(t, x_{t^{*}}(\psi)\right)\right)>\epsilon
$$

From now on, we denote by $\left(s_{H_{t}}, e_{H}^{s}(t), i_{H}(t), r_{H}(t), s_{M}(t), i_{M_{t}}\right)$ the solution with initial state $\psi$. There exists $T_{1}>0$ such that

$$
i_{H}(t)>\frac{1}{2} \epsilon \text { for all } t \geq T_{1}
$$

Take $T_{2}>0$ such that

$$
s_{H}(t)>\frac{1}{2} \frac{\xi}{\alpha+\xi} \quad \text { for all } t \geq T_{2} .
$$

Then,

$$
\begin{aligned}
\frac{d}{d t} e_{H}^{s}(t) & =p \alpha s_{H}(t) i_{M}(t)-\left(d_{s}+\xi\right) e_{H}^{s}(t) \\
& \geq \frac{1}{4} p \alpha \frac{\xi}{\alpha+\xi} \epsilon-\left(d_{s}+\xi\right) e_{H}^{s}(t)
\end{aligned}
$$

for all $t>\max \left\{T_{1}, T_{2}\right\}$, thus

$$
e_{H \infty}^{s} \geq \frac{p \alpha \xi \epsilon}{4\left(d_{s}+\xi\right)(\alpha+\xi)} .
$$


Combining Theorems 2.13, 2.14, 2.16, 2.17 and Proposition 2.10.1, we immediately obtain the following result.

Corollary 2.18. If $R_{0}>1$, there exists $\epsilon>0$ such that

$$
e_{H \infty}^{s}>\epsilon, \quad e_{H \infty}^{l}>\epsilon, \quad i_{H \infty}>\epsilon \quad \text { and } i_{M \infty}>\epsilon
$$

for every $\phi_{0} \in \tilde{X}$, i.e. the disease uniformly persists in each infected compartments of the human and the mosquito populations.

In the special case of $\omega=0$, which means that individuals acquire permanent immunity after recovering from the infection, we show that the endemic equilibrium is indeed globally asymptotically stable, provided that the basic reproduction number is greater than one.

Theorem 2.19. Assume that $\omega=0$. If $R_{0}>1$, then the endemic equilibrium is globally asymptotically stable in $\tilde{X}$.

Proof. First we define a subset of $X$ as

$$
\tilde{G}:=\left\{\begin{array}{l|l}
\phi \in X & \begin{array}{l}
f(\theta)>0, g(\theta)>0, \theta \in[-\tau, 0], \\
q_{j}>0, j \in\{2,3,4,5\} .
\end{array}
\end{array}\right\} .
$$

From Proposition 3 one can see that

$$
\Phi(t, \tilde{X}) \subset \tilde{G}, \quad t>\tau
$$

To prove the theorem we construct a Lyapunov functional on $\tilde{G}$. Let us denote by

$$
\left(s_{H}, e_{H}^{s}, i_{H}, r_{H}, s_{M}, i_{M}\right)
$$

the endemic equilibrium of (2.39), where each component is strictly positive. We define

$$
\begin{array}{lll}
c_{1}:=\frac{1}{\alpha i_{M}}\left(k_{1}+k_{2}\right), & c_{2}:=\left(\frac{\alpha s_{H} i_{M}}{e_{H}^{s}}\right)^{-1} \frac{d_{s}}{d_{s}+\xi}, \quad c_{3}:=\left(\frac{\alpha s_{H} i_{M}}{i_{H}}\right)^{-1}, \\
c_{4}:=\frac{1}{\beta i_{H}}\left(k_{1}+k_{2}\right), & c_{5}:=\left(\frac{\beta s_{M} i_{H}}{i_{M}}\right)^{-1}\left(k_{1}+k_{2}\right),
\end{array}
$$

where $k_{1}$ and $k_{2}$ are constants defined as

$$
k_{1}:=p \frac{d_{s}}{d_{s}+\xi}, \quad k_{2}:=(1-p) e^{-\xi \tau}
$$


For $\phi=\left(f, q_{2}, q_{3}, q_{4}, q_{5}, g\right) \in \tilde{G}$, we consider the following functional:

$$
V_{e}(\phi):=c_{1} h\left(\frac{f(0)}{s_{H}}\right)+c_{2} h\left(\frac{q_{2}}{e_{H}^{s}}\right)+c_{3} h\left(\frac{q_{3}}{i_{H}}\right)+c_{4} h\left(\frac{q_{5}}{s_{M}}\right)+c_{5} h\left(\frac{g(0)}{i_{M}}\right)+k_{2} U_{e}(\phi),
$$

where

$$
U_{e}(\phi):=\int_{-\tau}^{0} h\left(\frac{f(s) g(s)}{s_{H} i_{M}}\right) \mathrm{d} s
$$

and $h$ is defined as in (2.42) in Section 3. We differentiate $V_{e}$ with respect to $t$ along the solution of (2.39). Since one has

$$
\xi=\alpha s_{H} i_{M}+\xi s_{H}
$$

from the first equation of (2.39), we compute

$$
\begin{aligned}
& \frac{d}{d t} h\left(\frac{s_{H}(t)}{s_{H}}\right) \\
= & \frac{1}{s_{H}}\left(1-\frac{s_{H}}{s_{H}(t)}\right)\left(\alpha s_{H} i_{M}+\xi s_{H}-\alpha s_{H}(t) i_{M}(t)-\xi s_{H}(t)\right) \\
= & \frac{1}{s_{H}}\left(1-\frac{s_{H}}{s_{H}(t)}\right)\left\{\alpha s_{H} i_{M}\left(1-\frac{s_{H}(t) i_{M}(t)}{s_{H} i_{M}}\right)+\xi s_{H}\left(1-\frac{s_{H}(t)}{s_{H}}\right)\right\} \\
= & \frac{1}{s_{H}}\left\{\alpha s_{H} i_{M}\left(1-\frac{s_{H}}{s_{H}(t)}\right)\left(1-\frac{s_{H}(t) i_{M}(t)}{s_{H} i_{M}}\right)+\xi s_{H}\left(1-\frac{s_{H}}{s_{H}(t)}\right)\left(1-\frac{s_{H}(t)}{s_{H}}\right)\right\} \\
= & \alpha i_{M}\left(1-\frac{s_{H}(t) i_{M}(t)}{s_{H} i_{M}}-\frac{s_{H}}{s_{H}(t)}+\frac{i_{M}(t)}{i_{M}}\right)+\xi\left(1-\frac{s_{H}}{s_{H}(t)}\right)\left(1-\frac{s_{H}(t)}{s_{H}}\right) .
\end{aligned}
$$

From (2.39b), one has

$$
0=p \alpha s_{H} i_{M}-\left(d_{s}+\xi\right) e_{H}^{s}
$$

hence

$$
d_{s}+\xi=\frac{p \alpha s_{H} i_{M}}{e_{H}^{s}} .
$$

Then

$$
\begin{aligned}
\frac{d}{d t} h\left(\frac{e_{H}^{s}(t)}{e_{H}^{s}}\right) & =\frac{1}{e_{H}^{s}}\left(1-\frac{e_{H}^{s}}{e_{H}^{s}(t)}\right)\left(p \alpha s_{H}(t) i_{M}(t)-p \alpha s_{H} i_{M} \frac{e_{H}^{s}(t)}{e_{H}^{s}}\right) \\
& =p \frac{\alpha s_{H} i_{M}}{e_{H}^{s}}\left(1-\frac{e_{H}^{s}}{e_{H}^{s}(t)}\right)\left(\frac{s_{H}(t) i_{M}(t)}{s_{H} i_{M}}-\frac{e_{H}^{s}(t)}{e_{H}^{s}}\right) \\
& =p \frac{\alpha s_{H} i_{M}}{e_{H}^{s}}\left(\frac{s_{H}(t) i_{M}(t)}{s_{H} i_{M}}-\frac{e_{H}^{s}(t)}{e_{H}^{s}}-\frac{e_{H}^{s}}{e_{H}^{s}(t)} \frac{s_{H}(t) i_{M}(t)}{s_{H} i_{M}}+1\right) .
\end{aligned}
$$

From (2.39c), one can get

$$
r+\xi=\frac{1}{i_{H}}\left\{d_{s} e_{H}^{s}+(1-p) \alpha e^{-\xi \tau} s_{H} i_{M}\right\} .
$$


Then we obtain

$$
\frac{d i_{H}(t)}{d t}=d_{s} e_{H}^{s}\left(\frac{e_{H}^{s}(t)}{e_{H}^{s}}-\frac{i_{H}(t)}{i_{H}}\right)+(1-p) \alpha e^{-\xi \tau} s_{H} i_{M}\left(\frac{s_{H}(t-\tau) i_{M}(t-\tau)}{s_{H} i_{M}}-\frac{i_{H}(t)}{i_{H}}\right) .
$$

We compute

$$
\begin{aligned}
& \frac{d}{d t} h\left(\frac{i_{H}(t)}{i_{H}}\right) \\
= & \frac{1}{i_{H}}\left(1-\frac{i_{H}}{i_{H}(t)}\right)\left\{d_{s} e_{H}^{s}\left(\frac{e_{H}^{s}(t)}{e_{H}^{s}}-\frac{i_{H}(t)}{i_{H}}\right)\right. \\
& \left.+(1-p) \alpha e^{-\xi \tau} s_{H} i_{M}\left(\frac{s_{H}(t-\tau) i_{M}(t-\tau)}{s_{H} i_{M}}-\frac{i_{H}(t)}{i_{H}}\right)\right\} \\
= & \frac{d_{s} e_{H}^{s}}{i_{H}}\left(1-\frac{i_{H}}{i_{H}(t)}\right)\left(\frac{e_{H}^{s}(t)}{e_{H}^{s}}-\frac{i_{H}(t)}{i_{H}}\right) \\
& +(1-p) \frac{\alpha e^{-\xi \tau} s_{H} i_{M}}{i_{H}}\left(1-\frac{i_{H}}{i_{H}(t)}\right)\left(\frac{s_{H}(t-\tau) i_{M}(t-\tau)}{s_{H} i_{M}}-\frac{i_{H}(t)}{i_{H}}\right) .
\end{aligned}
$$

From (2.56), one finds that

$$
d_{s} e_{H}^{s}=p \alpha s_{H} i_{M} \frac{d_{s}}{d_{s}+\xi}=\alpha s_{H} i_{M} k_{1} .
$$

Therefore

$$
\begin{aligned}
& \frac{d}{d t} h\left(\frac{i_{H}(t)}{i_{H}}\right) \\
= & \frac{\alpha s_{H} i_{M}}{i_{H}}\left\{k_{1}\left(1-\frac{i_{H}}{i_{H}(t)}\right)\left(\frac{e_{H}^{s}(t)}{e_{H}^{s}}-\frac{i_{H}(t)}{i_{H}}\right)\right. \\
& \left.+k_{2}\left(1-\frac{i_{H}}{i_{H}(t)}\right)\left(\frac{s_{H}(t-\tau) i_{M}(t-\tau)}{s_{H} i_{M}}-\frac{i_{H}(t)}{i_{H}}\right)\right\} \\
= & \frac{\alpha s_{H} i_{M}}{i_{H}}\left\{k_{1}\left(\frac{e_{H}^{s}(t)}{e_{H}^{s}}-\frac{i_{H}(t)}{i_{H}}-\frac{i_{H}}{i_{H}(t)} \frac{e_{H}^{s}(t)}{e_{H}^{s}}+1\right)\right. \\
& \left.+k_{2}\left(\frac{s_{H}(t-\tau) i_{M}(t-\tau)}{s_{H} i_{M}}-\frac{i_{H}(t)}{i_{H}}-\frac{i_{H}}{i_{H}(t)} \frac{s_{H}(t-\tau) i_{M}(t-\tau)}{s_{H} i_{M}}+1\right)\right\} .
\end{aligned}
$$

We now use $\mu=\beta s_{M} i_{H}+\mu s_{M}$ from (2.39e). Then

$$
\begin{aligned}
& \frac{d}{d t} h\left(\frac{s_{M}(t)}{s_{M}}\right) \\
= & \frac{1}{s_{M}}\left(1-\frac{s_{M}}{s_{M}(t)}\right)\left(\beta s_{M} i_{H}+\mu s_{M}-\beta s_{M}(t) i_{H}(t)-\mu s_{M}(t)\right) \\
= & \frac{1}{s_{M}}\left(1-\frac{s_{M}}{s_{M}(t)}\right)\left\{\beta s_{M} i_{H}\left(1-\frac{s_{M}(t) i_{H}(t)}{s_{M} i_{H}}\right)+\mu s_{M}\left(1-\frac{s_{M}(t)}{s_{M}}\right)\right\} \\
= & \beta i_{H}\left(1-\frac{s_{M}(t) i_{H}(t)}{s_{M} i_{H}}-\frac{s_{M}}{s_{M}(t)}+\frac{i_{H}(t)}{i_{H}}\right)+\mu\left(1-\frac{s_{M}}{s_{M}(t)}\right)\left(1-\frac{s_{M}(t)}{s_{M}}\right) .
\end{aligned}
$$


Finally, from (2.39f) one has $0=\beta s_{M} i_{H}-\mu i_{M}$, thus

$$
\mu=\frac{\beta s_{M} i_{H}}{i_{M}}
$$

follows. Then

$$
\begin{aligned}
\frac{d}{d t} h\left(\frac{i_{M}(t)}{i_{M}}\right) & =\frac{1}{i_{M}}\left(1-\frac{i_{M}}{i_{M}(t)}\right)\left(\beta s_{M}(t) i_{H}(t)-\mu i_{M}(t)\right) \\
& =\frac{1}{i_{M}}\left(1-\frac{i_{M}}{i_{M}(t)}\right)\left(\beta s_{M}(t) i_{H}(t)-\beta s_{M} i_{H} \frac{i_{M}(t)}{i_{M}}\right) \\
& =\frac{\beta s_{M} i_{H}}{i_{M}}\left(1-\frac{i_{M}}{i_{M}(t)}\right)\left(\frac{s_{M}(t) i_{H}(t)}{s_{M} i_{H}}-\frac{i_{M}(t)}{i_{M}}\right) \\
& =\frac{\beta s_{M} i_{H}}{i_{M}}\left(\frac{s_{M}(t) i_{H}(t)}{s_{M} i_{H}}-\frac{i_{M}(t)}{i_{M}}-\frac{i_{M}}{i_{M}(t)} \frac{s_{M}(t) i_{H}(t)}{s_{M} i_{H}}+1\right) .
\end{aligned}
$$

Finally, we can compute that

$$
\begin{aligned}
\frac{d}{d t} U_{e}\left(x_{t}\right)= & h\left(\frac{s_{H}(t) i_{M}(t)}{s_{H} i_{M}}\right)-h\left(\frac{s_{H}(t-\tau) i_{M}(t-\tau)}{s_{H} i_{M}}\right) \\
= & \frac{s_{H}(t) i_{M}(t)}{s_{H} i_{M}}-\ln \left(\frac{s_{H}(t) i_{M}(t)}{s_{H} i_{M}}\right) \\
& -\frac{s_{H}(t-\tau) i_{M}(t-\tau)}{s_{H} i_{M}}+\ln \left(\frac{s_{H}(t-\tau) i_{M}(t-\tau)}{s_{H} i_{M}}\right) \\
= & \frac{s_{H}(t) i_{M}(t)}{s_{H} i_{M}}-\frac{s_{H}(t-\tau) i_{M}(t-\tau)}{s_{H} i_{M}}+\ln \left(\frac{s_{H}(t-\tau) i_{M}(t-\tau)}{s_{H}(t) i_{M}(t)}\right) .
\end{aligned}
$$

From (2.55)-(2.60) we get

$$
\begin{aligned}
\frac{d}{d t} V_{e}\left(x_{t}\right)= & \left(k_{1}+k_{2}\right) \frac{\xi}{\beta i_{M}}\left(1-\frac{s_{H}}{s_{H}(t)}\right)\left(1-\frac{s_{H}(t)}{s_{H}}\right) \\
& +\left(k_{1}+k_{2}\right) \frac{\mu}{\beta i_{H}}\left(1-\frac{s_{M}}{s_{M}(t)}\right)\left(1-\frac{s_{M}(t)}{s_{M}}\right) \\
& +\left(k_{1}+k_{2}\right) C_{0}(t)+k_{1} C_{1}(t)+k_{2} C_{2}(t),
\end{aligned}
$$

where

$$
\begin{aligned}
C_{0}(t)= & \left(1-\frac{s_{H}(t) i_{M}(t)}{s_{H} i_{M}}-\frac{s_{H}}{s_{H}(t)}+\frac{i_{M}(t)}{i_{M}}\right) \\
& +\left(1-\frac{s_{M}(t) i_{H}(t)}{s_{M} i_{H}}-\frac{s_{M}}{s_{M}(t)}+\frac{i_{H}(t)}{i_{H}}\right) \\
& +\left(\frac{s_{M}(t) i_{H}(t)}{s_{M} i_{H}}-\frac{i_{M}(t)}{i_{M}}-\frac{i_{M}}{i_{M}(t)} \frac{s_{M}(t) i_{H}(t)}{s_{M} i_{H}}+1\right), \\
C_{1}(t)= & \left(\frac{s_{H}(t) i_{M}(t)}{s_{H} i_{M}}-\frac{e_{H}^{s}(t)}{e_{H}^{s}}-\frac{e_{H}^{s}}{e_{H}^{s}(t)} \frac{s_{H}(t) i_{M}(t)}{s_{H} i_{M}}+1\right) \\
& +\left(\frac{e_{H}^{s}(t)}{e_{H}^{s}}-\frac{i_{H}(t)}{i_{H}}-\frac{i_{H}}{i_{H}(t)} \frac{e_{H}^{s}(t)}{e_{H}^{s}}+1\right),
\end{aligned}
$$


and

$$
\begin{aligned}
& C_{2}(t) \\
= & \left(\frac{s_{H}(t-\tau) i_{M}(t-\tau)}{s_{H} i_{M}}-\frac{i_{H}(t)}{i_{H}}-\frac{i_{H}}{i_{H}(t)} \frac{s_{H}(t-\tau) i_{M}(t-\tau)}{s_{H} i_{M}}+1\right) \\
& +\left(\frac{s_{H}(t) i_{M}(t)}{s_{H} i_{M}}-\frac{s_{H}(t-\tau) i_{M}(t-\tau)}{s_{H} i_{M}}+\ln \left(\frac{s_{H}(t-\tau) i_{M}(t-\tau)}{s_{H}(t) i_{M}(t)}\right)\right) .
\end{aligned}
$$

One can respectively simplify $C_{0,1,2}(t)$ as

$$
\begin{aligned}
C_{0}(t)= & \left(1-\frac{s_{H}(t) i_{M}(t)}{s_{H} i_{M}}-\frac{s_{H}}{s_{H}(t)}\right)+\left(1-\frac{s_{M}}{s_{M}(t)}+\frac{i_{H}(t)}{i_{H}}\right) \\
& +\left(-\frac{i_{M}}{i_{M}(t)} \frac{s_{M}(t) i_{H}(t)}{s_{M} i_{H}}+1\right), \\
C_{1}(t)= & \left(\frac{s_{H}(t) i_{M}(t)}{s_{H} i_{M}}-\frac{e_{H}^{s}}{e_{H}^{s}(t)} \frac{s_{H}(t) i_{M}(t)}{s_{H} i_{M}}+1\right) \\
& +\left(-\frac{i_{H}(t)}{i_{H}}-\frac{i_{H}}{i_{H}(t)} \frac{e_{H}^{s}(t)}{e_{H}^{s}}+1\right), \\
C_{2}(t)= & \left(\frac{s_{H}(t) i_{M}(t)}{s_{H} i_{M}}-\frac{i_{H}(t)}{i_{H}}-\frac{i_{H}}{i_{H}(t)} \frac{s_{H}(t-\tau) i_{M}(t-\tau)}{s_{H} i_{M}}+1\right) \\
& +\ln \left(\frac{s_{H}(t-\tau) i_{M}(t-\tau)}{s_{H}(t) i_{M}(t)}\right) .
\end{aligned}
$$

From (2.61)-(2.63) one can compute

$$
\begin{aligned}
& \left(k_{1}+k_{2}\right) C_{0}(t)+k_{1} C_{1}(t)+k_{2} C_{2}(t) \\
= & \left(k_{1}+k_{2}\right)\left\{\left(1-\frac{s_{H}}{s_{H}(t)}\right)+\left(1-\frac{s_{M}}{s_{M}(t)}\right)+\left(-\frac{i_{M}}{i_{M}(t)} \frac{s_{M}(t) i_{H}(t)}{s_{M} i_{H}}+1\right)\right\} \\
& +k_{1}\left\{\left(-\frac{e_{H}^{s}}{e_{H}^{s}(t)} \frac{s_{H}(t) i_{M}(t)}{s_{H} i_{M}}+1\right)+\left(-\frac{i_{H}}{i_{H}(t)} \frac{e_{H}^{s}(t)}{e_{H}^{s}}+1\right)\right\} \\
& +k_{2}\left(-\frac{i_{H}}{i_{H}(t)} \frac{s_{H}(t-\tau) i_{M}(t-\tau)}{s_{H} i_{M}}+1+\ln \left(\frac{s_{H}(t-\tau) i_{M}(t-\tau)}{s_{H}(t) i_{M}(t)}\right)\right) .
\end{aligned}
$$

Let us define

$$
\begin{aligned}
L(t):= & \left(k_{1}+k_{2}\right)\left(\ln \left(\frac{s_{H}}{s_{H}(t)}\right)+\ln \left(\frac{s_{M}}{s_{M}(t)}\right)+\ln \left(\frac{i_{M}}{i_{M}(t)} \frac{s_{M}(t) i_{H}(t)}{s_{M} i_{H}}\right)\right) \\
& +k_{1}\left(\ln \left(\frac{e_{H}^{s}}{e_{H}^{s}(t)} \frac{s_{H}(t) i_{M}(t)}{s_{H} i_{M}}\right)+\ln \left(\frac{i_{H}}{i_{H}(t)} \frac{e_{H}^{s}(t)}{e_{H}^{s}}\right)\right) \\
& +k_{2}\left(\ln \left(\frac{i_{H}}{i_{H}(t)} \frac{s_{H}(t-\tau) i_{M}(t-\tau)}{s_{H} i_{M}}\right)-\ln \left(\frac{s_{H}(t-\tau) i_{M}(t-\tau)}{s_{H}(t) i_{M}(t)}\right)\right) .
\end{aligned}
$$

We claim that $L(t)=0$ holds. Indeed, one can calculate

$$
L(t)=\left(k_{1}+k_{2}\right) \ln \left(\frac{s_{H}}{s_{H}(t)} \frac{i_{M}}{i_{M}(t)} \frac{i_{H}(t)}{i_{H}}\right)+k_{1} \ln \left(\frac{s_{H}(t) i_{M}(t)}{s_{H} i_{M}} \frac{i_{H}}{i_{H}(t)}\right)
$$




$$
\begin{aligned}
& +k_{2}\left\{\ln \left(\frac{i_{H}}{i_{H}(t)}\right)+\ln \left(\frac{s_{H}(t) i_{M}(t)}{s_{H} i_{M}}\right)\right\} \\
= & k_{2}\left\{\ln \left(\frac{s_{H}}{s_{H}(t)} \frac{i_{M}}{i_{M}(t)} \frac{i_{H}(t)}{i_{H}}\right)+\ln \left(\frac{i_{H}}{i_{H}(t)}\right)+\ln \left(\frac{s_{H}(t) i_{M}(t)}{s_{H} i_{M}}\right)\right\} \\
= & 0 .
\end{aligned}
$$

Therefore, we obtain

$$
\begin{aligned}
& \left(k_{1}+k_{2}\right) C_{0}(t)+k_{1} C_{1}(t)+k_{2} C_{2}(t) \\
= & \left(k_{1}+k_{2}\right) C_{0}(t)+k_{1} C_{1}(t)+k_{2} C_{2}(t)+L(t) \\
= & -\left(k_{1}+k_{2}\right)\left\{h\left(\frac{s_{H}}{s_{H}(t)}\right)+h\left(\frac{s_{M}}{s_{M}(t)}\right)+h\left(\frac{i_{M}}{i_{M}(t)} \frac{s_{M}(t) i_{H}(t)}{s_{M} i_{H}}\right)\right\} \\
& -k_{1}\left\{h\left(\frac{e_{H}^{s}}{e_{H}^{s}(t)} \frac{s_{H}(t) i_{M}(t)}{s_{H} i_{M}}\right)+h\left(\frac{i_{H}}{i_{H}(t)} \frac{e_{H}^{s}(t)}{e_{H}^{s}}\right)\right\} \\
& -k_{2} h\left(\frac{i_{H}}{i_{H}(t)} \frac{s_{H}(t-\tau) i_{M}(t-\tau)}{s_{H} i_{M}}\right)
\end{aligned}
$$

$\leq 0$

Thus it follows that

$$
\frac{d}{d t} V_{e}\left(x_{t}\right) \leq 0
$$

If $x_{0}$ is the function identically equal to the endemic equilibrium, then obviously $x_{t}=$ $\left(\hat{s_{H}}, e_{H}^{s}, i_{H}, r_{H}, s_{M}, \hat{i_{M}}\right)$ for $t>0$. Let's assume that $x_{t}$ is not identically equal to the endemic equilibrium. Then there exists $c>0$ such that $c=V_{e}\left(x_{t_{0}}\right)$ for some $t_{0}>\tau$. We define

$$
G_{c}:=\left\{\phi \in \tilde{G} \mid V_{e}(\phi) \leq c=V_{e}\left(x_{t_{0}}\right)\right\} .
$$

We see that $G_{c}$ is closed and positively invariant, thus the closure of $G_{c}$ is itself and $G_{c}$ contains $x_{t}$ for all $t \geq t_{0}$. Since $V_{e}$ is continuous on $G_{c}, V_{e}$ is a Lyapunov functional on $G_{c}$, see Chapter 5.3 in [23]. We define the set

$$
\Sigma:=\left\{\phi \in G_{c} \mid \dot{V}_{e(2.39)}(\phi)=0\right\} .
$$

We obtain

$$
\Sigma=\left\{\begin{array}{l|l}
\phi & \begin{array}{l}
f(0)=s_{H}, q_{5}=s_{M}, \\
\frac{q_{2}}{e_{H}^{s}}=\frac{q_{3}}{i_{H}}=\frac{g(0)}{i_{M}}=\frac{f(-\tau) g(-\tau)}{s_{H} i_{M}}
\end{array}
\end{array}\right\} .
$$

Let $L$ be the largest subset in $\Sigma$ that is invariant with respect to (2.39). One can see that $L$ is the set of initial functions satisfying

$$
0=\frac{d s_{M}(t)}{d t}=\mu-\beta s_{M} i_{H}(t)-\mu s_{M},
$$


for any $t$, thus one can identify the element $\left(f, q_{2}, q_{3}, q_{4}, q_{5}, g\right) \in L$ as $q_{3}=i_{H}$. Then we get $q_{2}=e_{H}^{s}$ and $g(0)=i_{M}$. Next one can see that

$$
\begin{aligned}
& \frac{d s_{H}(t)}{d t}=\xi-\alpha s_{H} i_{M}-\xi s_{H}=0, \\
& \frac{d i_{M}(t)}{d t}=\beta s_{M} i_{H}-\mu i_{M}=0
\end{aligned}
$$

thus $f(\theta)=s_{H}$ and $g(\theta)=i_{M}$ for every $\theta \in[-\tau, 0]$. Then, by LaSalle's invariance principle, see Theorem 3.1 in [23], we conclude that the solution tends to the endemic equilibrium of (2.39). Since for every solution we can choose such a $c$, the positive equilibrium is globally attractive. Similarly as we mentioned in the proof of Theorem 2.9, for the stability of the endemic equilibrium, one can compute the characteristic equation and show that if $R_{0}>1$ and $\omega=0$ hold, then all roots of the characteristic equation have negative real parts. Thus the endemic equilibrium is globally asymptotically stable.

\subsection{Study on $P$. vivax models with seasonality}

So far, we have investigated the qualitative and quantitative differences of the two models in non-seasonal environment. In temperate regions, mosquito populations and their activity show seasonal variation, and so the transmission of $P$. vivax malaria is seasonal as well. In this section, we study the disease dynamics given by those two models in a periodic environment.

We consider the seasonal variation in mosquito population

$$
M^{\prime}(t)=(\mu(t)-d(t)) M(t)
$$

where the term $M(t)$ represents the number of female adult mosquitoes at time $t$, and $\mu(t)$ and $d(t)$ represent the birth and death rate of mosquitoes at time $t$. To account for seasonal activity of mosquitoes, a year is divided into an on-season, during which the mosquitoes search for bloodmeals and the parasite is transmitted to hosts via the mosquito bites, and an off-season, during which mosquitoes go to hibernate and no new infection occurs. Let $L$ be the length of on-season and $P$ be the natural period (one year). Thus we consider the temporal variation of the biting rate, replacing the constant $a$ by

$$
a(t)=\left\{\begin{array}{rl}
a_{s} & k P \leq t<k P+L \\
0 & k P+L \leq t<(k+1) P
\end{array}\right.
$$


where $k$ is an integer and $L \leq P$. The following is the transmission dynamics on the population level considering seasonality:

$$
\begin{aligned}
\frac{d S_{H}(t)}{d t} & =\xi H-a(t) b \frac{S_{H}(t)}{H} I_{M}(t)-\xi S_{H}(t)+\omega R_{H}(t), \\
E_{H}^{s}(t) & =\int_{0}^{\infty} p a(t) b \frac{S_{H}(t-u)}{H} I_{M}(t-u) P_{S}(u) e^{-\xi u} \mathrm{~d} u \\
E_{H}^{l}(t) & =\int_{0}^{\infty}(1-p) a(t) b \frac{S_{H}(t-u)}{H} I_{M}(t-u) P_{l}(u) e^{-\xi u} \mathrm{~d} u \\
I_{H}(t) & =H-S_{H}(t)-E_{H}^{s}(t)-E_{H}^{l}(t)-R_{H}(t), \\
\frac{d R_{H}(t)}{d t} & =r I_{H}(t)-(\omega+\xi) R_{H}(t), \\
\frac{d S_{M}(t)}{d t} & =\mu(t) M(t)-a(t) c S_{M}(t) \frac{I_{H}(t)}{H}-d(t) S_{M}(t), \\
I_{M}(t) & =M(t)-S_{M}(t) .
\end{aligned}
$$

We rescale the system (2.66) with time-varying mosquito population (2.64) and constant human population, by introducing new variables

$$
\begin{array}{ccrl}
s_{H}(t)=\frac{S_{H}(t)}{H}, & e_{H}^{s}(t)=\frac{E_{H}^{s}(t)}{H}, & e_{H}^{l}(t)=\frac{E_{H}^{l}(t)}{H}, & i_{H}(t)=\frac{I_{H}(t)}{H}, \\
r_{H}(t)=\frac{R_{H}(t)}{H}, & s_{M}(t)=\frac{S_{M}(t)}{M(t)}, & i_{M}(t)=\frac{I_{M}(t)}{M(t)} \quad \text { and } & m(t)=\frac{M(t)}{H} .
\end{array}
$$

The population dynamics for a susceptible mosquito population would be rescaled to

$$
\begin{aligned}
\frac{d s_{M}(t)}{d t} & =\frac{d}{d t}\left(\frac{S_{M}(t)}{M(t)}\right) \\
& =\frac{S_{M}^{\prime}(t) M(t)-S_{M}(t) M^{\prime}(t)}{M^{2}(t)} \\
& =\frac{1}{M(t)}\left(\mu(t) M(t)-a(t) c S_{M}(t) \frac{I_{H}(t)}{H}-d(t) S_{M}(t)\right)-s_{M}(t) \frac{M^{\prime}(t)}{M(t)} \\
& =\mu(t)-a(t) c s_{M}(t) i_{H}(t)-d(t) s_{M}(t)-s_{M}(t)(\mu(t)-d(t)) \\
& =\mu(t)-a(t) c s_{M}(t) i_{H}(t)-\mu(t) s_{M}(t) .
\end{aligned}
$$


From the similar calculation for other variables, we generalize the autonomous ODE system $(2.2)$ to

$$
\begin{aligned}
& \frac{d s_{H}(t)}{d t}=\xi-a(t) b m(t) s_{H}(t) i_{M}(t)+\omega r_{H}(t)-\xi s_{H}(t) \\
& \frac{d e_{H}^{s}(t)}{d t}=p a(t) b m(t) s_{H}(t) i_{M}(t)-d_{s} e_{H}^{s}(t)-\xi e_{H}^{s}(t) \\
& \frac{d e_{H}^{l}(t)}{d t}=(1-p) a(t) b m(t) s_{H}(t) i_{M}(t)-d_{l} e_{H}^{l}(t)-\xi e_{H}^{l}(t) \\
& \frac{d i_{H}(t)}{d t}=d_{s} e_{H}^{s}(t)+d_{l} e_{H}^{l}(t)-r i_{H}(t)-\xi i_{H}(t) \\
& \frac{d r_{H}(t)}{d t}=r i_{H}(t)-\omega r_{H}(t)-\xi r_{H}(t) \\
& \frac{d s_{M}(t)}{d t}=\mu(t)-a(t) c s_{M}(t) i_{H}(t)-\mu(t) s_{M}(t) \\
& \frac{d i_{M}(t)}{d t}=a(t) c s_{M}(t) i_{H}(t)-\mu(t) i_{M}(t)
\end{aligned}
$$

with time-varying coefficients $a(t), \mu(t)$ and $m(t)$.

Similarly, the DDE model in a constant environment (2.21) would be generalized to

$$
\begin{aligned}
\frac{d s_{H}(t)}{d t}= & \xi-a(t) b m(t) s_{H}(t) i_{M}(t)+\omega r_{H}(t)-\xi s_{H}(t) \\
\frac{d e_{H}^{s}(t)}{d t}= & p a(t) b m(t) s_{H}(t) i_{M}(t)-d_{s} e_{H}^{s}(t)-\xi e_{H}^{s}(t) \\
\frac{d e_{H}^{l}(t)}{d t}= & (1-p) a(t) b m(t) s_{H}(t) i_{M}(t) \\
& -(1-p) a(t) b m(t) s_{H}(t-\tau) i_{M}(t-\tau) e^{-\xi \tau}-\xi e_{H}^{l}(t) \\
\frac{d i_{H}(t)}{d t}= & d_{s} e_{H}^{s}(t)+(1-p) a(t) b m(t) s_{H}(t-\tau) i_{M}(t-\tau) e^{-\xi \tau} \\
& -r i_{H}(t)-\xi i_{H}(t) \\
\frac{d r_{H}(t)}{d t}= & r i_{H}(t)-\omega r_{H}(t)-\xi r_{H}(t) \\
\frac{d s_{M}(t)}{d t}= & \mu(t)-a(t) c s_{M}(t) i_{H}(t)-\mu(t) s_{M}(t) \\
\frac{d i_{M}(t)}{d t}= & a(t) c s_{M}(t) i_{H}(t)-\mu(t) i_{M}(t) .
\end{aligned}
$$

To describe a mosquito dynamics within one period, we use a Gaussian type function

$$
M(t)=e^{\left(\frac{\nu}{\eta}\right)^{2}} e^{-\left(\frac{t / 7-\nu}{\eta}\right)^{2}}+M_{0} \quad \text { for } 0 \leq t<P .
$$

The literature [44] provides parameters for the function (2.69), by fitting to the monthly prevalence data of $A$. sinensis mosquitoes, the main vector of $P$. vivax malaria in Korea. Figure 2.8 presents the modelled mosquito population dynamics. 


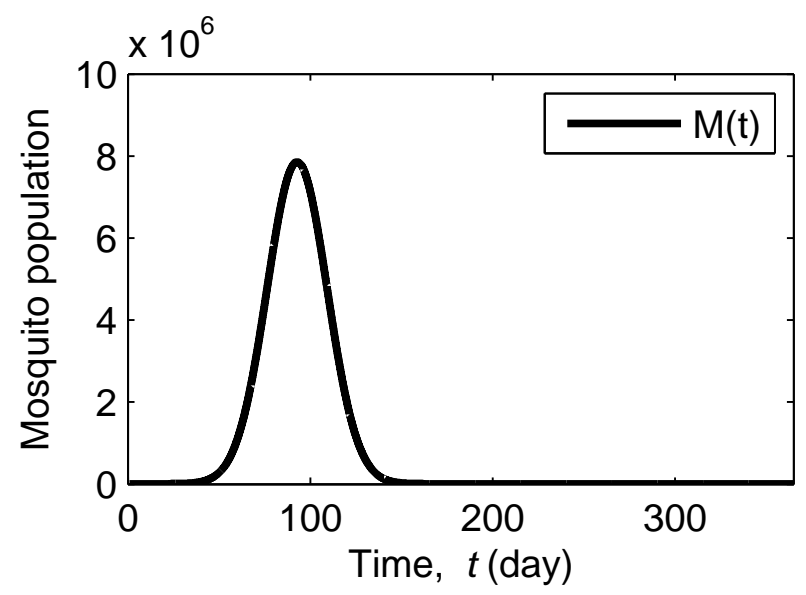

FIGURE 2.8: Gaussian function describing mosquito dynamics. Parameters $\nu=13.26$ and $\eta=-3.328$ and $M_{0}=10000$ are from the literature [44]. Time $t=0$ corresponds to May 1st, when mosquito population starts growing.

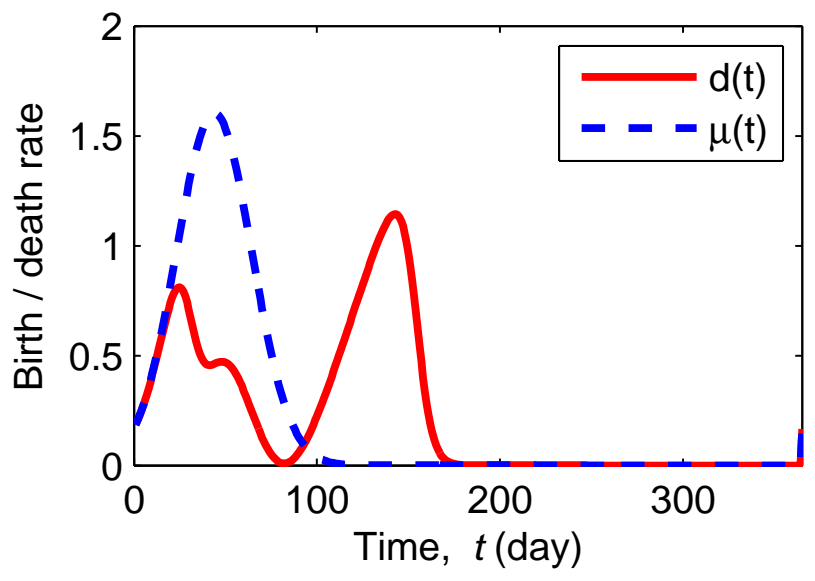

Figure 2.9: Birth function $\boldsymbol{\mu}(\boldsymbol{t})$ and death function $\boldsymbol{d}(\boldsymbol{t})$ of mosquitoes described in equations (2.70) and (2.71), respectively. Parameters values are $\delta=6.26, \kappa=-4.16$ and $\rho=1.6$.

The birth rate $\mu(t)$ in (2.64) depends on a variety of factors, such as oviposition rate, survival probability of eggs, and adolescent stages of mosquitoes. Those factors are highly seasonal dependent. For example, the parous rate fluctuated from $0.0 \%$ to $92.9 \%$ during summer season [47]. For simplicity, we consider a Gaussian type birth function

$$
\mu(t)=\rho e^{-\left(\frac{t / 7-\delta}{\kappa}\right)^{2}} \quad \text { for } 0 \leq t<P
$$

with the position of the center of the peak $\delta$ to be less than $\nu$ considering a maturation time. Figure 2.9 shows the birth function and the corresponding death function obtained from the equation

$$
d(t)=\mu(t)-\frac{M^{\prime}(t)}{M(t)} .
$$

The death function described in Figure 2.9 matches with the empirical observation of the mosquito survival rate increasing during August and September [47]. 
Assuming the annual population dynamics of mosquitoes is homogeneous with its interannual change, we extend the domain of functions

$$
M(t+k P):=M(t) \quad \text { and } \quad \mu(t+k P):=\mu(t)
$$

where $k$ is an integer. The inter-annual functions $M(t)$ and $\mu(t)$ presented in Figure 2.9 and Figure 2.8 could be extended on real line keeping its continuity.

Results of numerical simulations are shown in Figures 2.10, 2.11 and 2.12 (compare to Figure 2.4, Figure 2.5). With such a periodic coefficients, $i_{\mathrm{H}}(t)$ converges to a periodic attractor, instead of a steady state. Generally, the DDE model shows larger oscillations and predicts higher peaks and lower yearly bottoms of malaria prevalence. In contrast to the non-seasonal case, in some situations the DDE model even has higher annual average of infectious humans (Figure 2.11) than its ODE counterpart. In addition, in some cases the DDE model predicts the persistence of the disease even though the infection dies out for the ODE model with the same parameter values (Figure 2.12). In other cases, the DDE predicts lower average prevalence (as in the autonomous case), depending on the particular choice of parameters (Figure 2.10). To illustrate this striking behavior, we prepared Figure 2.13, where we plotted these domains on the $L-\tau$ parameter plane (length of mosquito season and long incubation period).

\subsection{Implication of the results}

The exact mechanism governing the development of malaria parasites from dormancy to activation is not known [25]. Motivated by the empirical estimations of the incubation times in Korea, we compared two models having different distribution of long-term incubation time, resulting an ODE and a DDE system. For both models we identified the basic reproduction number as a threshold value determining the stability of the disease-free equilibrium and the existence of the endemic equilibrium. We did further investigation on the global behavior of DDE model. When $R_{0} \leq 1$, it was shown that the disease-free equilibrium is globally attractive, which means the disease dies out. When $R_{0}>1$, the disease uniformly persists. Moreover, in the special case of lifelong immunity, the endemic equilibrium is globally asymptotically stable. We observe from numerical simulations that the solutions converge to the endemic equilibrium also in the case without the specific assumption of lifelong immunity.

We show that, while the qualitative behaviors of the two models are similar, the ODE model overestimates the basic reproduction number and also the level of endemicity, compared to the DDE model. By calculating $R_{0}$, we can see that long incubation time 


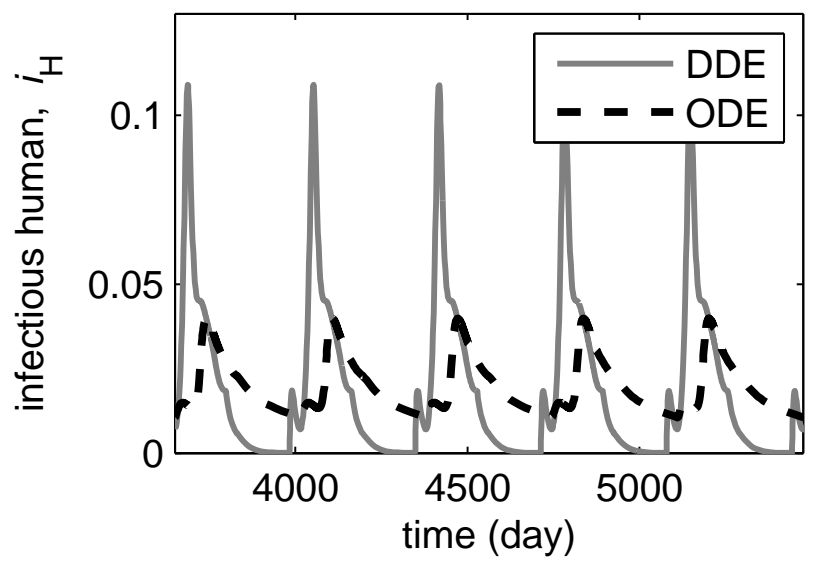

Figure 2.10: Dynamics of the infectious human population proportion in system (2.67) and system (2.68), together with periodic biting rate (2.65) and seasonal mosquito dynamics in Figure2.8. In both models, $i_{H}(t)$ converges to a periodic attractor. While the DDE model has a higher peak of infection, its annual average is smaller than that of the ODE model. Parameter values are $P=365, L=180$ and $a_{s}=0.3$ and $H=10000$, in addition to the values present in 2.3. Initial condition is the same as the one used for Figure 2.4.

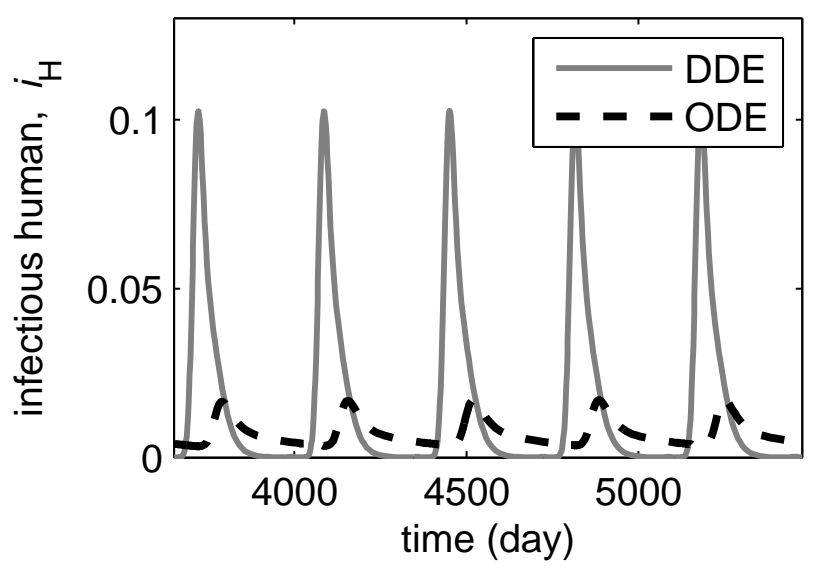

Figure 2.11: To compare with Figure 2.10, we used the parameter value $H=1400000$. Other parameter values and initial condition are the same as in Figure 2.10. The DDE model has a higher peak of infection, just as in Figure 2.10, however, its annual average is also greater than that of the ODE model.

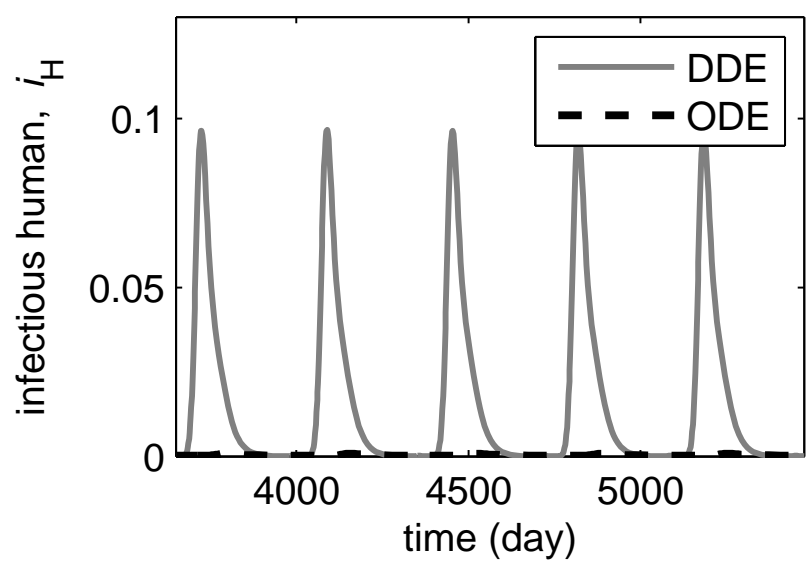

Figure 2.12: For comparison, we use $H=2000000$. Here $i_{H}(t)$ dies out in the ODE model, however, it converges to a periodic attractor in the DDE model. 


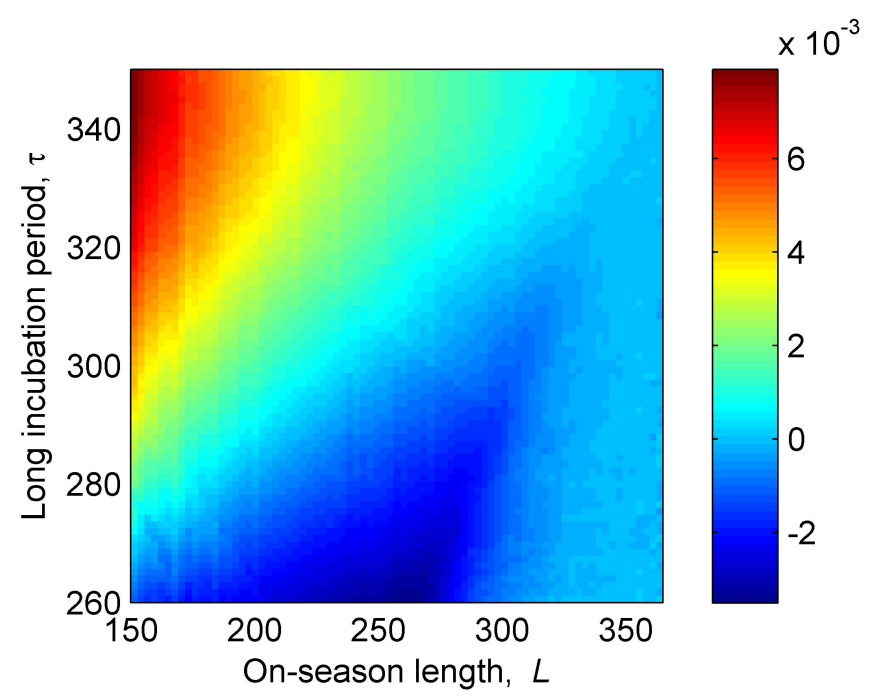

FiguRE 2.13: Differences between the yearly average number of infections for the ODE and the DDE model (2.67) and (2.68), respectively, as a function of length of incubation period $\tau$ and on-season length $L$. To observe the influence of the on-season length in explicit way, with single parameter $L$, we incorporate seasonal biting rate (2.65), but consider other seasonal factors as a constant function $m(t)=2$ and $\mu(t)=0.2$. Blue (red) areas represent a parameter region where the DDE (ODE) model predicts higher prevalence of malaria.

is not beneficial to the parasite in a constant environment, thus its presence is connected to the seasonal mosquito activity in Korea. From (2.22), we observe that $R_{0}$ increases with respect to $p$ if $\frac{d_{s}}{d_{s}+\xi}>e^{-\xi \tau}$, and decreases with respect to $p$ otherwise. In reality, it is natural to assume that the average short incubation time is less than the length of long-term incubation time, i.e. $\frac{1}{d_{s}}<\tau$. With this restriction, we have

$$
\frac{d_{s}}{d_{s}+\xi}=\frac{1}{1+\frac{\xi}{d_{s}}}>\frac{1}{1+\xi \tau}>e^{-\xi \tau}
$$

which leads to the conclusion that $R_{0}$ is an increasing function of $p$. Note that $R_{0}$ will be overestimated if we ignore long-term incubation period in the modeling. It further indicates that for the parasites, inducing long-term incubation period in humans is not beneficial for their reproduction. The observed bimodality of the incubation periods suggests that an another underlying mechanism plays a role, possibly seasonal effects, which are relevant in malaria transmission in Korea [46].

In contrast to the autonomous case, when we incorporate seasonality into our model equations, the interplay of the time delay and the periodicity results that in some situations the DDE model predicts higher prevalence of malaria. It is known that periodic delay differential equations can produce unexpected behavior, such as resonances [58], and their dynamics is not completely understood even in the scalar case [51]. In the present situation, the time periodic DDE results larger annual oscillations than the ODE 
(i.e. higher peaks and lower bottoms); as expected in the case of time delays. However, due to the complicated interplay of the time delay and periodicity, in some situations the DDE model predicts a higher number of infections throughout a year than the ODE, in contrast with the autonomous case. In other cases, the DDE predicts lower average prevalence (as in the autonomous case), depending on the particular choice of parameters. The results stress the importance of future work incorporating both delay and seasonality into $P$. vivax models in temperate regions.

It is known that hypnozoites are responsible for late relapses in P. vivax infections as well as long incubation. Some previous studies considered relapse in the transmission model $[1,34,48]$. For future works on more realistic $P$. vivax transmission modeling, the effect of multiple blood stage infections and seasonality is a natural next step to be investigated. However, both have its inherent difficulties (such as analysis of timeperiodic delay differential equations). Our study shows that it is possible to perform a rigorous mathematical analysis when the basic malaria transmission model is extended to include short- and long-term incubation in humans, thus it is a step toward more realistic $P$. vivax models in the future. 


\section{Chapter 3}

\section{Latent period as an adaptation strategy to seasonal forcing}

\subsection{Motivation of the study}

Many infectious diseases exhibit seasonal dynamics. Several biologically distinct mechanisms contribute to the seasonal dynamics of disease transmission, such as fluctuating vector population densities, yearly behavioral and contact patterns of hosts, seasonal changes in pathogen transmission rate, varying immune status of hosts, etc. [2]. Hostparasite interactions provide a good platform for evolution, given the short reproduction times and high mutation rates of pathogens. For several infectious diseases in temperate climates (such as malaria [6]), we observe long latent periods up to ten months.

From an evolutionary point of view, a prolonged latent period seems problematic, as one would normally expect the pathogen to reproduce as soon as it can, especially when competing with other strains for the available susceptible hosts. Delaying the onset of the disease involves the risk that the host dies before transmitting the pathogen to other hosts (a similar problem arises in regard of seed dormancy, see [54]). Hence, one might ask under which conditions the evolution of long latent periods is favored. Under seasonal forcing, one expects that pathogens are adapted to their seasonal environment in numerous ways. Adaptation of the transmission rate and virulence has been studied in Koelle [28] and recently in Donnelly [17]. One of the potential adaptation methods of parasites to unfavorable seasonal conditions is developing liver or deep tissue stages $[42,50,62]$. The dormant stage of the parasite manifests in a prolonged latent period, and starting the infectious period at a suitable part of the year can help to maximize the transmission potential of the pathogen. 
In this chapter, we consider pathogens capable of evolving a trait, expressed by a single parameter, that determines the average length of the latent period in the infected host, as a response to seasonal variability. We introduce a theoretical framework, based on adaptive dynamics, for predicting the evolution of latent periods of parasites in hosts in seasonal environments. Climate change affects the seasonality of environmental factors, thus having a large impact on the evolution of the pathogens and consequently on the dynamics of infectious diseases. Recently, some tropical diseases have recently spread to more temperate climates, for example, dengue, see [61], where seasonality plays and important role together with the latent period because of the seasonality in vector activity. Our model also provides a framework for examining these effects on pathogen evolution and the associated disease dynamics, as well as for the geographic variance in latent periods of various diseases, such as malaria [6].

\subsection{Introduction to adaptive dynamics}

The evolutionary process is a sequence of mutations, reproduction and selection. The spread of a mutation influences the dynamics of a population, and eventually the environment itself. Change of the fitness landscape may give possibilities for new mutations to spread. Adaptive dynamics studies the phenotypic evolution by deterministic demographic models, taking into account the feedback loop of demographic and evolutionary changes. It assumes that individuals are characterized by their phenotypic values which are asexually inherited, with the possibility of small mutations. When mutation is a rare event, genotypic change by sexual reproduction can be ignored on long-term time scale, because the effect of genetical inheritance on the distribution of traits following after mutation average out on a relatively short time scale. That is to say, adaptive dynamics assumes that the variability of traits is generated by mutations [13].

The resident-mutant models of the adaptive dynamics literature describe the competition between resident and mutant populations. The model is useful in studying frequency-dependent selection, the case when the reproductive success of an individual not only depends on its own trait, but also depends on the population abundance. As an example, when the selection gives an advantage to rare phenotypes, mutants with smaller baseline fitness than that of the residents may also invade the population, which in some cases leads to the evolutionary coexistence of different traits. When frequency-dependent selection plays a role, evolution does not necessary choose the trait with maximal fitness. In this case, the demographic dynamics with a single trait is not sufficient for predicting long-term dynamics. 
We now introduce the basic concepts of resident-mutant dynamics based on the book [13]. Let $n_{\mathrm{r}}, n_{\mathrm{m}}$ and $N$ be the population abundances of the resident, mutant and other population in the community. Parameters $x_{\mathrm{r}}$ and $x_{\mathrm{m}}$ refer to the traits of residents and mutants, respectively, and $X$ is an environmental parameter. Then, the demographic dynamics is described by

$$
\begin{aligned}
\frac{d N}{d t} & =F\left(N, n_{\mathrm{r}}, n_{\mathrm{m}}, X, x_{\mathrm{r}}, x_{\mathrm{m}}\right) \\
\frac{d n_{\mathrm{r}}}{d t} & =n_{\mathrm{r}} f\left(N, n_{\mathrm{r}}, n_{\mathrm{m}}, X, x_{\mathrm{r}}, x_{\mathrm{m}}\right) \\
\frac{d n_{\mathrm{m}}}{d t} & =n_{\mathrm{m}} g\left(N, n_{\mathrm{r}}, n_{\mathrm{m}}, X, x_{\mathrm{r}}, x_{\mathrm{m}}\right) .
\end{aligned}
$$

with

$$
g\left(N, n_{\mathrm{r}}, n_{\mathrm{m}}, X, x_{\mathrm{r}}, x_{\mathrm{m}}\right)=f\left(N, n_{\mathrm{m}}, n_{\mathrm{r}}, X, x_{\mathrm{m}}, x_{\mathrm{r}}\right) .
$$

In the absence of the mutant dynamics, the resident-mutant model (3.1) is reduced to the so-called resident model

$$
\begin{aligned}
& \frac{d N}{d t}=F\left(N, n_{\mathrm{r}}, 0, X, x_{\mathrm{r}}, \cdot\right) \\
& \frac{d n_{\mathrm{r}}}{d t}=n_{\mathrm{r}} f\left(N, n_{\mathrm{r}}, 0, X, x_{\mathrm{r}}, \cdot\right) .
\end{aligned}
$$

Assume that the system (3.2) has only one stable and strictly positive equilibrium, $\left(\bar{N}, \bar{n}_{\mathrm{r}}\right)$. Then, the invasion success of mutants is determined by the stability of the mutant-free equilibrium $\left(\bar{N}, \bar{n}_{\mathrm{r}}, 0\right)$ of system (3.1). Linearizing (3.1) at $\left(\bar{N}, \bar{n}_{\mathrm{r}}, 0\right)$, we obtain the Jacobian matrix

$$
J:=\left.\left(\begin{array}{ccc}
\frac{\partial F}{\partial N} & \frac{\partial F}{\partial n_{\mathrm{r}}} & \frac{\partial F}{\partial n_{\mathrm{m}}} \\
n_{\mathrm{r}} \frac{\partial f}{\partial N} & n_{\mathrm{r}} \frac{\partial f}{\partial n_{\mathrm{r}}}+f & n_{\mathrm{r}} \frac{\partial f}{\partial n_{\mathrm{m}}} \\
n_{\mathrm{m}} \frac{\partial g}{\partial N} & n_{\mathrm{m}} \frac{\partial g}{\partial n_{\mathrm{r}}} & n_{\mathrm{m}} \frac{\partial g}{\partial n_{\mathrm{m}}}+g
\end{array}\right)\right|_{\left(\bar{N}, \overline{n_{\mathrm{r}}}, 0, X, x_{\mathrm{r}}, x_{\mathrm{m}}\right)}
$$

Since $\left(\bar{N}, \bar{n}_{\mathrm{r}}\right)$ is the strictly positive equilibrium of $(3.2), f\left(\bar{N}, \bar{n}_{\mathrm{r}}, 0, X, x_{\mathrm{r}}, x_{\mathrm{m}}\right)=0$. Evaluating the Jacobian matrix at the equilibrium, we have the following block triangular matrix

$$
\left(\begin{array}{ccc}
\frac{\partial F}{\partial N}\left(\bar{N}, \bar{n}_{\mathrm{r}}, 0, X, x_{\mathrm{r}}, x_{\mathrm{m}}\right) & \frac{\partial F}{\partial n_{\mathrm{r}}}\left(\bar{N}, \bar{n}_{\mathrm{r}}, 0, X, x_{\mathrm{r}}, x_{\mathrm{m}}\right) & \frac{\partial F}{\partial n_{\mathrm{m}}}\left(\bar{N}, \bar{n}_{\mathrm{r}}, 0, X, x_{\mathrm{r}}, x_{\mathrm{m}}\right) \\
\overline{n_{\mathrm{r}}} \frac{\partial f}{\partial N}\left(\bar{N}, \bar{n}_{\mathrm{r}}, 0, X, x_{\mathrm{r}}, x_{\mathrm{m}}\right) & \overline{n_{\mathrm{r}}} \frac{\partial f}{\partial n_{\mathrm{r}}}\left(\bar{N}, \bar{n}_{\mathrm{r}}, 0, X, x_{\mathrm{r}}, x_{\mathrm{m}}\right) & \overline{n_{\mathrm{r}}} \frac{\partial f}{\partial n_{\mathrm{m}}} \\
0 & 0 & g\left(\bar{N}, \bar{n}_{\mathrm{r}}, 0, X, x_{\mathrm{r}}, x_{\mathrm{m}}\right)
\end{array}\right)
$$




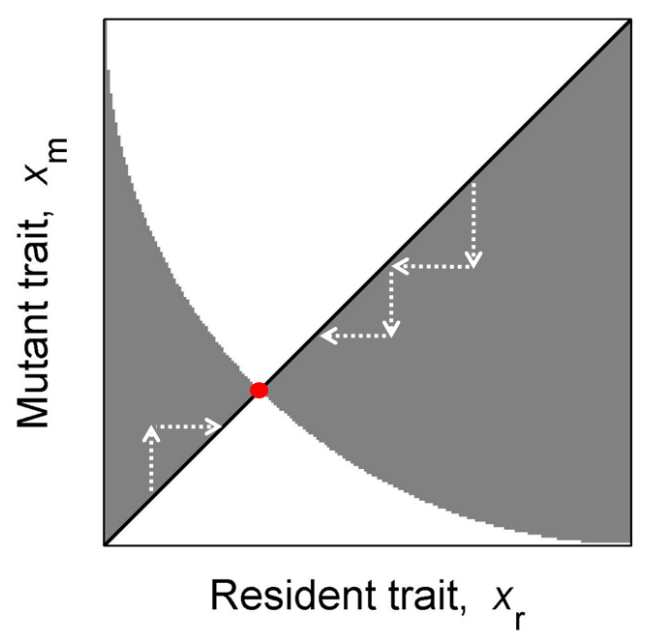

Figure 3.1: A Pairwise Invasibility Plot of resident-mutant dynamics.

Since $\left(\bar{N}, \bar{n}_{\mathrm{r}}\right)$ is a stable equilibrium of $(3.2)$, the eigenvalues of the upper diagonal matrix

$$
\left(\begin{array}{cc}
\frac{\partial F}{\partial N}\left(\bar{N}, \bar{n}_{\mathrm{r}}, 0, X, x_{\mathrm{r}}, x_{\mathrm{m}}\right) & \frac{\partial F}{\partial n_{\mathrm{r}}}\left(\bar{N}, \bar{n}_{\mathrm{r}}, 0, X, x_{\mathrm{r}}, x_{\mathrm{m}}\right) \\
\overline{n_{\mathrm{r}}} \frac{\partial f}{\partial N}\left(\bar{N}, \bar{n}_{\mathrm{r}}, 0, X, x_{\mathrm{r}}, x_{\mathrm{m}}\right) & \bar{n}_{\mathrm{r}} \frac{\partial f}{\partial n_{\mathrm{r}}}\left(\bar{N}, \bar{n}_{\mathrm{r}}, 0, X, x_{\mathrm{r}}, x_{\mathrm{m}}\right)
\end{array}\right)
$$

have negative real parts. Therefore, the stability of the mutant-free equilibrium $\left(\bar{N}, \bar{n}_{\mathrm{r}}, 0\right)$ in resident-mutant dynamics would be determined by the growth rate of the mutant population at the equilibrium, more specifically by the sign of

$$
\omega\left(x_{\mathrm{r}}, x_{\mathrm{m}}, X\right):=g\left(\bar{N}\left(x_{\mathrm{r}}, X\right), \bar{n}_{\mathrm{r}}\left(x_{\mathrm{r}}, X\right), 0, X, x_{\mathrm{r}}, x_{\mathrm{m}}\right),
$$

which is called invasion fitness. When $g\left(\bar{N}, \bar{n}_{\mathrm{r}}, 0, X, x_{\mathrm{r}}, x_{\mathrm{m}}\right)$ is a matrix, invasion fitness is defined as the spectral abscissa of the matrix (largest real part of eigenvalues).

By the invasion fitness obtained from local stability analysis, we can identify whether the given mutants can invade the environment manifested by the residents. One needs to study the global dynamics in order to know whether the invaded mutants population further grows to substitute resident population. However, if we allow only small steps of mutation, successful invasion generally leads to the substitution of the residents (see the Tube theorem in Appendix B of [13]).

The information concerning the course of the trait evolution can be shown graphically in a so-called PIP, a Pairwise Invasibility Plot (Figure 3.1). The color at a point $\left(x_{\mathrm{r}}, x_{\mathrm{m}}\right)$ in PIP is determined by the sign of the invasion fitness $\omega\left(x_{\mathrm{r}}, x_{\mathrm{m}}, X\right)$. The pair of traits $\left(x_{\mathrm{r}}, x_{\mathrm{m}}\right)$ lying in a white region corresponds to negative invasion fitness and the pair lying in a gray corresponds to positive invasion fitness. Points on the diagonal line of $x_{\mathrm{r}}=$ 
$x_{\mathrm{m}}$ corresponds to the monomorphic state. When mutants appear in a monomorphic population, a point on the diagonal line jumps to the vertical direction. If the point jumps to the white region, mutants cannot invade the resident, and the point jumps back to the point on the diagonal line. Nevertheless, when a point in a diagonal line jumps to the gray region, mutants can successfully invade. If the invasion further leads to the substitution, the point in a gray region would now move horizontally to the diagonal line, and population would again settle down to the monomorphic state with the invader trait.

We call a trait an Evolutionarily Stable Strategy (ESS) if no mutants with rare and small mutation can invade when the majority of the population has this trait. A trait is called Convergence Stable Strategy if it is an evolutionary attractor, which means, its nearby resident traits evolve towards the convergence strategy by a sequence of small mutations and substitutions. A Convergence Stable ESS is called as a Continuously Stable Strategy (CSS). A red point in Figure 3.1 is CSS. Allowing only small mutations, a CSS would be the locally stable evolutionarily attractor.

\subsection{Classic SLIS model with seasonality}

In this chapter, we investigate the role of latency on the classic SLIS disease transmission model with periodic seasonal parameters.

\subsubsection{Model description}

We consider a host-pathogen system in which the pathogen is a (micro)parasite that generates a latent period in the host. Assuming no or very short-term immunity upon recovery, the population dynamics is governed by susceptible-latent-infectious-susceptible compartmental model (SLIS). Seasonal diseases can be driven by multiple extrinsic drivers, but for simplicity, we assume that the seasonal driver affects only the transmission rate of the pathogen. The dynamics is governed by the system

$$
\begin{aligned}
\frac{d S(t)}{d t} & =b(1-S(t))-\beta(t) S(t) I(t)+r I(t), \\
L(t) & =\int_{-\infty}^{t} \beta(u) S(u) I(u) F(t-u) e^{-b(t-u)} \mathrm{d} u, \\
I(t) & =1-S(t)-L(t),
\end{aligned}
$$

where $S(t), L(t), I(t)$ denote the susceptible, latent and infectious compartments, respectively, parameter $r$ is the recovery rate. We consider a constant host population (normalized to 1), and $b$ represents both birth and mortality rate. 
Seasonality is incorporated into the transmission term by assuming $\beta(t)=\beta(t+P)$ with some period $P$ (usually one year). In the literature, typically a sinusoid forcing

$$
\beta(t)=\beta_{0}\left(1+\beta_{1} \cos (2 \pi t / P)\right)
$$

is used (Figure 3.2). Here we use a square wave approximation. To investigate the robustness of our results, a triangular wave (tent function) approximation is also used (Figure 3.3). In both approximations, each year is divided into an on-season, during which the pathogen can be transmitted, and an off-season, during which no new infections can occur.

Let $\lambda$ be the length of on-season, with $P$ being the sum of the lengths of the on-season and the off-season. The time $t=k P$, where $k$ is an integer, corresponds to the beginning of each on-season. In the square wave approximation, the transmission function is a piecewise constant periodic function, taking the value zero or $\beta_{*}$, which represents onand off-seasons:

$$
\beta(t)= \begin{cases}\beta_{*} & k P \leq t<k P+\lambda \\ 0 & k P+\lambda \leq t<(k+1) P\end{cases}
$$

where $\lambda \leq P$. Similarly, the tent map is defined by

$$
\beta(t)= \begin{cases}\beta_{*}\left(1-\frac{1}{\lambda}|2 t-(2 k P+\lambda)|\right) & \text { for } k P \leq t<k P+\lambda, \\ 0 & \text { for } k P+\lambda \leq t<(k+1) P .\end{cases}
$$

While the square wave and tent function approximations are somewhat oversimplified, they have the advantage that the on-season length is explicitly given by a single parameter $\lambda$, thus the influence of the on-season length on the disease dynamics as well as on the direction of the evolution of the latent period when on-season length is changing is more easily tractable. Also, we can now compare different shapes of the seasonal driver.

We introduce the latency distributions as described in [76]. The term $F(t-u)$ denotes the probability that a latent host individual which entered the latent class at time $u$ still remains in the latent class by time $t$, without taking into account a mortality. Assuming the probability depends only on the duration of time an individual spent in the latent class, not on the particular point of time individual entered or left, we let $F: R \rightarrow[0,1]$ a piecewise continuous function satisfying $F(t)=0$ for $t<0$, non-increasing for $t>0$, $F\left(0^{+}\right)=1, \lim _{t \rightarrow \infty} F(t)=0$ with $\int_{-\infty}^{\infty} F(t) \mathrm{d} t$ positive and finite. The following is a special case with

$$
F(t)=e^{-\theta t}
$$




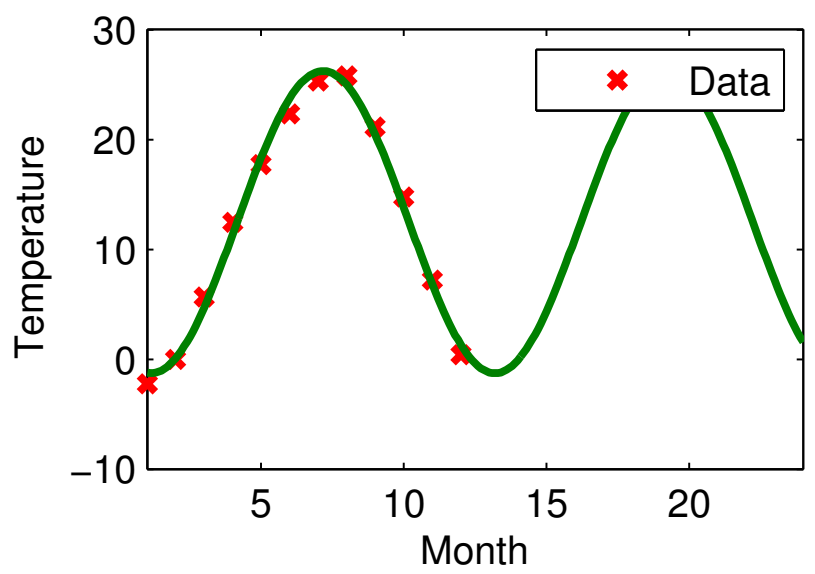

FIGURE 3.2: Sinusoid fitting to the average monthly temperature in Seoul from 1971 to 2000, South Korea [30].

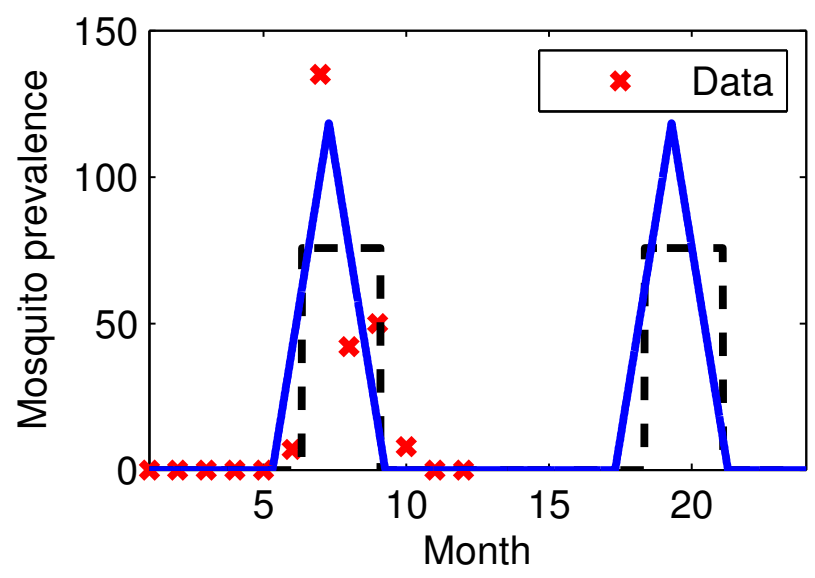

FIGURE 3.3: Least square fitting of vector abundance to square wave and triangular wave functions. Vector abundance is a monthly data of $A$. sinensis mosquitoes collected at Gunsan, Republic of Korea, 2007 [27].

which is commonly studied in many literatures.

$$
\begin{aligned}
& \frac{d S(t)}{d t}=b(1-S(t))-\beta(t) S(t) I(t)+r I(t), \\
& \frac{d L(t)}{d t}=\beta(t) S(t) I(t)-\theta^{-1} L(t)-b L(t) \\
& \frac{d I(t)}{d t}=\theta^{-1} L(t)-(r+b) I(t)
\end{aligned}
$$

Model (3.6) assumes that the lengths of the latent period are exponentially distributed, which is unrealistic $[36,46]$. To avoid artifacts arising from this distribution, we consider a more general distribution, namely the Gamma distribution

$$
g(s)=\frac{\alpha^{k} s^{k-1} e^{-\alpha s}}{\Gamma(k)} .
$$

When $k=1$, it is just an exponential distribution, but when $k$ is large enough, the 


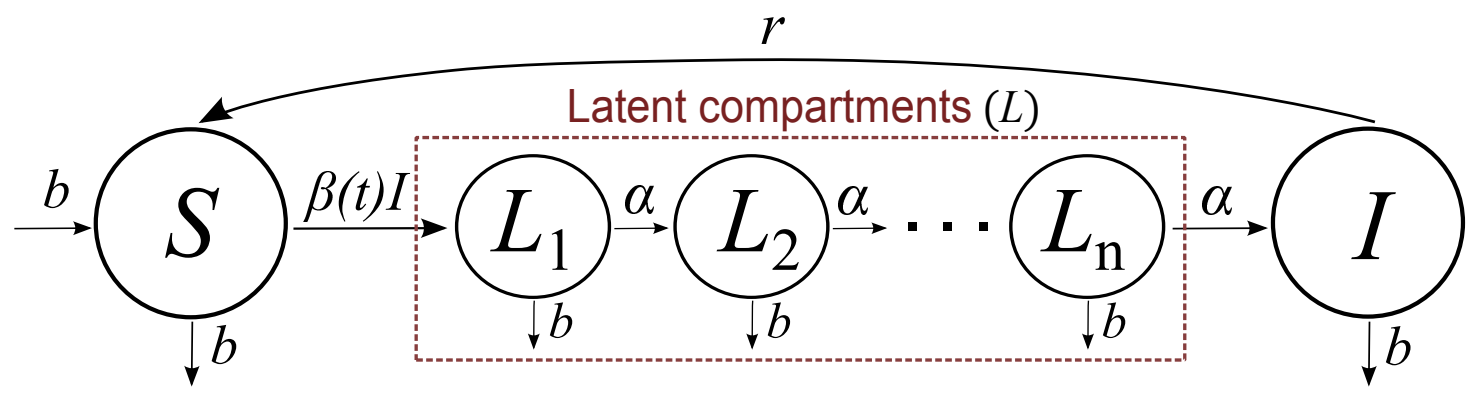

Figure 3.4: A conceptual diagram of the model (3.10)

Gamma distribution has much less variance than the exponential distribution. When $k$ is a natural number, the distribution is called an Erlang distribution. The Erlang distribution can be easily be incorporated into a system of differential equations using so called linear chain trick [65]: we divide the latent compartment $L$ with several subcompartments $L_{j} \mathrm{~s}, j=1,2, \ldots, n$, defined as

$$
\begin{aligned}
& L_{1}(t):=\int_{-\infty}^{t} \alpha \beta(u) S(u) I(u) e^{-\alpha(t-u)} e^{-b(t-u)} \mathrm{d} u, \\
& L_{j}(t):=\int_{-\infty}^{t} \alpha L_{j-1}(u) e^{-\alpha(t-u)} e^{-b(t-u)} \mathrm{d} u, \quad j=2, \ldots, n,
\end{aligned}
$$

Note that the probability distribution of lengths of stay in each compartments $L_{j}$ are the same as

$$
f_{j}(l):=\alpha e^{-\alpha l}
$$

Considering the latent compartment

$$
L(t):=L_{1}(t)+L_{2}(t)+\cdots+L_{n}(t)
$$

the probability distribution of latent period $f(s)$ is

$$
\begin{aligned}
f(s) & =\int_{0}^{s} \ldots \int_{0}^{l_{3}} \int_{0}^{l_{2}} f_{1}\left(l_{1}\right) f_{2}\left(l_{2}\right) \ldots f_{n}\left(s-l_{1}-l_{2}-\cdots-l_{n-1}\right) \mathrm{d} l_{1} \mathrm{~d} l_{2} \ldots \mathrm{d} l_{n-1} \\
& =\alpha^{n} \int_{0}^{s} \ldots \int_{0}^{l_{3}} \int_{0}^{l_{2}} e^{-\alpha l_{1}} e^{-\alpha l_{2}} \ldots e^{-\alpha\left(s-l_{1}-l_{2}-\cdots-l_{n-1}\right)} \mathrm{d} l_{1} \mathrm{~d} l_{2} \ldots \mathrm{d} l_{n-1} \\
& =\alpha^{n} e^{-\alpha s} \int_{0}^{s} \ldots \int_{0}^{l_{3}} \int_{0}^{l_{2}} \mathrm{~d} l_{1} \mathrm{~d} l_{2} \ldots \mathrm{d} l_{n-1} \\
& =\frac{\alpha^{n} e^{-\alpha s} s^{n-1}}{(n-1) !}
\end{aligned}
$$

Note that $f(s)$ is the special case of (3.7) with integer $k$. We put $\alpha:=n \theta^{-1}$, so that the average of the two distributions of latent period $f(s)$ in (3.9) and $F(s)$ in (3.5) to 


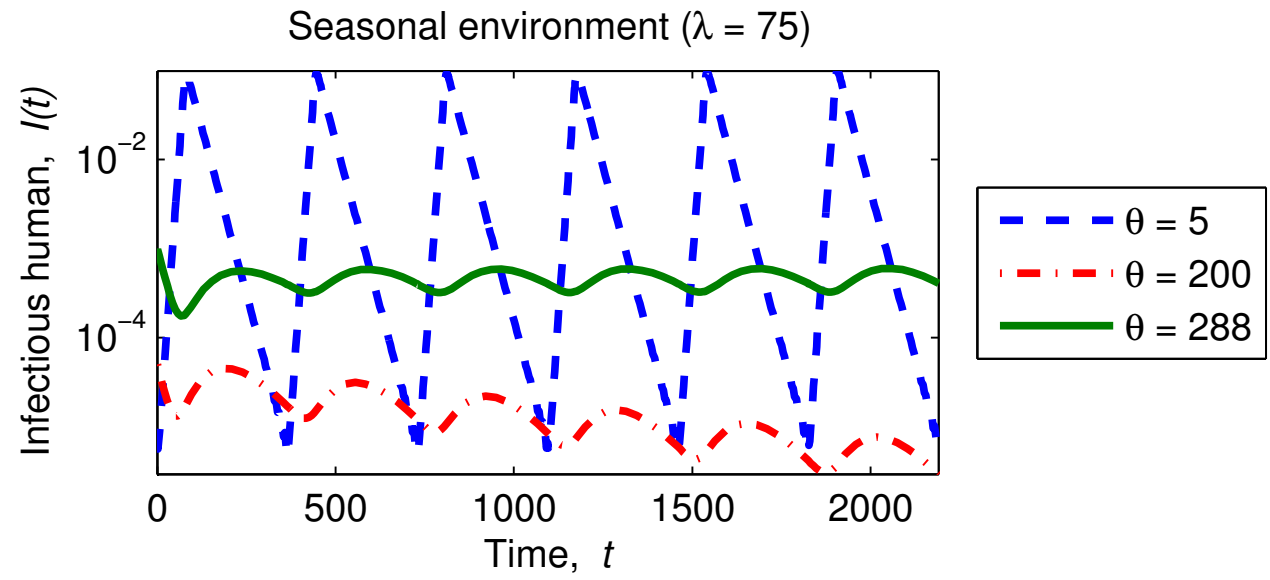

FIGURE 3.5: Infectious host dynamics (3.10) in seasonal environment with different average length of latent periods, which shows sharp peak for short latency, extinction for intermediate latency, and moderate oscillation for long latency.

Parameter values used in all simulations are as indicated in Table 3.1.

\begin{tabular}{lll}
\hline Parameter & Description & Value \\
\hline$P$ & sum of on-season and off-season lengths & 365 \\
$b$ & birth rate & $1 / 1000$ \\
$r$ & recovery rate & $1 / 30$ \\
$n$ & number of sub-compartments for latent class & 3 \\
$\beta_{*}$ & transmission rate during on-season & 0.3 \\
$\theta$ & average length of latent period & - \\
$\lambda$ & length of on-season & - \\
\hline
\end{tabular}

TABLE 3.1: Parameter values for simulations

be same. Finally, differentiation of both sides of equations (3.8) and

$$
I(t):=\int_{-\infty}^{t} \alpha L_{n}(u) e^{-r(t-u)} e^{-b(t-u)} \mathrm{d} u
$$

yields the the system

$$
\begin{aligned}
\frac{d S(t)}{d t} & =b(1-S(t))-\beta(t) S(t) I(t)+r I(t), \\
\frac{d L_{1}(t)}{d t} & =\beta(t) S(t) I(t)-n \theta^{-1} L_{1}(t)-b L_{1}(t), \\
\frac{d L_{j}(t)}{d t} & =n \theta^{-1} L_{j-1}(t)-n \theta^{-1} L_{j}(t)-b L_{j}(t), \quad j=2, \ldots, n, \\
\frac{d I(t)}{d t} & =n \theta^{-1} L_{n}(t)-(r+b) I(t) .
\end{aligned}
$$

Figure 3.5 presents numerical solutions corresponding to three different average lengths of latent periods. In this example, the disease sustains either with short or long latency, but not with intermediate one. To examine this behavior in more detail, we consider the basic reproduction number, $R_{0}$, the stability threshold of the disease-free equilibrium. 
Usually, $R_{0}=1$ is the bifurcation point between eradication and persistence of the disease $[15,70]$. More precisely, $R_{0}>1$ implies the instability of the disease-free state and the invasion of the host population by the disease, while $R_{0}<1$ implies the stability of the disease-free state and hence invasion is not possible.

In the case of a constant environment (when $\beta(t)=\beta_{0}$ for all $t$ ), the basic reproduction number $R_{0}$ of (3.10) is given as the product of the transmission rate, the length of infectious period and the probability of surviving the latent period, that is

$$
R_{0}=\frac{\beta_{0}}{r+b}\left(\frac{n \theta^{-1}}{n \theta^{-1}+b}\right)^{n} .
$$

The term $\beta_{0}$ describes transmission rate, $\left(\frac{n \theta^{-1}}{n \theta^{-1}+b}\right)^{n}$ is the probability that an infected human survives the exposed state and becomes infectious, and $\frac{1}{r+b}$ is the length of infectious period.

Proposition 3.1. Consider system (3.10) with a constant transmission function $\beta(t)=$ $\beta_{0}$. The disease-free equilibrium $(1,0, \ldots, 0)$ is locally asymptotically stable if $R_{0}<1$, and unstable if $R_{0}>1$.

Proof. To find a stability threshold, we follow a method described in [69]. Linearization of the system (3.10) with constant transmission function $\beta(t)=\beta_{0}$ at the disease free equilibrium leads to

$$
\begin{aligned}
\frac{d S(t)}{d t} & =-b S(t)-\beta_{0} I(t)+r I(t), \\
\frac{d L_{1}(t)}{d t} & =\beta_{0} I(t)-n \theta^{-1} L_{1}(t)-b L_{1}(t), \\
\frac{d L_{j}(t)}{d t} & =n \theta^{-1} L_{j-1}(t)-n \theta^{-1} L_{j}(t)-b L_{j}(t), \quad j=2, \ldots, n, \\
\frac{d I(t)}{d t} & =n \theta^{-1} L_{n}(t)-(r+b) I(t) .
\end{aligned}
$$

We rewrite the linear system restricted to the infected compartments as

$$
x^{\prime}(t)=(F-V) x(t)
$$

where $F$ and $V$ are matrices representing reproduction of new infections and transition between compartments by other means. When $n=3$ (and similarly for any other $n$ ), 
they take the form

$$
F=\left(\begin{array}{cccc}
0 & 0 & 0 & \beta_{0} \\
0 & 0 & 0 & 0 \\
0 & 0 & 0 & 0 \\
0 & 0 & 0 & 0
\end{array}\right) \quad \text { and } \quad V=\left(\begin{array}{cccc}
3 \theta^{-1}+b & 0 & 0 & 0 \\
-3 \theta^{-1} & 3 \theta^{-1}+b & 0 & 0 \\
0 & -3 \theta^{-1} & 3 \theta^{-1}+b & 0 \\
0 & 0 & -3 \theta^{-1} & r+b
\end{array}\right)
$$

By Theorem 2 of [69], the spectral radius of

$$
F V^{-1}=\left(\begin{array}{cccc}
\frac{\beta_{0}}{r+b}\left(\frac{3 \theta^{-1}}{3 \theta^{-1}+b}\right)^{3} & \frac{\beta_{0}}{r+b}\left(\frac{3 \theta^{-1}}{3 \theta^{-1}+b}\right)^{2} & \frac{\beta_{0}}{r+b}\left(\frac{3 \theta^{-1}}{3 \theta^{-1}+b}\right) & \frac{\beta_{0}}{r+b} \\
0 & 0 & 0 & 0 \\
0 & 0 & 0 & 0 \\
0 & 0 & 0 & 0
\end{array}\right)
$$

becomes a stability threshold of the disease-free equilibrium. Since

$$
\begin{aligned}
\operatorname{det}\left(F V^{-1}-z I\right) & =\left|\begin{array}{cccc}
\frac{\beta_{0}}{r+b}\left(\frac{3 \theta^{-1}}{3 \theta^{-1}+b}\right)^{3}-z & \frac{\beta_{0}}{r+b}\left(\frac{3 \theta^{-1}}{3 \theta^{-1}+b}\right)^{2} & \frac{\beta_{0}}{r+b}\left(\frac{3 \theta^{-1}}{3 \theta^{-1}+b}\right) & \frac{\beta_{0}}{r+b} \\
0 & -z & 0 & 0 \\
0 & 0 & -z & 0 \\
0 & 0 & 0 & -z
\end{array}\right| \\
& =z^{3}\left(z-R_{0}\right),
\end{aligned}
$$

there exist only two characteristic roots, $R_{0}$ and zero. Since $R_{0}$ is positive with positive parameters, the spectral radius of $F V^{-1}$ is equal to $R_{0}$.

Note that $R_{0}$ defined in (3.11) can be rewritten as

$$
R_{0}=\frac{\beta_{0}}{(r+b)\left(1+b n^{-1} \theta\right)^{n}},
$$

and it is observable that $R_{0}$ in constant environment is monotone decreasing in $\theta$, the average length of latent period. Now, we would like to study the relation between $R_{0}$ and $\theta$ in a periodic environment. For some special cases of periodic disease models, $R_{0}$ can be simply obtained by replacing $\beta$ by its time average $\frac{1}{P} \int_{0}^{P} \beta(u) \mathrm{d} u[59,71]$. However, in this way, $R_{0}$ is monotonically decreasing with respect to $\theta$, and it contradicts with what we have observed from Figure 3.5. The precise concept of $R_{0}$ in seasonal environment is more complicated as it should be defined as the spectral radius of a suitable operator $[5,70,75]$. Here, we use a recently developed general approach [70] to compute $R_{0}$. 


\subsubsection{The basic reproduction number in seasonal environment}

First we rewrite the linearized system at the disease free equilibrium restricted to the infected compartments as

$$
x^{\prime}(t)=(F(t)-V(t)) x(t)
$$

where $F(t)$ and $V(t)$ are time periodic matrix valued functions representing reproduction of new infections and transition between compartments by other means, respectively, analogously to the autonomous case (see [69]). For system (3.10) with $n=3$ (and similarly for any other $n$ ), they take the form

$$
\begin{gathered}
F(t)=\left(\begin{array}{cccc}
0 & 0 & 0 & \beta(t) \\
0 & 0 & 0 & 0 \\
0 & 0 & 0 & 0 \\
0 & 0 & 0 & 0
\end{array}\right), \\
V(t)=\left(\begin{array}{cccc}
3 \theta^{-1}+b & 0 & 0 & 0 \\
-3 \theta^{-1} & 3 \theta^{-1}+b & 0 & 0 \\
0 & -3 \theta^{-1} & 3 \theta^{-1}+b & 0 \\
0 & 0 & -3 \theta^{-1} & r+b
\end{array}\right) .
\end{gathered}
$$

The work in Bacaër and Guernaoui [5] and Wang and Zhao [70] develops a general approach that ties the fundamental matrix solution of the above linear system and the growth or decay rate of infected population to the evolution operator $Y(t, s)$, defined by $y^{\prime}(t)=-V(t) y(t)$ for $t \geq s$ with $Y(s, s)=\mathbb{I}$, where $\mathbb{I}$ is the $(n+1) \times(n+1)$ identity matrix. In our case $V(t)=V$ is time invariant so $Y(t, s)=e^{(t-s) V}$. To relate to the basic reproduction number, we let $C_{P}$ denote the collection of all possible initial infected populations distributed over the period $[0, P]$, the space of all continuous periodic functions from $[0, P]$ to $R^{n+1}$, equipped with the supremum norm. For a fixed initially introduced infected population distribution $\phi \in C_{P}, F(s) \phi(s)$ is the rate at which new infections are generated by infected individuals introduced at time $s$, and $Y(t, s) F(s) \phi(s)$ represents how many of them are still in the infected compartments at time $t \geq s$. This naturally leads to the linear operator $L: C_{P} \rightarrow C_{P}$ given by

$$
L \phi(t)=\int_{0}^{\infty} Y(t, t-a) F(t-a) \phi(t-a) \mathrm{d} a
$$

for $t \in \mathbb{R}$ and $\phi \in C_{P}$. It then follows from [70] that $L$ is the next generation operator, and the basic reproduction number is $R_{0}=\rho(L)$, the spectral radius of $L$.

It is known that the explicit formula for $R_{0}$ can be derived only for some special cases, when both the matrix of new infection rate $F(t)$ and the matrix of transition $V(t)$ are 
diagonal, or when both matrix functions are constant [70]. Though our model is none of the special cases, we could use a theorem of Wang and Zhao [70], which characterizes $R_{0}$, further enabling to estimate $R_{0}$ numerically.

Theorem 3.2 ([70]). Consider the linear P-periodic system

$$
\frac{d w}{d t}=\left(-V(t)+\frac{1}{\lambda} F(t)\right) w
$$

with parameter $\lambda \in(0, \infty)$. Let $W(t, \lambda), t \geq 0$ be the standard fundamental matrix of the system with $W(0, \lambda)=I$. If $R_{0}>0, \lambda=R_{0}$ is the unique solution of

$$
\rho(W(P, \lambda))=1
$$

We solve (3.12) by the method of nested intervals. In each iteration step, we numerically estimate the eigenvalues of $\rho(W(P, \lambda))$ for a given $\lambda$ by integrating

$$
\left\{\begin{array}{l}
W^{\prime}(t, \lambda)=\left(-V(t)+\frac{1}{\lambda} F(t)\right) W(t) \\
W(0, \lambda)=I
\end{array}\right.
$$

Figure 3.6 illustrates the dependence of $R_{0}$ on the length of latent period. We observe two possible profiles depending on seasonal forcing and model parameters: (i) $R_{0}$ monotonically decreases with latency; (ii) $R_{0}$ has a bimodal shape. Profile (i) is observed in a non-seasonal environment, when the length of on-season is approximately equal to the period. In other cases, we observe profile (ii), the non-monotonicity of $R_{0}$ with respect to the length of latent period. In some cases, it leads to die-off intervals of latency: the disease can sustain with short or long latent periods, but not with the medium range of latent periods as in the example of Figure 3.5. We also observe that solutions with different $\theta$ can look dissimilar even though their $R_{0}$ s are the same.

\subsection{Evolutionary model with seasonality}

As we discussed in Chapter 3.1, pathogens are suspected to change their latent period in hosts in order to increase their reproducibility in response of heterogeneous seasonal environment, such as a seasonal fluctuation in vector abundance. Our goal is to characterize evolutionary traits driven by the selective pressure for invasion. We consider the average latent period $\theta$ to be a trait of a strain, capable of evolving via a series of mutations. 

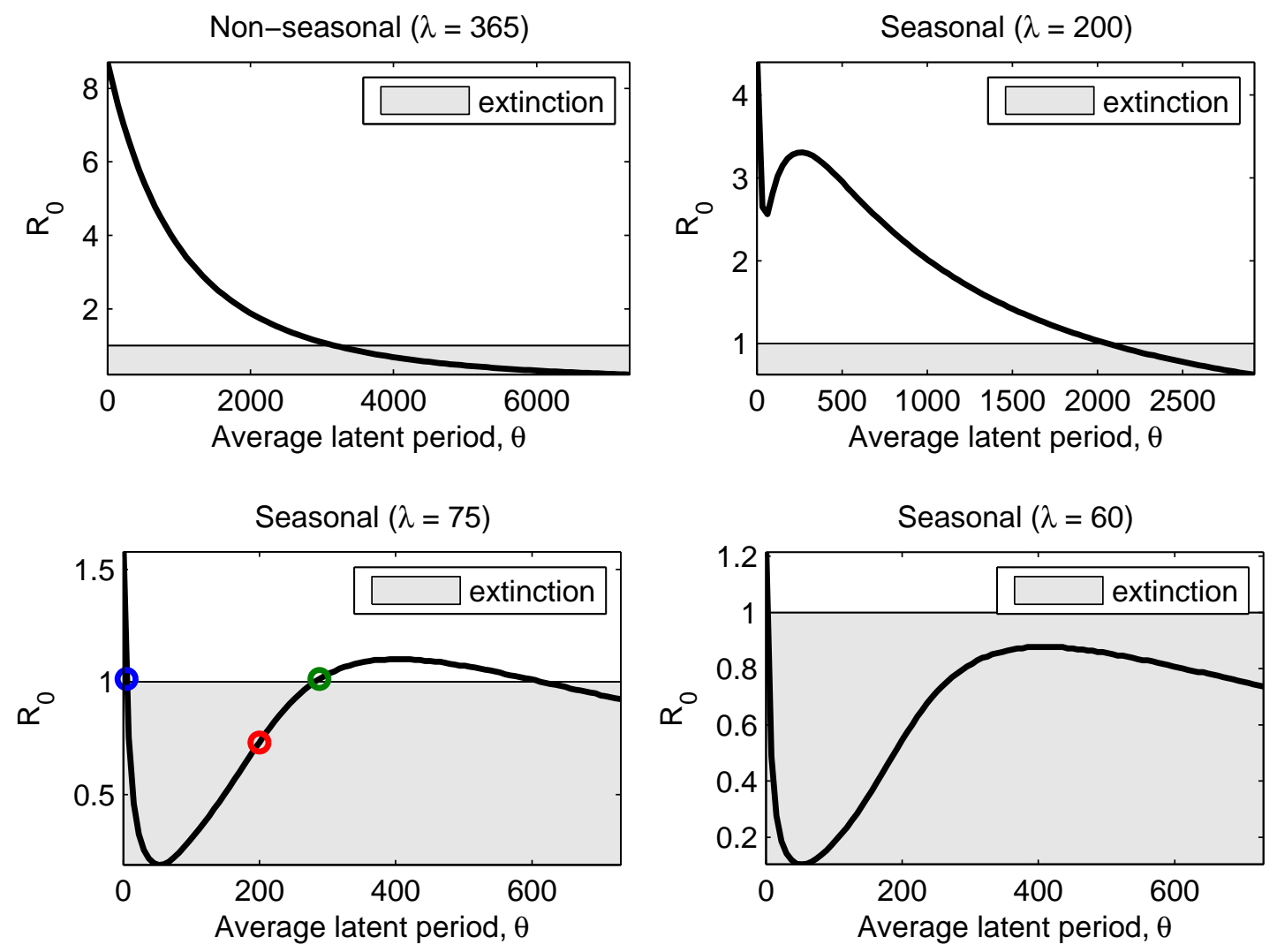

FIGURE 3.6: Qualitatively distinct $\left(\theta, R_{0}\right)$-graphs with various on-season length, $\lambda$. (i) When $\lambda=365, R_{0}$ monotonically decreases with $\theta$. (ii) $R_{0}$ has a bimodal shape when $\lambda=60, \lambda=75$ and $\lambda=200$. When $\lambda=75$, there exists a die-off interval of latent period. $R_{0}$ corresponding to $\theta=200$ (red) is 0.732 , and infectious human solution in Figure 3.5 goes extinct. $R_{0}$ s corresponding to $\theta=5$ (blue) and $\theta=288$ (green) are same as 1.013, so that the infectious human solutions persist. We see from Figure 3.5 that solutions with different $\theta$ can look dissimilar even though $R_{0} \mathrm{~s}$ are the same.

Invasibility of a mutant strain depends on the environment already manifested by a resident strain. To be more specific, the environment refers to $S_{\mathrm{r}}(t)$, the susceptible population component of the periodic attractor with absence of invaders. By periodic attractor, we mean the periodic solution which is observed to attract all solutions in the numerical simulations.

Figure 3.7 illustrate environments settled by resident strains with trait value $\theta=18$ and $\theta=140$, respectively. Figure 3.8 shows the corresponding transmission potential for invaders, $\beta(t) S_{\mathrm{r}}(t)$. We observe that the pool of susceptibles generated by $\theta=$ 18 dominates the one generated by $\theta=5$. Therefore, the resident strain with $\theta=$ 18 provides "better environment" than the resident strain with $\theta=5$, to any type of invaders. We also observe that resident strain of $\theta=140$ is favorable to invaders compared to the one with $\theta=300$. However, comparison between $\theta=18$ and $\theta=140$ is not straightforward. Which of the two strains generates better environment could 

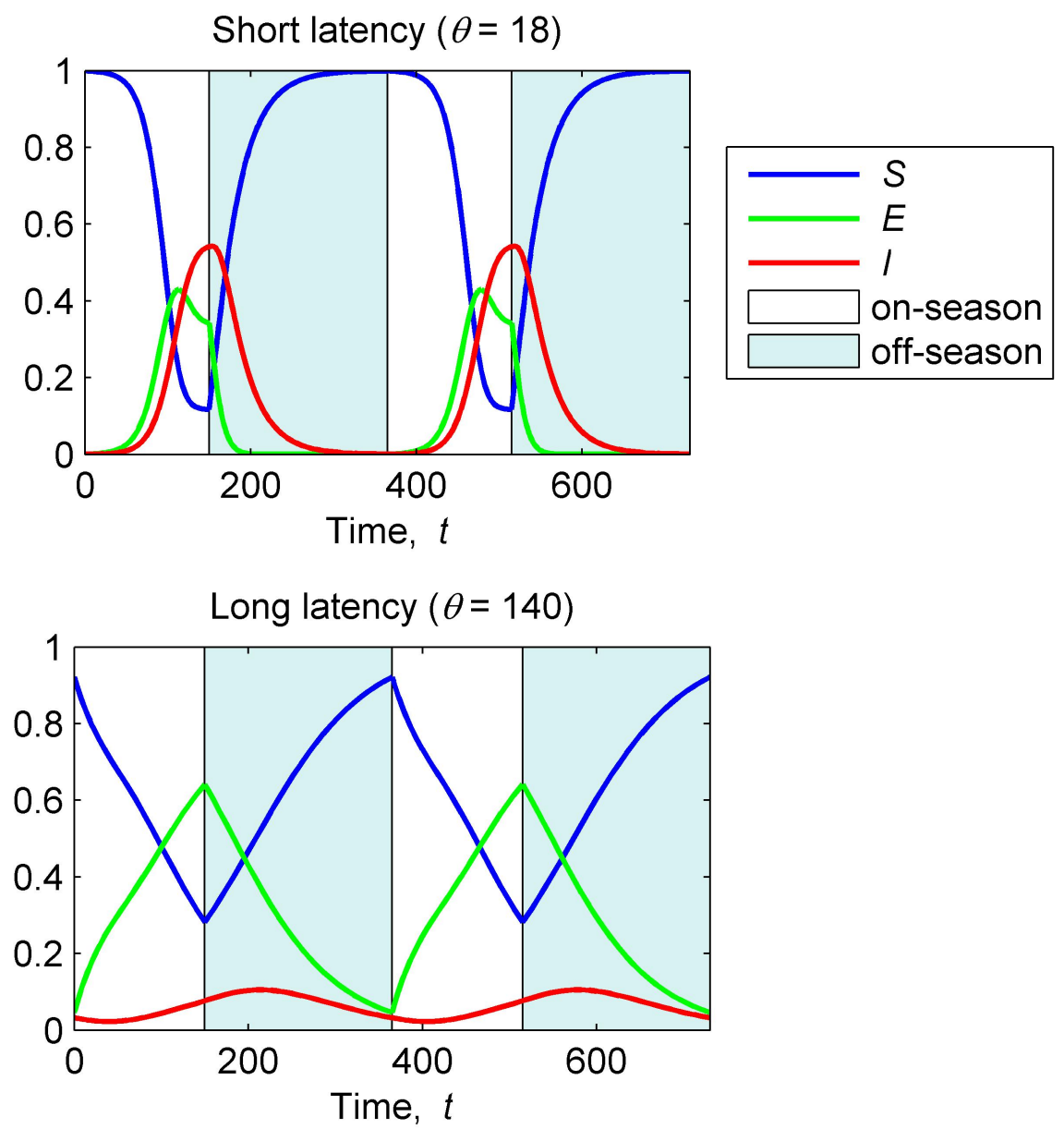

Figure 3.7: Seasonal environments (temporal variation of the pool of susceptibles) generated by resident strains with two different length of latent periods, $\theta=18$ and $\theta=140$. On-season length, $\lambda$, is 150 .

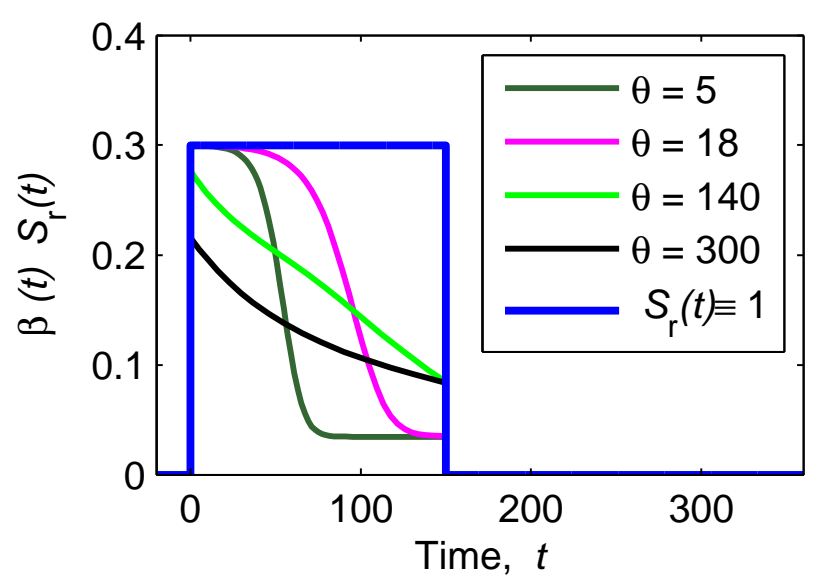

FIGURE 3.8: Effect of the resident's latency on the environment for invaders. Transmission potential $\beta(t) S_{\mathrm{r}}(t)$ with various resident strains. On-season length, $\lambda$, is 150. 
depend on the traits of invaders. This example shows a limitation of single-strain models in studying evolutionary processes. In the following chapter, we study resident-mutant models, a type of multi-strain models.

\subsubsection{Resident-mutant system}

In this chapter, we introduce resident-mutant dynamics. We characterize infected host individuals by the length of latency, which is the adaptive trait of the parasite that caused the infection. This way, the evolution of latency can be studied via a resident-mutant model, describing the competition between the resident and mutant populations. Lower index $\mathbf{r}$ stands for resident strain, $\mathbf{m}$ for invader mutant strain. Resident and mutant populations are differentiated by their traits, $\theta_{\mathrm{r}}^{-1}$ and $\theta_{\mathrm{m}}^{-1}$. The equations read as

$$
\begin{aligned}
\frac{d S(t)}{d t} & =b(1-S(t))-\beta(t) S(t)\left(I_{\mathrm{r}}(t)+I_{\mathrm{m}}(t)\right)+r\left(I_{\mathrm{r}}(t)+I_{\mathrm{m}}(t)\right), \\
\frac{d L_{\mathrm{r}, 1}(t)}{d t} & =\beta(t) S(t) I_{\mathrm{r}, 1}(t)-n \theta_{\mathrm{r}}^{-1} L_{\mathrm{r}, 1}(t)-b L_{\mathrm{r}, 1}(t), \\
\frac{d L_{\mathrm{r}, j}(t)}{d t} & =n \theta_{\mathrm{r}}^{-1} L_{\mathrm{r}, j}(t)-n \theta_{\mathrm{r}}^{-1} L_{\mathrm{r}, j}(t)-b L_{\mathrm{r}, j}(t), \quad j=2, \ldots, n \\
\frac{d I_{\mathrm{r}}(t)}{d t} & =n \theta_{\mathrm{r}}^{-1} L_{\mathrm{r}, n}(t)-(r+b) I_{\mathrm{r}}(t), \\
\frac{d L_{\mathrm{m}, 1}(t)}{d t} & =\beta(t) S(t) I_{\mathrm{i}, 1}(t)-n \theta_{\mathrm{m}}^{-1} L_{\mathrm{m}, 1}(t)-b L_{\mathrm{i}, 1}(t), \\
\frac{d L_{\mathrm{m}, j}(t)}{d t} & =n \theta_{\mathrm{m}}^{-1} L_{\mathrm{m}, j-1}(t)-n \theta_{\mathrm{m}}^{-1} L_{\mathrm{m}, j}(t)-b L_{\mathrm{m}, j}(t), \quad j=2, \ldots, n \\
\frac{d I_{\mathrm{m}}(t)}{d t} & =n \theta_{\mathrm{m}}^{-1} L_{\mathrm{m}, n}(t)-(r+b) I_{\mathrm{m}}(t) .
\end{aligned}
$$

When the mutation is a rare event, we may assume that the resident population is already settled at a periodic attractor. Linearizing the entire system of (3.13) around the mutant-free attractor, we have a decoupled system for the invaders:

$$
\begin{aligned}
\frac{d L_{\mathrm{m}, 1}(t)}{d t} & =\beta(t) S_{\mathrm{r}}(t) I_{\mathrm{m}, 1}(t)-n \theta_{\mathrm{m}}^{-1} L_{\mathrm{m}, 1}(t)-b L_{\mathrm{m}, 1}(t) \\
\frac{d L_{\mathrm{m}, \mathrm{j}}(t)}{d t} & =n \theta_{\mathrm{m}}^{-1} L_{\mathrm{m}, j-1}(t)-n \theta_{\mathrm{m}}^{-1} L_{\mathrm{m}, j}(t)-b L_{\mathrm{m}, j}(t), \quad j=2, \ldots, n \\
\frac{d I_{\mathrm{m}}(t)}{d t} & =n \theta_{\mathrm{m}}^{-1} L_{\mathrm{m}, n}(t)-(r+b) I_{\mathrm{m}}(t),
\end{aligned}
$$

where $S_{\mathrm{r}}(t)$ is the susceptible component of the periodic attractor. We define the invasion fitness as the stability threshold of the linear periodic system (3.14). According to the Floquet theory, for a fundamental matrix $X(t)$, there exists non-singular matrix $C$ such that $X(t+P)=X(t) C$ for all $t$. The stability of zero is determined by the Floquet multipliers, which are the eigenvalues of the matrix $C$. Using $X(P)=X(0) C$, we can find $C$ numerically. In detail, 
1. Obtain $S_{\mathrm{r}}(t)$ by solving the resident-mutant system (3.13) numerically with an initial condition satisfying

$$
L_{\mathrm{m}, 1}(0)=\cdots=L_{\mathrm{m}, \mathrm{j}}(0)=I_{\mathrm{m}}(0)=0 .
$$

2. For each $j=1, \ldots, n+1$, find the numerical solution of the decoupled invader system (3.14) at $t=P$ with initial condition $x(0)=\boldsymbol{e}_{\boldsymbol{j}}$. It gives an estimation of $j$-th column of the matrix $C$.

3. Find eigenvalues of the matrix $C$ numerically.

4. Estimate the invasion fitness by the spectral radius of $C$ minus one.

Now we produce PIP by calculating invasion fitnesses for each given parameter pair $\left(\theta_{\mathrm{r}}, \theta_{\mathrm{m}}\right)$. We designate white color for the parameter region with negative invasion fitness, and dark gray color for the region with positive invasion fitness. For the parameter region where resident go extinct, light gray color is designated.

Figure 3.9 shows distinct profiles of PIPs: (i) In the harsh environment $(\lambda=60)$, only the residents with short latency can survive. Shortest latency $\theta=0$ is evolutionarily stable and convergence strategy (CSS); (ii) In a less harsh environment $(\lambda=75)$, residence population with intermediate latency cannot survive. We identify two distinct CSSs, one short and the other long; (iii) When the on-season length is long enough $(\lambda=200)$, residence population survives with any latency. Two distinct CSSs exist; (iv) In nonseasonal environment $(\lambda=365)$, any type of resident survives. There exists only one CSS, the short one.

\subsubsection{Dependence of CSS on the on-season length}

We investigate the dependence of the location of CSS on the on-season length. Figure 3.10 shows PIPs with two distinctive CSSs. Note that these type of PIPs are observed only with intermediate on-season length. Figure 3.11 plot CSSs with various on-season length. The longer the on-season, the shorter the gap between two CSSs. When onseason length is long enough so that almost the whole year is season, two CSSs eventually converges to the short CSS.

\subsubsection{The road to frequency dependent selection}

To find out if there is a frequency dependent selection for our model, we draw so called pairwise $R_{0}$ plots in Figure 3.12, in comparison with PIPs in Figure 3.9. Pairwise $R_{0}$ 

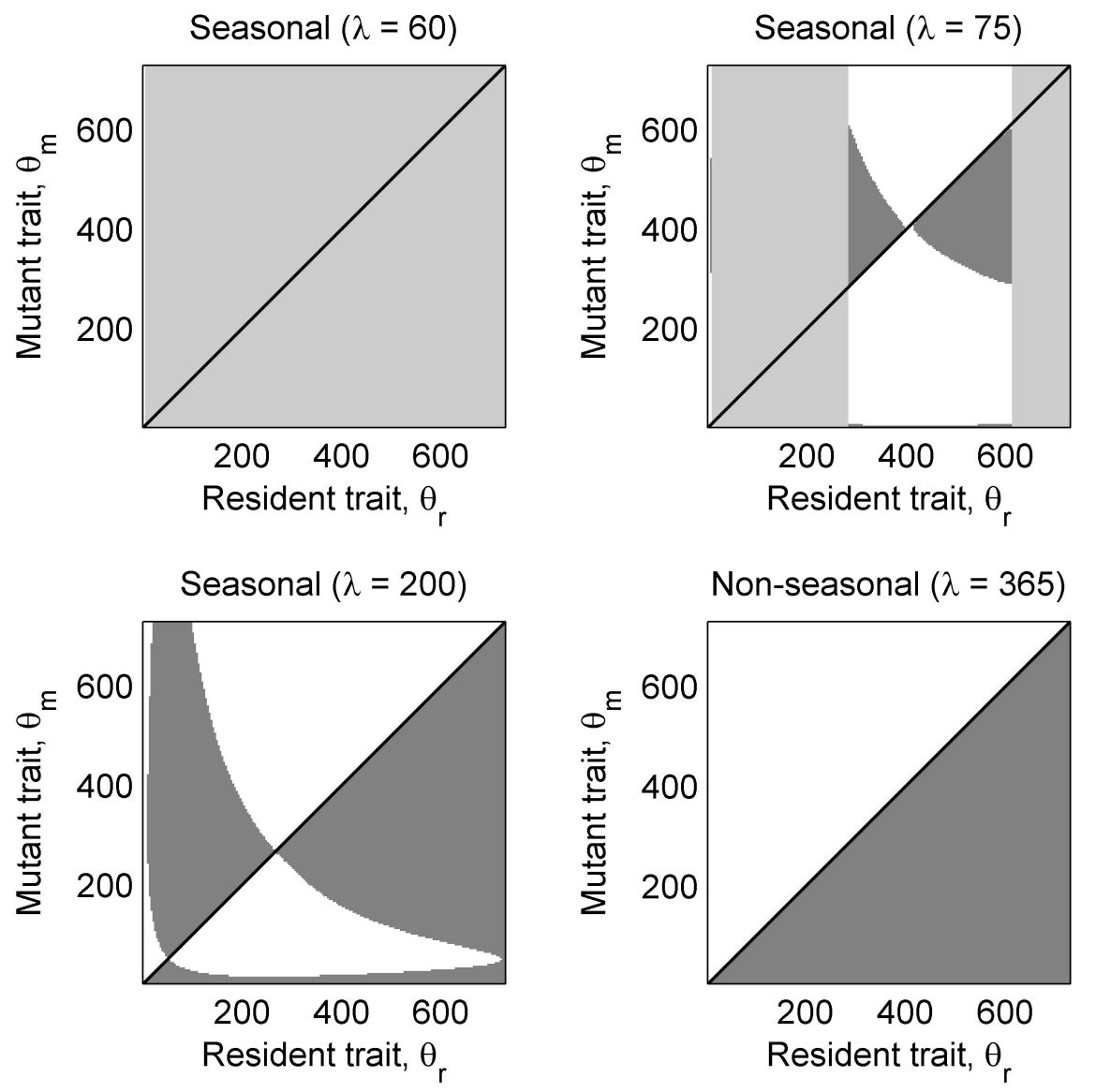

Figure 3.9: Qualitatively distinct PIPs with various on-season length. Each of area colored with light gray, white and dark gray represents where residents go extinct, resident settled but invadable, and resident non-invadable, respectively. (i) When $\lambda=60$, resident go extinct, except for those with short latency. Short latency $\theta=0$ becomes CSS. (ii) When $\lambda=75$, resident population with intermediate latency cannot survive. There exist two CSSs, with one short and another long. (iii) When $\lambda=200$, any type of resident survives. Two CSSs exist. (iv) When $\lambda=365$, there exists only the short CSS.

plot was produced by comparing $R_{0} \mathrm{~s}$ of $\theta_{\mathrm{r}}$ and $\theta_{\mathrm{m}}$. On the parameter region of resident trait and mutant trait, we designate dark gray color for the region where $\theta_{\mathrm{m}}$ induces higher $R_{0}$ than $\theta_{\mathrm{r}}$, and white color for vise versa. Right gray color is designated for regions with $\theta_{\mathrm{r}}<1$. If there is no frequency dependent selection, a pairwise $R_{0}$ plot in Figure 3.12 should be exactly the same as its PIP counterpart in Figure 3.9.

Though the effect seems very small, the result shows that the selection is frequency dependent. A PIP with $\lambda=200$ in Figure 3.9 is asymmetric, different from the corresponding one in Figure 3.12. The frequency dependent selection is necessary to explain the coexistence of two different traits. 

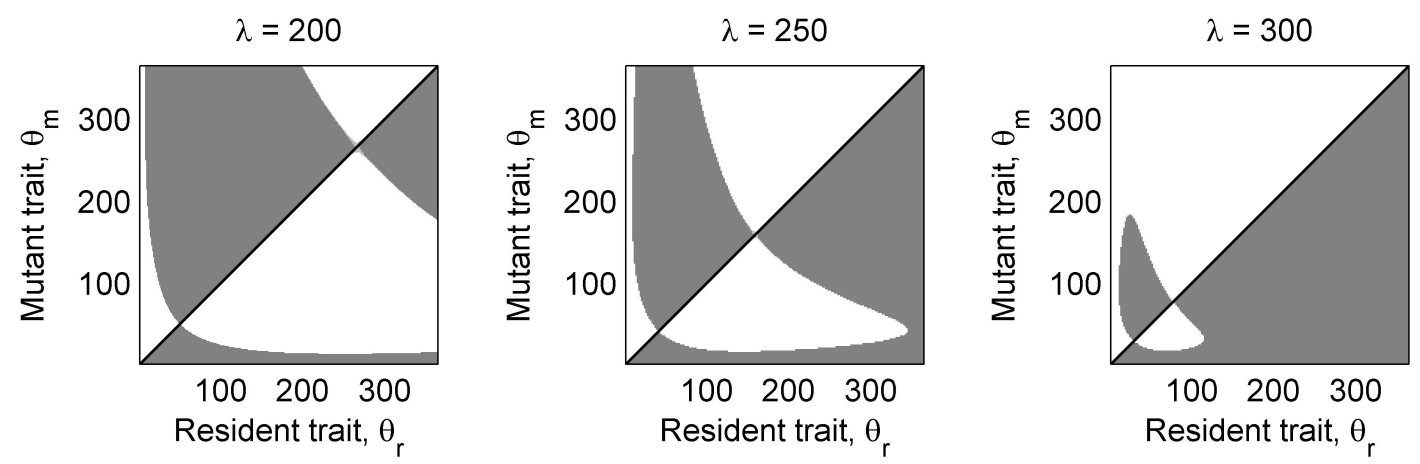

Figure 3.10: The long on-season leads to the short latency. PIPs with onseason length $\lambda=200, \lambda=250$ and $\lambda=300$.

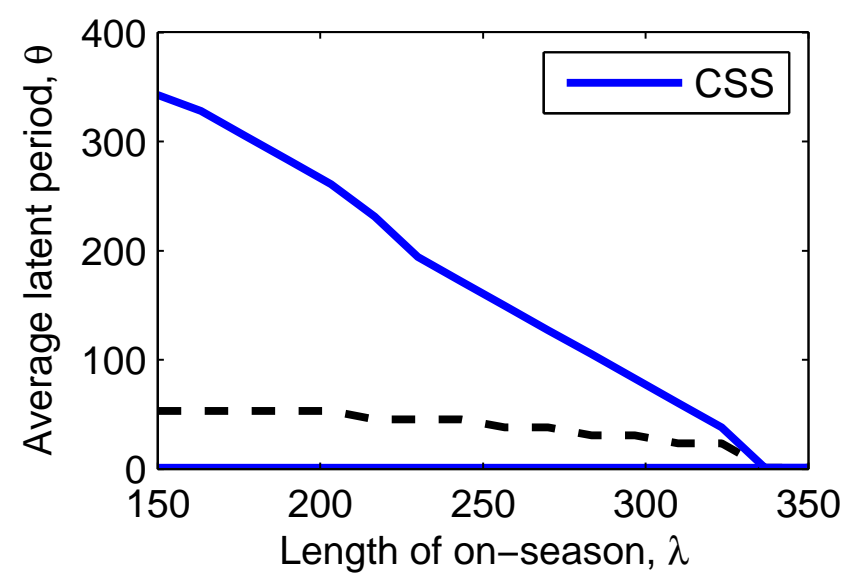

FIGURE 3.11: Location of CSSs depending on $\lambda$. CSSs are plotted with blue line. Black dot corresponds to the (residence) trait which allows invasion of any local mutants. The longer the on-season, the shorter the gap between two CSSs, which eventually converges to $\theta=0$.

\subsubsection{Coexistence and the evolutionary state of dimorphism}

If we overlap the second PIP in Figure 3.10 with its reflected image over the main diagonal, there exist a region where it is gray in both plots. The region is shown in Figure 3.13 with black color. Two different traits from the region can mutually invade each other and consequently coexist. Figure 3.14 is a solution showing coexistence of two strains with short and long latent periods.

We investigate if the observed dimorphism is either evolutionarily stable (protected dimorphism) or just a temporary phase leading to monomorphism (converging dimorphism). Consider the residence population with two different coexisting traits, $\theta_{\mathrm{r}, 1}$ and $\theta_{\mathrm{r}, 2}$. By similar methods presented in Chapter 3.4.1, we define resident-mutant system with two resident strains and numerically calculate the invasion fitness $F\left(\theta_{\mathrm{r}, 1}, \theta_{\mathrm{r}, 2}, \theta_{\mathrm{m}}\right)$.

Figure 3.15 presents the invasion fitness $F\left(\theta_{\mathrm{r}, 1}, \theta_{\mathrm{r}, 2}, \theta_{\mathrm{m}}\right)$ when a residence population have two coexisting traits $\left(\theta_{\mathrm{r}, 1}, \theta_{\mathrm{r}, 2}\right)$. In the upper figure, resident population is dimorphic 

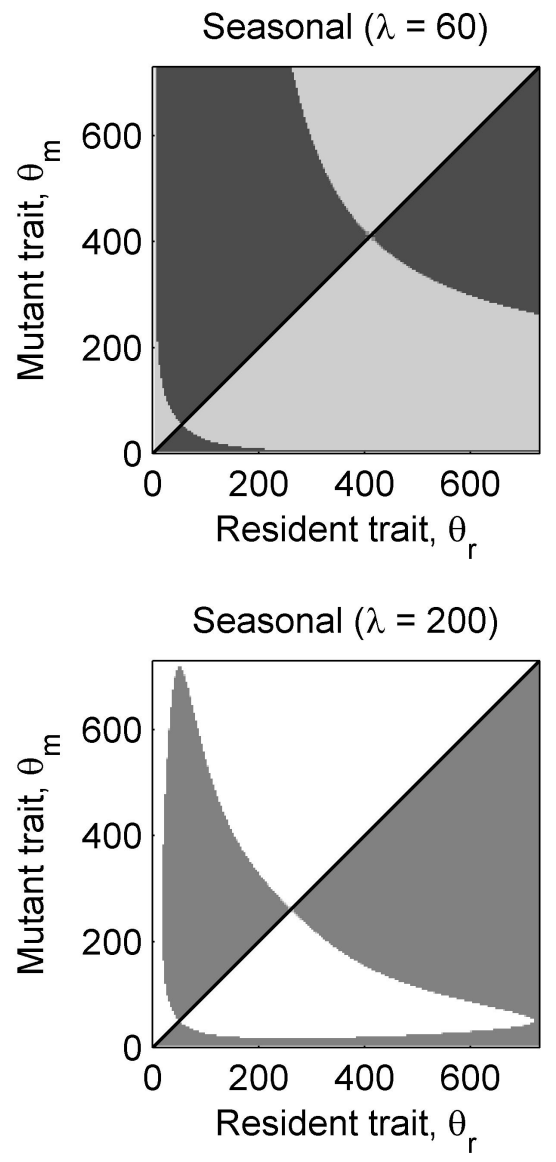

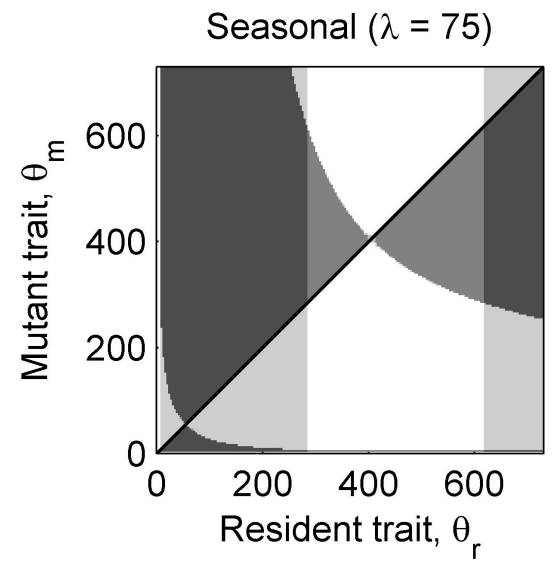

Non-seasonal $(\lambda=365)$

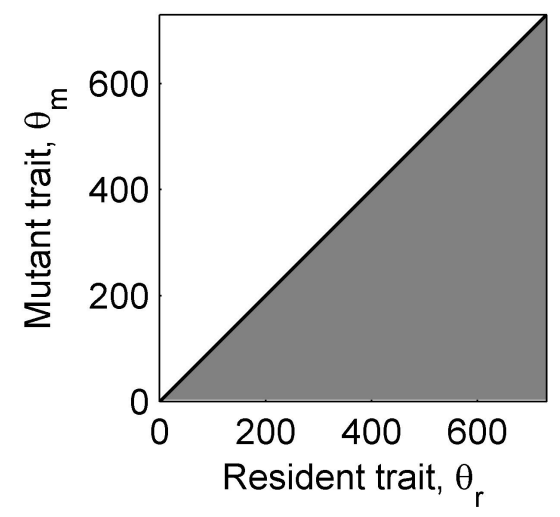

Figure 3.12: Pairwise $\boldsymbol{R}_{\mathbf{0}}$ plots with various on-season length, each is comparable with PIPs in Figure 3.9. Discrepancy of two plots observed from the case $\lambda=200$ indicates the existence of a frequency dependent selection.

with two traits $\theta=100$ and $\theta=260$. The mutant trait which lies between the two resident traits can invade either of the resident traits. Repeating this, the distance between the two traits narrows. In the lower figure, two resident traits are $\theta=20$ and $\theta=300$. A mutant trait with slightly smaller value than one of the two resident traits can invade.

Figure 3.16 distinguishes the parameter region of coexistence depending on their qualitative shape of the corresponding invasion fitness. A pair of resident traits in red region induces the qualitatively same invasion fitness graph as in the upper figure of Figure 3.15 , and a pair lies in the green region has similar invasion fitness to the graph in the lower figure. Consider a dimorphic population with a pair of resident traits in a red area. Successful mutants are those having trait values in-between two resident traits. Thus, the evolution would move the original pair either upward or leftward, while the point remains in the coexistence region. Once it leaves the coexistence region, it is observable from the PIP 3.13 that a sequence of small mutations and selections would lead to the long CSS. Similarly, a point in a green region moves either downwards or leftwards while 


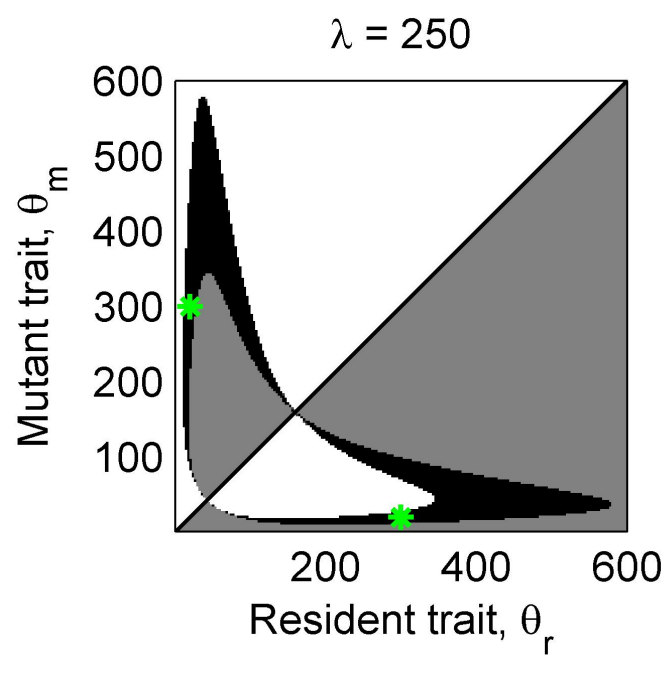

Figure 3.13: PIP with coexistence region. A pair of trait from the black region are mutually invadable and coexist. For other strains, either one of the two strains can invade the other strain but not vice versa.

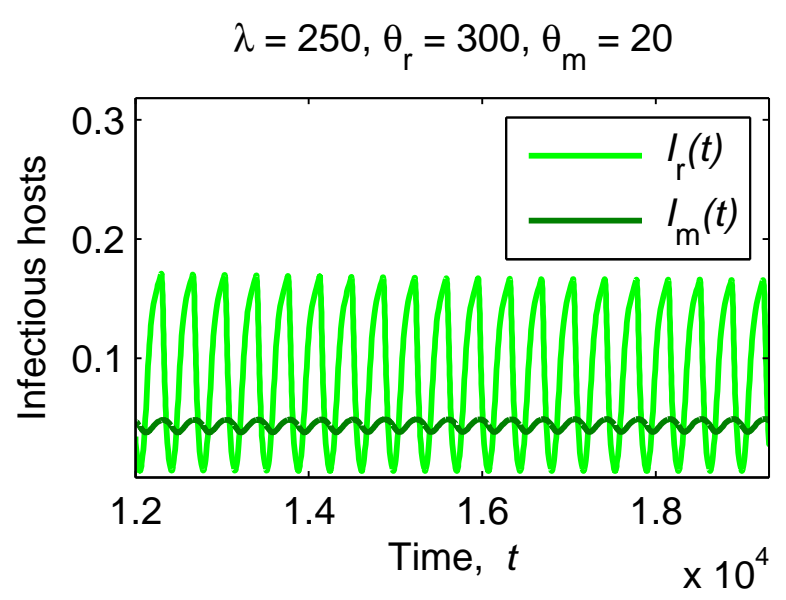

FIGURE 3.14: Infectious human dynamics of the resident-mutant system (3.13) with initial condition is $\left(S, L_{\mathrm{r}, 1}, L_{\mathrm{r}, 2}, L_{\mathrm{r}, 3}, I_{\mathrm{r}}, L_{\mathrm{m}, 1}, L_{\mathrm{m}, 2}, L_{\mathrm{m}, 3}, I_{\mathrm{m}}\right)(0)=$ $(0.95,0,0,0,0.0495,0,0,0,0.0005)$. Two different strains with each of trait value $\theta=20$ and $\theta=300$ can coexist.

it remains in the coexistence region. If it leaves the region, the evolution would choose the short CSS.

In conclusion, the observed coexistence is the converging dimorphism. Depending on the values of the coexisting traits, they will either converge to the long CSS or short CSS after long-term evolutionary process. Coexisting traits in green region would converge to long CSS, and traits in red region converge to short CSS. 

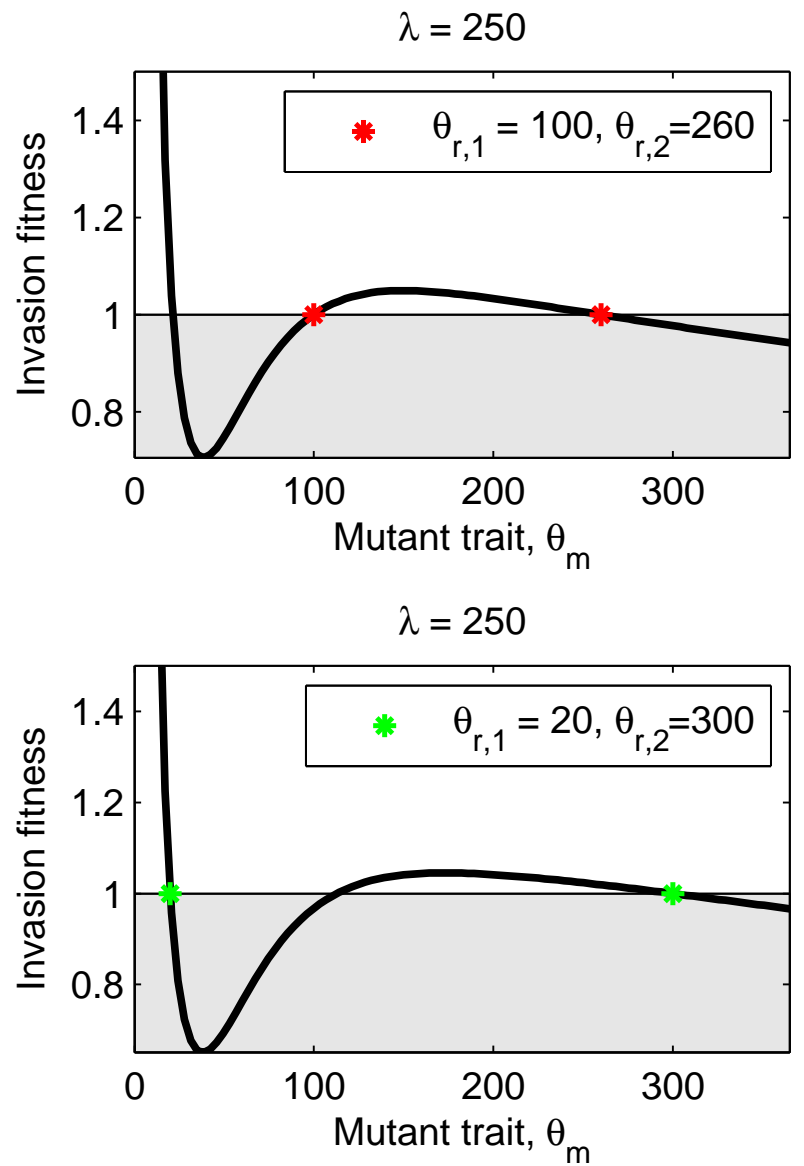

Figure 3.15: Dependence of the invasion fitness $\boldsymbol{F}\left(\boldsymbol{\theta}_{\mathrm{r}, \mathbf{1}}, \boldsymbol{\theta}_{\mathrm{r}, \mathbf{2}}, \boldsymbol{\theta}_{\mathrm{m}}\right)$ on mutant trait $\theta_{\mathrm{m}}$ when a residence population have two coexisting traits $\left(\theta_{\mathrm{r}, 1}, \theta_{\mathrm{r}, 2}\right)$. In the upper figure, mutant trait in-between the two resident traits can invade either of the resident trait. In the lower figure, mutant trait with smaller value than any of two resident traits can invade the resident trait.

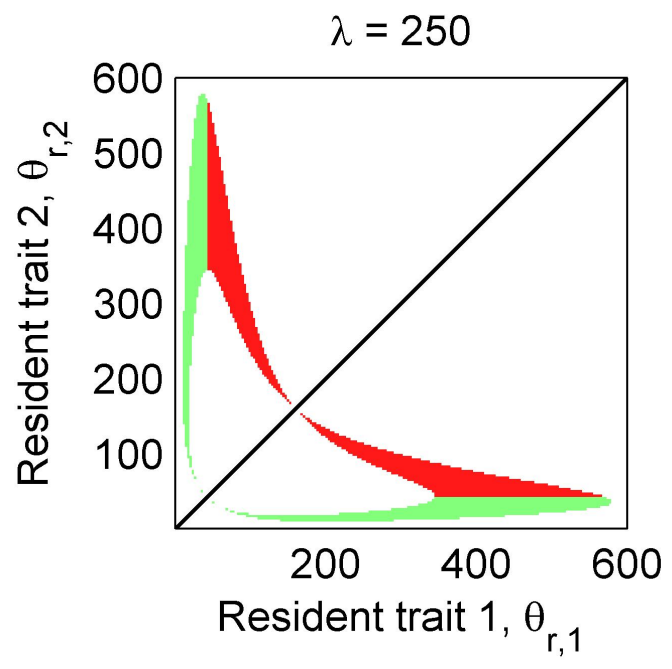

FigURE 3.16: Classification of the parameter region of coexistence depending on their qualitative shape of the corresponding invasion fitness. A pair of resident traits in red region induces the qualitatively same invasion fitness graph with the upper figure of Figure 3.15, and a pair lies on the green region has similar invasion fitness with the lower figure. Coexisting traits in green region of would converge to long CSS, while the traits in red region converge to short CSS. 


\subsection{Robustness of results}

In all previous numerical simulations, we used a square wave transmission function to incorporate seasonality. To show the robustness of the results, we present analogous results with a triangular wave transmission function defined by

$$
\beta(t)= \begin{cases}2 \beta_{*}\left(1-\frac{1}{\lambda}|2 t-(2 k P+\lambda)|\right) & \text { for } k P \leq t<k P+\lambda, \\ 0 & \text { for } k P+\lambda \leq t<(k+1) P .\end{cases}
$$

The shape of both square and triangular waves are presented in Figure 3.3. Figure 3.17 is the $R_{0}$ graph depending on the length of latent period, with the two types of transmission functions. Though there exists a quantitative difference between two results, but they are qualitatively very similar. The non-monotonicity of $R_{0}$ with respect to $\theta$ in the seasonal case is also observed with triangular wave transmission function. We observe from Figure 3.18 that PIPs corresponding to both functions have the similar shapes including the region of coexistence, and the evolutionary consequences on the region is also the same.

\subsection{Interpretation of the results}

Pathogens are expected to have been adapted to their seasonal environment in numerous ways. The prolonged incubation time of $P$. vivax malaria in temperate regions is one example. In order to investigate the role of latency in a seasonal environment, we considered the classic SLIS disease transmission model with periodic seasonal parameters. Applying a recently developed approach, we calculated $R_{0}$ numerically. In seasonal environment, $R_{0}$ depends non-monotonically on the average latent period, in sharp contrast with the non-seasonal case.

We characterize infected host individuals by the length of latency, which is the adaptive trait of the parasite that caused the infection. This way, the evolution of latency can be studied via a resident-mutant model, describing the competition between the resident and mutant populations. Using theories of adaptive dynamics, we explored the direction of the evolution depending on the length of the mosquito season, and predict the result of the long-term evolution process by subsequent invasions and substitutions. Based on Floquet theory, we developed a numerical algorithm to calculate the invasion fitness. Using the algorithm, we produced pairwise invasibility plots (PIPs) to visualize the course of trait evolution. 


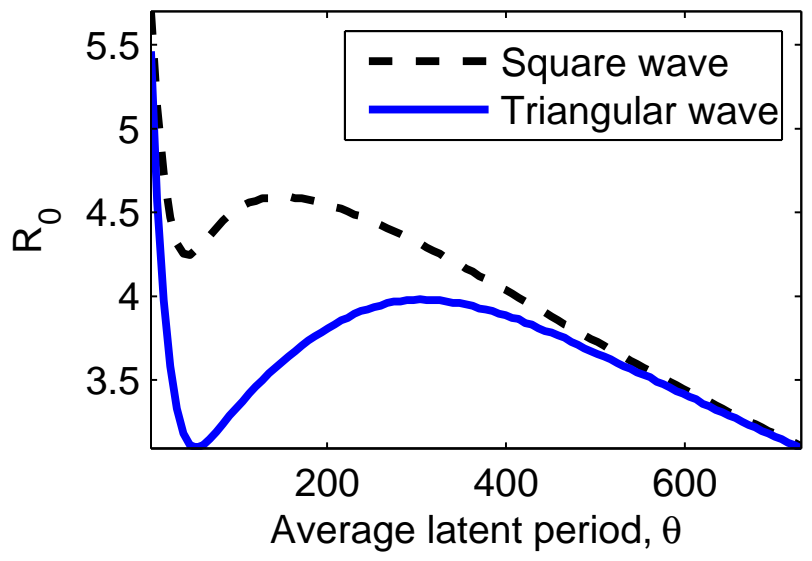

FiguRE 3.17: $R_{0}$ dependence on $\theta$ with two types of seasonal function, a square wave function and a triangular wave function. $\lambda=250$. Two graphs have similar nonmonotonicity, with quantitative difference.

$\lambda=250$

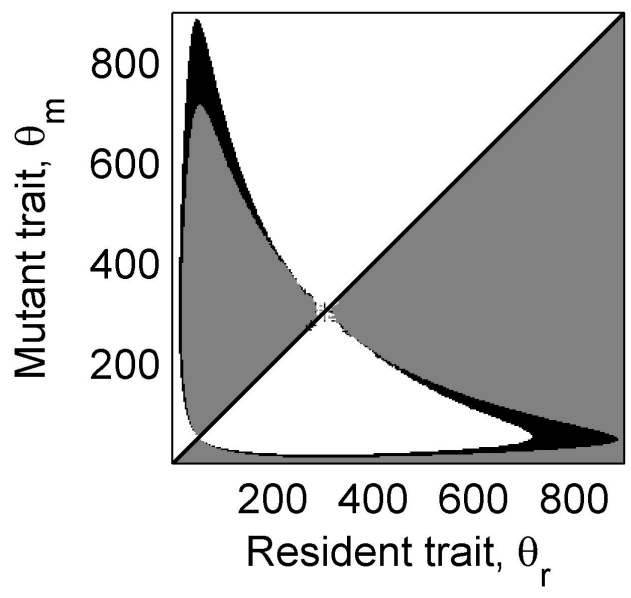

$\lambda=250$

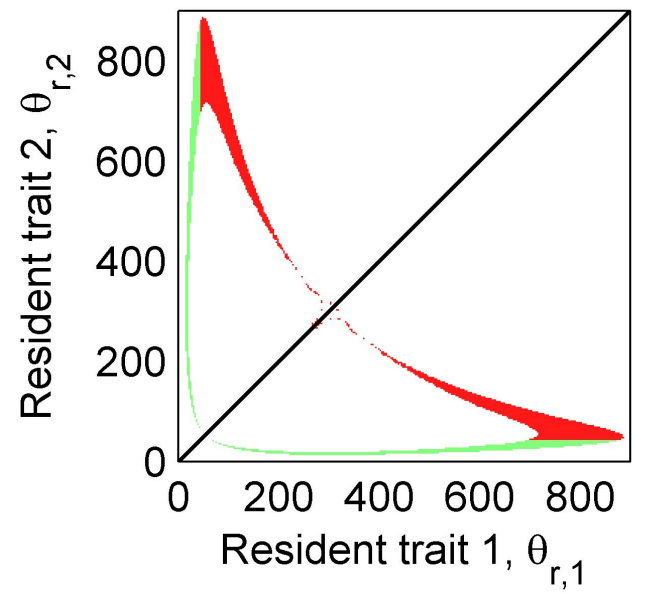

FIGURE 3.18: Our result is robust with a triangular wave type of seasonal function. $\mathbf{b}$, PIP with triangular wave seasonal function, $\lambda=250$. Region of coexistence is observed as we observe from the PIP with a square wave seasonal function (Figure 3.13a). c, Distinction of the coexistence region depending on their evolutionary fate. Coexisting traits in green and red regions converge to long and short CSS, respectively.

We could observe from PIP that the shortest latent period is always a convergence stable strategy (CSS), a local attractor of the adaptive dynamics. In seasonal environment, there can exist one more CSS with long latent period, which decreases as on-season length increases. Though we identified the two CSSs, we note that the short CSS $(\theta=0)$ would not be realized in practice, because there may be physiological difficulties for a non-zero latent period to be established.

We show that two distinctive strains of short and long latent periods can possibly coexist, matching the observations from Korea and other temperate regions. Our results explain how longer latent periods can sustain in temperate regions. However, the observed 
coexistence of short- and long-latency strains is predicted to be evolutionarily unstable, though it is epidemiologically stable. P. Vivax in Korea may persist (or appear to persist) because of the influx of two types of strains from adjacent larger geographical pools.

The knowledge of the latent period is important in disease control. Our research helps understanding the relation between seasonality and latent period. It also allows to predict the change of latent period as a consequence of climate change, for example, if climate change leads to prolonged on-season, evolution would lead the latent period to be shorter. 


\section{Chapter 4}

\section{Study of}

\section{$\dot{x}(t)=-a(t) x(t)+b(t) x(t-1)$}

\subsection{Motivation of the study}

In this chapter, we investigate the scalar periodic delay-differential equation

$$
\dot{x}(t)=-a(t) x(t)+b(t) x(t-1),
$$

where $a, b$ are assumed to be $P$-periodic continuous real functions with $a(t) \geq 0$ and $b(t) \geq 0$. Equation (4.1) has been studied as a linear variational equation of

$$
x^{\prime}(t)=g(t, x(t), x(t-1))
$$

where $g(t, 0,0)=0$ and $g(t, \xi, \eta)=g(t+P, \xi, \eta)$ for all $t, \xi, \eta \in \mathbb{R}$. Similarly, for a smooth nonlinearity $f(x, y)$, the linearization of

$$
u^{\prime}(t)=f(u(t), u(t-1))
$$

around a periodic orbit $p(t)$ is

$$
u^{\prime}(t)=f_{x}(p(t), p(t-1)) u(t)+f_{y}(p(t), p(t-1)) u(t-1),
$$

having the same form as (4.1). Such equations arise in several mathematical models; such as neural networks [10], or transmission dynamics of vector-borne diseases [9] and population growth models [35, 77] with seasonality, where the non-negativity assumptions on the coefficients $a(t)$ and $b(t)$ are biologically natural. One example is the SEIS 
model (3.3) introduced in the previous chapter, with a probability function

$$
F(s):= \begin{cases}1, & s \in[0, \theta], \\ 0, & s \in(\theta, \infty),\end{cases}
$$

which expresses that the latent period has fixed length $\theta$, and the system (3.3) can be written as

$$
\begin{aligned}
& \frac{d S(t)}{d t}=b(1-S(t))-\beta(t) S(t) I(t)+r I(t) \\
& \frac{d L(t)}{d t}=\beta(t) S(t) I(t)-\beta(t-\theta) S(t-\theta) I(t-\theta) e^{-b \theta}-b L(t) \\
& \frac{d I(t)}{d t}=\beta(t-\theta) S(t-\theta) I(t-\theta) e^{-b \theta}-r I(t)-b I(t)
\end{aligned}
$$

Linearizing (4.2) around the disease-free equilibrium $(\hat{1}, 0, \hat{0})$, we obtain a decoupled equation for $I(t)$,

$$
\frac{d I(t)}{d t}=\beta(t-\theta) I(t-\theta) e^{-b \theta}-r I(t)-b I(t)
$$

a special case of (4.1), after rescaling time.

Let $\Omega:=C([-1,0], \mathbb{R})$ be the Banach space of real valued continuous functions on $[-1,0]$ with the usual supremum norm. For any $\phi \in \Omega$, a unique solution $x(t ; \phi)$ exists for all $t \geq 0$ with

$$
x(\theta)=\phi(\theta), \quad-1 \leq \theta \leq 0 .
$$

From the non-negativity of the coefficients, it follows that the non-negative cone $\Omega_{+}:=$ $C\left([-1,0], \mathbb{R}_{+}\right)$is positively invariant, and non-negative solutions remain non-negative. We use the notation $x_{t}=x_{t}^{\phi} \in \Omega$ for the function $x_{t}(\theta)=x(t+\theta), \theta \in[-1,0]$. Let $\mathcal{U}: \mathbb{R}_{+} \times \mathbb{R} \times \Omega \rightarrow \Omega$ be the solution operator of (4.1). That is,

$$
\mathcal{U}(t, \sigma, \phi)=x_{t+\sigma}
$$

where $x_{t+\sigma}$ is the solution curve of the initial value problem

$$
\begin{aligned}
\dot{x}(t) & =-a(t) x_{t}(0)+b(t) x_{t}(-1), \quad t \geq \sigma \\
x_{\sigma} & =\phi
\end{aligned}
$$

at time $t+\sigma$. We now define the Poincaré operator $\mathcal{M}: \Omega \rightarrow \Omega$ as

$$
\mathcal{M}(\psi)=\mathcal{U}(P, 0, \psi)
$$

The stability of zero is determined by the spectral radius of $\mathcal{M}$. 
In the special case when $a(t)=a_{*}$ and $b(t)=b_{*}$ are constants, the sharp stability condition $a_{*} \geq b_{*}$ is very well known. The periodic case was addressed in [22], where it was shown that the solution $x=0$ of Equation (4.1) is uniformly asymptotically stable if $\max _{t \in[0, P]} b(t)<a(t)-\epsilon$ for some $\epsilon>0$. For $P=1$, the characteristic equation was derived in [57] using Floquet theory, and the stability threshold in this case is $\int_{0}^{1}(b(s)-a(s)) \mathrm{d} s$, see also [77]. More recently, the special case of $a(t)$ being a constant function, but $P$ is arbitrary, was considered by Chen and Wu [10]. Using a discrete Lyapunov functional and the variation of constants formula, they found that for any $b(t)>0$ there is a critical $a^{+}>0$ that is the stability threshold. Some estimates were provided for $a^{+}$, but the exact value was not determined.

In this paper, we derive the explicit threshold formula, determining the stability of zero for (4.1), using an elementary approach, which is valid for any $P$ (generalizing [77]), and for any $P$-periodic $a(t) \geq 0, b(t) \geq 0$ of which $b(t+1)-a(t)$ does not change its sign. Our theorem provides some new results compared to [22], since following example does not fit there but covered in this chapter:

$$
\begin{aligned}
a(t)=t(P-t)+1, & 0 \leq t \leq P, \\
b(t+1)=t(P-t)+1-\epsilon, & 0 \leq t+1 \leq P,
\end{aligned}
$$

where $a, b$ are extended to the real line periodically, so that they are $P$-periodic functions with $P>1$ and $\epsilon<P-1$. Moreover, our stability threshold is given explicitly, improving [10].

\subsection{Stability theorem}

Without the loss of generality, we can assume $P>1$. Define

$$
r:=\int_{0}^{P}(b(s)-a(s)) \mathrm{d} s .
$$

Theorem 4.1. For Equation (4.1), the following holds if the sign of $b(u+1)-a(u)$ does not change:

1. if $r>0$, zero is unstable;

2. if $r=0$, zero is stable, but not asymptotically stable;

3. if $r<0$, zero is asymptotically stable. 
Proof. Proof of 1: It is sufficient to show that $\lim _{t \rightarrow \infty} x(t ; \phi)=\infty$ for $\phi \in \Omega_{+}$with

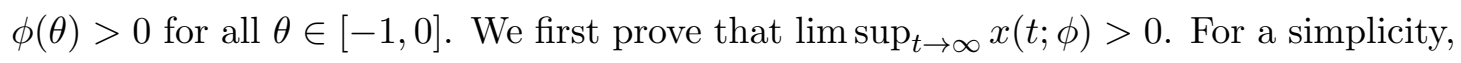
we write $x(t)$ for $x(t ; \phi)$. Suppose $\lim \sup _{t \rightarrow \infty} x(t)=0$. It implies

$$
\lim _{t \rightarrow \infty} x(t)=0
$$

by non-negativeness of $x(t)$. We define a function $V: \mathbb{R} \rightarrow \mathbb{R}$ by

$$
V(t)=\int_{t-1}^{t} b(u+1) x(u) \mathrm{d} u+x(t) .
$$

The boundedness of $b(t)$ and (4.4) imply

$$
\lim _{t \rightarrow \infty} V(t)=0
$$

One can see from (4.5) that $\dot{V}(t)=(b(t+1)-a(t)) x(t)$ and

$$
V(t)=V(0)+\int_{0}^{t}(b(u+1)-a(u)) x(u) \mathrm{d} u .
$$

For any integer $n \geq 1$,

$$
\begin{aligned}
V(n P) & =V(0)+\sum_{k=1}^{n} \int_{(k-1) P}^{k P}(b(u+1)-a(u)) x(u) \mathrm{d} u \\
& =V(0)+\sum_{k=1}^{n} x\left(u_{k}^{*}\right) \int_{(k-1) P}^{k P}(b(u+1)-a(u)) \mathrm{d} u \\
& =V(0)+\sum_{k=1}^{n} x\left(u_{k}^{*}\right) \int_{0}^{P}(b(u+1)-a(u)) \mathrm{d} u \\
& =V(0)+r \sum_{k=1}^{n} x\left(u_{k}^{*}\right)
\end{aligned}
$$

for $u_{k}^{*} \in((k-1) P, k P)$. Positiveness of $x(t)$ and $r>0$ implies $\{V(n P)\}_{n \in \mathbb{N}}$ is strictly increasing with $V(0) \geq 0$, which contradicts to (4.6). Hence, $x^{\infty}>0$.

Now we will show that $\lim _{t \rightarrow \infty} x(t)=\infty$. Non-negativity of $x(t)$ on (4.1) implies

$$
\dot{x}(t) \geq-a(t) x(t)
$$

for all $t \geq 0$. By the comparison method described in Theorem 3.6 of [65],

$$
x(t) \geq x(0) e^{-\int_{0}^{t} a(u) \mathrm{d} u} .
$$


Since $x(t)$ is continuous, it has a minimum $m_{k}$ and a maximum $M_{k}$ on each interval $[(k-1) P, k P], k=1,2, \ldots$ One can easily see that

$$
m_{k+1} \geq M_{k} e^{-\int_{(k-1) P}^{(k+1) P} a(u) \mathrm{d} u}=M_{k} e^{-2 \int_{0}^{P} a(u) \mathrm{d} u},
$$

and

$$
\limsup _{k \rightarrow \infty} m_{k} \geq \limsup _{k \rightarrow \infty} M_{k} e^{-2 \int_{0}^{P} a(u) \mathrm{d} u}=x^{\infty} e^{-2 \int_{0}^{P} a(u) \mathrm{d} u}>0 .
$$

Since $\{V(n P)\}_{n \in \mathbb{N}}$ is strictly increasing, either it converges or $\lim _{n \rightarrow \infty} V(n P)=\infty$. If it converges, by (4.9), $x\left(u_{k}^{*}\right) \rightarrow 0$ as $k \rightarrow \infty$, which contradicts to (4.11). Therefore, $\lim _{n \rightarrow \infty} V(n P)=\infty$. Applying $t=n P$ to (4.5), we have

$$
\begin{aligned}
V(n P) & =\int_{n P-1}^{n P} b(u+1) x(u) \mathrm{d} u+x(n P) \\
& =x\left(t_{n}^{*}\right) \int_{n P-1}^{n P} b(u+1) \mathrm{d} u+x(n P) \\
& \leq M_{n}\left(1+\int_{P-1}^{P} b(u+1) \mathrm{d} u\right)
\end{aligned}
$$

for $t_{n}^{*} \in[n P-1, n P] \subset[(n-1) P, n P]$. Boundedness of $b(t)$ and $\lim _{n \rightarrow \infty} V(n P)=\infty$ implies $\lim _{n \rightarrow \infty} M_{n}=\infty$. It follows from (4.10) that $\lim _{n \rightarrow \infty} m_{n}=\infty$, implying $\lim _{t \rightarrow \infty} x(t)=\infty$.

Proof of (ii): Assume that $r=0$. By the following equality

$$
0=\int_{0}^{P}(b(u)-a(u)) \mathrm{d} u=\int_{0}^{P}(b(u+1)-a(u)) \mathrm{d} u,
$$

together with the assumption that $b(u+1)-a(u)$ does not change its sign, we conclude

$$
b(u+1)-a(u)=0 \quad \text { for all } u \in R .
$$

By (4.7), we obtain

$$
V(t)=V(0) \text { for all } t
$$

If $\phi \geq 0$, by (4.5),

$$
0 \leq x(t) \leq V(t)=V(0) \leq\left(b_{\max }+1\right)\|\phi\| .
$$

If $\phi \leq 0$, by $(4.5)$,

$$
0 \geq x(t) \geq V(t)=V(0) \geq-\left(b_{\max }+1\right)\|\phi\| .
$$


Now, for any $\phi \in \Omega$, let initial functions $\xi \geq 0$ and $\psi \leq 0$ s.t. $\psi<\phi<\xi$. By comparison method,

$$
-\left(b_{\max }+1\right)\|\phi\| \leq x(t ; \psi) \leq x(t ; \phi) \leq x(t ; \xi) \leq\left(b_{\max }+1\right)\|\phi\| .
$$

Therefore, the zero is stable. One can easily see that zero is not asymptotically stable by (4.12) and (4.5).

Proof of 3: It is sufficient to prove that $\lim _{t \rightarrow \infty} x(t ; \phi)=0$ for any $\phi \in \Omega$. We first prove it when $\phi \geq 0$, and we show that it also holds for $\phi \leq 0$. Finally we prove it for general $\phi$.

If $\phi \geq 0$, since $r<0$, one can see from (4.9) that $\{V(n P)\}_{n \in \mathbb{N}}$ is decreasing with lower bound 0 . Therefore, $\{V(n p)\}$ is converging, implying $x\left(u_{k}^{*}\right) \rightarrow 0$ as $k \rightarrow \infty$. In a meanwhile,

$$
x\left(u_{k+1}^{*}\right) \geq m_{k+1} \geq M_{k} e^{-2 \int_{0}^{P} a(u) \mathrm{d} u},
$$

which implies $M_{k} \rightarrow 0$ as $k \rightarrow \infty$. Hence, $x(t) \rightarrow 0$ as $t \rightarrow \infty$.

Consider the case with non-positive $\phi$. One can see from (4.1) that $x(t ;-\phi)=-x(t ; \phi)$ and

$$
\lim _{t \rightarrow \infty} x(t ; \phi)=-\lim _{t \rightarrow \infty}(-x(t ; \phi))=-\lim _{t \rightarrow \infty} x(t ;-\phi)=0 .
$$

Now, for any $\phi \in \Omega$, let initial functions $\xi \geq 0$ and $\psi \leq 0$ s.t. $\psi<\phi<\xi$. By comparison method,

$$
x(t ; \psi) \leq x(t ; \phi) \leq x(t ; \xi) .
$$

We know that $\lim _{t \rightarrow \infty} x(t ; \xi)=0=\lim _{t \rightarrow \infty} x(t ; \psi)$. Therefore, $\lim _{t \rightarrow \infty} x(t ; \phi)=0$.

\subsection{Case of $r$ not being a stability threshold}

In this section, we present the particular example showing that the assumption in Theorem 4.1 is critical.

Consider a special case $a(t)=\alpha$ and $b(t)$ continuous function such that

$$
\begin{cases}b(t)=0 & \text { if } k P \leq t \leq k P+L, \quad k=0,1,2, \ldots \\ b(t)>0 & \text { elsewhere }\end{cases}
$$

where $1 \leq L<P<L+1$. 
Lemma 4.2. Let

$$
\mathcal{A}:=\left\{\psi \in \Omega \mid \psi(\theta)=\left\{\begin{array}{ll}
\psi(-1) e^{-\alpha(1+\theta)} & \text { if } \theta \in[-1, L-P] \\
\psi(-1) e^{-\alpha(1+\theta)}\left(e^{\alpha} \int_{L-P}^{\theta} b(s) \mathrm{d} s+1\right) & \text { if } \theta \in(L-P, 0] .
\end{array}\right\} .\right.
$$

Then, $\mathcal{M}(\Omega) \subset \mathcal{A}$. Consequently, $\mathcal{A}$ is forward invariant under $\mathcal{M}$.

Proof. Let $\psi \in \Omega$. Then $\mathcal{M}(\psi)=\mathcal{U}(P, 0, \psi)=x_{P}$ where $x_{P}$ is the solution of

$$
\begin{aligned}
\dot{x}(t) & =-\alpha x_{t}(0)+b(t) x_{t}(-1), \quad t \geq 0 \\
x_{0} & =\psi
\end{aligned}
$$

For $P-1 \leq t<L, x^{\prime}(t)=-\alpha x(t)$ and

$$
x(t)=x(P-1) e^{-\alpha(t-(P-1))}
$$

Therefore, for $-1 \leq \theta<L-P$,

$$
x_{P}(\theta)=x_{P}(-1) e^{-\alpha(\theta+1)} .
$$

For $L \leq t<P, 0 \leq t-1<L$ and we have

$$
x(t-1)=x(P-1) e^{-\alpha(t-P)} .
$$

Therefore,

$$
x^{\prime}(t)=-\alpha x(t)+b(t) x(P-1) e^{-\alpha(t-P)},
$$

and the solution is

$$
x(t)=x(P-1) e^{-\alpha(t+1-P)}\left(e^{\alpha} \int_{L}^{t} b(s) \mathrm{d} s+1\right) .
$$

Therefore, for $L-P \leq \theta<0$,

$$
x_{P}(\theta)=x_{P}(-1) e^{-\alpha(1+\theta)}\left(e^{\alpha} \int_{L-P}^{\theta} b(s) \mathrm{d} s+1\right) .
$$

Theorem 4.3. Let

$$
\gamma:=-\alpha+\frac{1}{P} \ln \left(e^{\alpha} \int_{L-P}^{0} b(s) \mathrm{d} s+1\right) .
$$

The solution $x=0$ of the equation (4.13) is stable if and only if $\gamma \leq 0$. 
Proof. From the calculations of the proof of Lemma (4.2), we find that for any $\phi \in \mathcal{M}$,

$$
x(P ; \phi)=x(0 ; \phi) e^{\gamma}=\phi(0) e^{\gamma} .
$$

Inductively, for any $n$, we have

$$
x(n P ; \phi)=\phi(0) e^{\gamma n}
$$

If there exists a $K>0$ such that, for any solution, $x_{n P}(\theta) \leq K x_{(n-1) P}(0)$ for all $\theta \in[-1,0]$, the stability result follows and $\gamma<0$ gives asymptotic stability. For

$$
(n-1) P \leq t<n P-1<(n-1) P+L,
$$

$x^{\prime}(t)=-\alpha x(t)$ and

$$
x(n P-1)=x((n-1) P) e^{-\alpha(P-1)}
$$

By (4.14), for $L-P \leq \theta<0$,

$$
\begin{aligned}
x_{n P}(\theta) & =x_{n P}(-1) e^{-\alpha(1+\theta)}\left(e^{\alpha} \int_{L-P}^{\theta} b(s) \mathrm{d} s+1\right) \\
& =x_{(n-1) P}(0) e^{-\alpha(P-1)} e^{-\alpha(1+\theta)}\left(e^{\alpha} \int_{L-P}^{\theta} b(s) \mathrm{d} s+1\right) \\
& \leq x_{(n-1) P}(0) e^{-\alpha(P-1)} e^{-\alpha(1+L-P)}\left(e^{\alpha} \int_{L-P}^{0} b(s) \mathrm{d} s+1\right) \\
& =x_{(n-1) P}(0) e^{-\alpha L}\left(e^{\alpha} \int_{L-P}^{0} b(s) \mathrm{d} s+1\right)
\end{aligned}
$$

so we can choose $K=e^{-\alpha L}\left(e^{\alpha} \int_{L-P}^{0} b(s) \mathrm{d} s+1\right)$.

We now address an example where the sign of $r$ does not always coincide with the sign of $\gamma$. Consider the special case of (4.13),

$$
b(t)=\left\{\begin{array}{l}
0 \text { if } k P \leq t \leq k P+L \\
\frac{4 \beta}{P-L}\left(-\left|t-\frac{P+L}{2}\right|+\frac{P-L}{2}\right) \quad \text { if } \quad k P+L \leq t \leq(k+1) P,
\end{array}\right.
$$

where $k=0,1,2, \ldots$ In this case,

$$
\gamma=-\alpha+\frac{1}{P} \ln \left(e^{\alpha} \beta(P-L)+1\right)
$$

and

$$
r=\beta(P-L)-\alpha P .
$$


There would be four possible cases: (i) $r>0, \gamma>0$ (Unstable) (ii) $r<0, \gamma>0$ (Unstable), (iii) $r>0, \gamma<0$ (Unstable) and (iv) $r<0, \gamma<0$ (Stable). Figure 4.1 shows the parameter sets of each cases. The area with $\gamma<0$ but $r>0$, and the area with $\gamma>0$ but $r<0$ are the regions where $r$ in (4.3) does not work as a stability threshold.

\subsection{Implication of the results}

Proving stability, we restricted initial function $\phi_{[\sigma-1, \sigma]}$ with $\sigma=0$. We can easily generalize the result for $\sigma \in \mathbb{R}$ by considering a shift in periodic coefficients $\tilde{a}(t):=$ $a(t-\sigma)$ and $\tilde{b}(t):=b(t-\sigma)$.

In a biological context, $r$ can be interpreted as an averaged Malthusian parameter, and $R_{0}=\frac{\int_{0}^{P} b(s) \mathrm{d} s}{\int_{0}^{P} a(s) \mathrm{d} s}$ can be interpreted as an averaged reproduction number, and then $R_{0}>1$ is equivalent to $r>0$. 


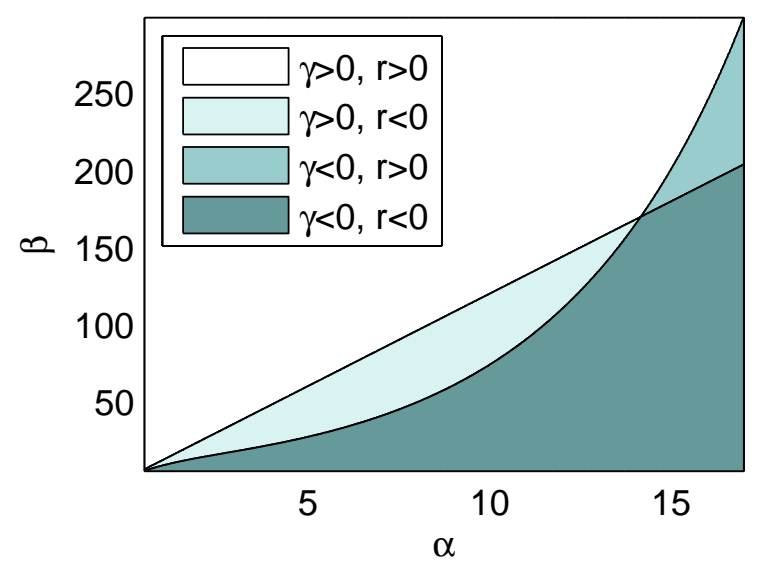

Figure 4.1: Special case of (4.13) with function $\boldsymbol{b}(\boldsymbol{t})$ as in (4.15) with $\boldsymbol{P}=\mathbf{1 . 2}$ and $\boldsymbol{L}=1.1$. Distinctive $\alpha-\beta$ parameter regions are determined by the signs of $\gamma$ and $r$.

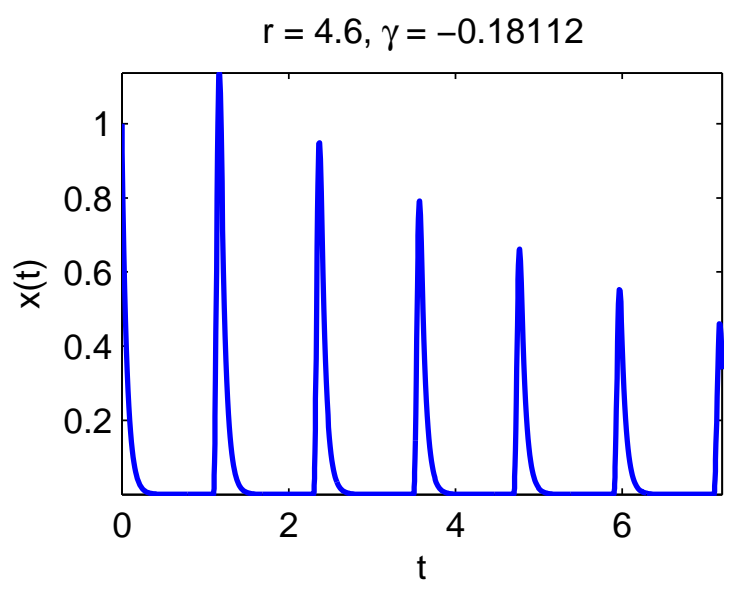

Figure 4.2: Solution with parameters $\alpha=\mathbf{1 7}$ and $\beta=\mathbf{2 5 0}$, which implies $\boldsymbol{r}>\mathbf{0}$ but $\gamma<\mathbf{0}$. Zero solution is stable. Initial function is given by $\phi(\theta)=1$ for all $\theta \in[-1,0]$.

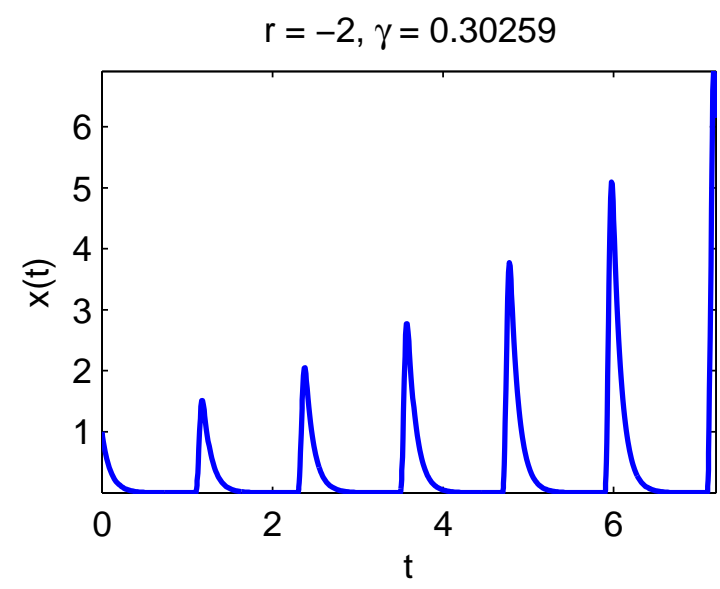

FigURE 4.3: Solution with parameters $\alpha=10$ and $\beta=100$, which implies $\boldsymbol{r}<\mathbf{0}$ but $\gamma>\mathbf{0}$. Zero solution is unstable. Initial function is given by $\phi(\theta)=1$ for all $\theta \in[-1,0]$. 


\section{Chapter 5}

\section{Summary}

The incubation period of malaria can vary depending on the species of parasite or the geographic regions. In particular, in endemic areas of temperate climate (for example in Korea), the incubation period of Plasmodium vivax shows bimodal distribution of short and long-term incubation periods. Assuming fixed length for the long-term incubation period gives a distribution that is much closer to the empirical distribution, than the exponentially distributed long-term incubation period. In Chapter 2, we compare two transmission models for $P$. vivax, where we model the long-term incubation period using ordinary differential equations (ODE) (2.2) or delay differential equations (DDE) (2.39). From the mathematical analysis of the two models in non-seasonal environment, we have the following results:

- The basic reproduction number of the ODE model is derived based on the epidemiological interpretation (2.4). We showed that the basic reproduction number works as a threshold for the existence and stability of equilibria (Lem. 2.1, Thm. 2.2).

- We identified the feasible domain of the DDE model in the infinite dimensional phase space, and showed that it is forward invariant (Prop. 2.6).

- The basic reproduction number of the DDE model is defined (2.22). We showed that the basic reproduction number works as a threshold for the existence and stability of equilibria (Prop. 2.7, Thm. 2.8).

- It is further shown that the basic reproduction number of DDE model, $R_{d}$, is a threshold parameter for the global dynamics. If $R_{d} \leq 1$, the disease goes extinct, while the disease uniformly persists in the human and mosquito populations when $R_{d}>1$ (Thm. 2.9, Cor. 2.18). In the special case of lifelong immunity, we proved the global stability of endemic equilibrium when $R_{d}>1$, by constructing a nontrivial Lyapunov functional (Thm. 2.19). 
- While the qualitative behaviors of the two models are similar, the ODE model overestimates the basic reproduction number and also the level of endemicity, compared to the DDE model (Prop. 2.5, Fig. 2.4, Fig. 2.5).

- Observing the expression of the basic reproduction numbers of the ODE and the DDE models, we conclude that long incubation time is not beneficial to the parasite in a constant environment, thus its presence is connected to the seasonal mosquito activity in Korea.

We compare two P. vivax transmission models in a periodic environment, (2.67) and (2.68), with seasonal variation of mosquito population and biting rate. We observe the followings by numerical studies:

- The periodic DDE model showed lager oscillations and predicts higher peaks and lower yearly bottoms of malaria prevalence (Fig. 2.10, Fig. 2.11, Fig. 2.12).

- In contrast to the autonomous case, when we incorporate seasonality, the interplay of the time delay and the periodicity results that in some situations the DDE model predicts higher prevalence of malaria (Fig. 2.11, Fig. 2.12).

Pathogens are expected to have been adapted to their seasonal environment in numerous ways. The prolonged incubation time of $P$. vivax malaria in temperate region is considered to be an adaptation strategy to the seasonal environment as well. Assuming that pathogens are capable of mutations that modifying a latency in the infected host, in Chapter 3, we consider the length of the latent period as a single trait expressed by a single parameter, and study its evolution in a seasonal environment. Using theories of adaptive dynamics, we explore the direction of the evolution depending on the length of the mosquito season, and predict the result of the long-term evolution process by subsequent invasions and substitutions. This is the first theoretical work for predicting the evolution of latent periods of parasites in hosts in seasonal environment, and it is expected to provide a important step toward understanding the documented bimodality in $P$. vivax incubation time.

In order to investigate the role of latency in a seasonal environment, we first consider the classic SEIS disease transmission model with periodic seasonal parameters. To express various distributions of latency, we incorporate multiple latent compartments (3.10). The main results are the following:

- Latency has a significant impact on the disease dynamics. The infectious host dynamics in seasonal environment shows sharp peaks for short latency, extinction for intermediate latency, and moderate oscillation for long latency (Fig. 3.5). 
- Applying a recently developed approach, we calculate $R_{0}$ numerically. A key finding is that in seasonal environment, $R_{0}$ depends non-monotonically on the average latent period, in sharp contrast with the non-seasonal case (Fig. 3.6).

We characterize infected host individuals by the length of latency, which is the adaptive trait of the parasite that caused the infection. This way, the evolution of latency can be studied via a resident-mutant model, describing the competition between the resident and mutant populations (3.13). We investigate which mutant population has the potential to spread and later replace the resident population. When the mutation is a rare event, we may assume that the resident population is already settled at an equilibrium or a periodic attractor. To calculate the invasion fitness, we linearize the entire system (3.13) around the periodic attractor of the resident strain, and compute the stability threshold of the decoupled periodic system of invaders (3.14).

- Based on Floquet theory, we developed a numerical algorithm to calculate the invasion fitness.

- Using the algorithm, we produced pairwise invasibility plots (PIPs) to visualize the course of trait evolution.

- From each PIP having various season lengths, we identify at most two evolutionarily stable and convergence strategies (CSSs), the short CSS and the long CSS. In non-seasonal environment, there exists only a short CSS, while there exist two CSSs in seasonal environment (Fig. 3.9).

- As the season length decreases, the magnitude of long CSS increases (Fig. 3.10, Fig. 3.11). The biological interpretation of this is that short season length leads to longer latency.

- We found that two different traits could coexist in seasonal environment, similar to what we observed from Korea (Fig. 3.14). On PIP we identified the region of coexistence, the set of trait piars which could coexist (Fig. 3.13).

We investigate the long-term evolutionary result of the coexistence, by studying an invasion fitness of mutants when the resident population is settled with two different traits.

- The coexistence of short and long latency strains is predicted to be evolutionary unstable, though it is epidemiologically stable (Fig. 3.16). 
A related mathematical problem we study is a linear scalar delay differential equation with a single delay and positive periodic coefficients:

$$
\dot{x}(t)=-a(t) x(t)+b(t) x(t-1),
$$

where $a, b$ are assumed to be $P$-periodic continuous real functions with $a(t) \geq 0$ and $b(t) \geq 0$. It has been studied in many papers, however, still there is no complete answer to the stability of the zero solution. It is known that if the delay is an integer multiple of the period, the stability threshold is $r=0$, where

$$
r:=\int_{0}^{P}(b(s)-a(s)) \mathrm{d} s .
$$

In section 4, we generalize this principle to situations when the delay and the period are not related. We also construct an example showing that $r$ does not work as a stability threshold in general.

- We proved that $r$ is the stability threshold if $b(u+1)-a(u)$ does not change its sign (Thm. 4.1).

- We constructed a class of equations of which $r$ fails to be a stability threshold without the condition $b(u+1)-a(u)$ keeping its sign (Thm. 4.3, Fig. 4.2, Fig. 4.3).

The dissertation is based on the following publications of the author:

- K. Nah, G. Röst and Y. Kim. Modelling malaria dynamics in temperate regions with long term incubation period. BIOMAT 2013 - Proc. International Symposium on Mathematical and Computational Biology, 263-285, 2014.

- K. Nah, Y. Nakata and G. Röst. Malaria dynamics with long incubation period in hosts. Computers and Mathematics with Applications, 68(9):915-930, 2014

- K. Nah and G. Röst, Stability threshold for scalar linear periodic delay differential equations (Submitted)

- K. Nah, Å. Brännström, U. Dieckmann, R. Mazzucco and G. Röst. Pathogen adaptation to seasonal forcing and climate change by varying latent periods (manuscript) 


\section{Chapter 6}

\section{Összefoglalás}

A malária lappangási ideje parazitafajonként, illetve földrajzi régiónként különböző lehet. A mérsékelt égövi endemikus régiókban (pl. Koreában) a Plasmodium vivax lappangási ideje bimodális eloszlást követ hosszú és rövid távú lappangási idővel. Ha a hosszú lappangási idő tartamát állandónak feltételezzük, akkor olyan összesített eloszlást kapunk, amely sokkal jobban approximálja az empirikus eloszlást, mint ha exponenciális eloszlást feltételeznénk a hosszú távú lappangási időre. A 2. fejezetben a Plasmodium vivax terjedésének két modelljét hasonlítjuk össze, amelyekben a hosszú lappangási időszakot közönséges (2.2), illetve késleltetett differenciálegyenletekkel (2.39) írjuk le. A két modell vizsgálata alapján a következő eredményeket kapjuk állandó környezetben.

- A közönséges differenciálegyenletes modellben a reprodukciós számot a modell járványtani interpretációja alapján (2.4) vezettük le. Megmutattuk, hogy a reprodukciós szám küszöbszám az egyensúlyi helyzetek létezésére és stabilitására vonatkozóan (2.1. Lemma, 2.2. Tétel).

- Meghatároztunk egy alkalmas tartományt a funkcionál-differenciálegyenletes modell végtelen dimenziós fázisterében, ami tartalmazza a biológiailag értelmes megoldásokat, és megmutattuk róla, hogy pozitív invariáns (2.6. Állítás).

- Megadtuk a funkcionál-differenciálegyenletes modell reprodukciós számát (2.22). Megmutattuk, hogy a reprodukciós szám küszöbszám az egyensúlyi helyzetek létezésére és stabilitására vonatkozóan (2.7. Állítás, 2.8. Tétel).

- Megmutattuk, hogy a funkcionál-differenciálegyenletes modell reprodukciós száma, $R_{d}$, küszöbparaméter a globális dinamikára vonatkozóan. Ha $R_{d} \leq 1$, a betegség kihal, míg erősen egyenletesen perzisztens mind az emberi, mind a szúnyogpopulációban, amikor $R_{d}>1$ (2.9. Tétel, 2.18. Következmény). Abban a speciális esetben, ha a betegségből való felgyógyulás életre szóló védettséget ad, egy nemtriviális 
Ljapunov-függvény segítségével beláttuk az endemikus egyensúlyi helyzet globális stabilitását $R_{d}>1$ esetén (2.19. Tétel).

- Míg a két modell kvalitatív viselkedése hasonló, a közönséges differenciálegyenletes modell a funkcionál-differenciálegyenletes modellel összevetve túlbecsüli a reprodukciós számot és az endemicitás mértékét is (2.5. Állítás, 2.4. ábra, 2.5. ábra).

- A reprodukciós számra a közönséges, illetve a funkcionál-differenciálegyenletes modell esetén adott formulákat összevetve megállapítottuk, hogy az állandó környezetben élő paraziták számára a hosszú lappangási idő nem kedvező, így a Koreában megfigyelt hosszú lappangás a szúnyogok szezonális aktivitásához köthető.

Összehasonlítunk két modellt ((2.67) és (2.68)), amelyek a $P$. vivax terjedését írják le periodikusan változó környezetben, a szúnyogpopuláció és a csípések számának szezonális változása mellett. Numerikus vizsgálatok segítségével a következő megfigyeléseket tettük.

- A periodikus funkcionál-differenciálegyenletes modell nagyobb oszcillációt mutatott, a malária prevalenciájának nagyobb maximumát és alacsonyabb éves minimumát mutatta (2.10. ábra, 2.11. ábra, 2.12. ábra).

- Az autonóm esettel ellentétben, ha a szezonalitást is figyelembe vesszük, a késleltetés és a periodicitás kölcsönös hatása azt eredményezi, hogy bizonyos esetekben a funkcionál-differenciálegyenletes modell a malária magasabb prevalenciáját jelzi (2.11. ábra, 2.12. ábra).

A patogének többféle módon alkalmazkodtak a szezonálisan változó környezethez. A $P$. vivax maláriának a mérsékelt égövben megfigyelhető megnövekedett lappangási idejét a szezonális környezethez való alkalmazkodási stratégiának is tekinthetjük. Feltéve, hogy a patogének képesek olyan mutációkra, amelyek megváltoztatják a lappangási időt a fertőzött gazdaszervezetben, a 3. fejezetben a lappangási idő hosszát egy egy paraméter által meghatározott tulajdonságnak tekintjük, és e tulajdonság evolúcióját vizsgáljuk szezonálisan változó környezetben. Az adaptív dinamika elméletét használva meghatározzuk az evolúció irányát a moszkitószezon hosszának függvényében, és előrejelzéseket teszünk a hosszú távú evolúciós folyamatokra. Ez az első olyan elméleti munka, amely a paraziták lappangási idejének evolúcióját vizsgálja, és reményeink szerint fontos lépést jelent a $P$. vivax megfigyelt bimodális lappangási idejének megértésében.

A lappangási idő szezonálisan változó környezetben betöltött szerepének tanulmányozására először egy klasszikus SEIS betegségterjedési modellt tekintünk periodikus szezonális együtthatókkal. A lappangási idő különböző eloszlásainak flexibilis leírására 
modellünkben több, láncszerủen összekapcsolt látens osztályt tekintünk (3.10). Fő eredményeink a következők.

- A lappangási időszak jelentős hatással van a betegség dinamikájára. Bizonyos paramétertartományban a fertőző kompartment dinamikája a szezonálisan változó környezetben rövid lappangási idő esetén éles csúcsokat mutat, közepesen hosszú lappangási idő esetén kihalást, hosszú lappangási idő esetén pedig mérsékelt oszcillációt (3.5. ábra).

- Egy nemrég kidolgozott módszer segítségével numerikusan meghatároztuk az $R_{0}$ értékét a periodikus rendszerben. Fő eredményünk, hogy szezonálisan változó környezetben $R_{0}$ nemmonoton módon függ a lappangási időszak átlagos hosszától, ami éles ellentétben áll a nemszezonális esettel (3.6. ábra).

A lappangási idő evolúcióját egy rezidens-mutáns modell (3.13) segítségével vizsgáljuk, amely a rezidens és a mutáns populáció közti versengést írja le, azzal a feltevéssel, hogy a fertőzött gazdaegyedeket a fertőzés lappangási idejének hossza karakterizálja adaptív tulajdonságukként. Megvizsgáljuk, hogy melyik mutáns populáció képes elterjedni, majd később a rezidens populáció helyére lépni. Ha a mutáció ritka esemény, feltehetjük, hogy a rezidens populáció már egyensúlyi helyzetbe vagy periodikus attraktorba állt be. Az inváziós fitnesz kiszámításához a teljes (3.13) rendszert linearizáljuk a rezidens törzs periodikus attraktora körül, és kiszámítjuk az invazív populációra vonatkozó periodikus rendszer (3.14) stabilitási küszöbszámát.

- A Floquet-elméletet felhasználva kidolgoztunk egy numerikus algoritmust az inváziós fitnesz kiszámítására.

- Az algoritmust alkalmazva páronkénti inváziós diagramot (pairwise invasibility plot, PIP) készítettünk a tulajdonság evolúciójának vizualizálására, ami az összes rezidens-mutáns páros viselkedését kirajzolja.

- A különböző szezonhosszúságokkal számított PIP-k alapján minden esetben legfeljebb két konvergenciastabil stratégiát (CSS) találtunk, a rövid CSS-t és a hosszú CSS-t. Nemszezonális környezetben csak egy, rövid CSS van, míg szezonális környezetben két CSS létezik (3.9. ábra).

- A szezon hosszának csökkenésével a hosszú CSS-hez tartozó lappangási periódus hossza növekszik (3.10. ábra, 3.11. ábra). Ennek az a biológiai jelentése, hogy rövidebb szezon hosszabb látens periódushoz vezet.

- Azt tapasztaltuk, hogy szezonális környezetben két különböző tulajdonság is együttélhet, hasonlóan ahhoz, ahogy azt Koreában megfigyelték (3.14. ábra). A PIP-n 
meghatároztuk a koegzisztencia paramétertartományát, vagyis azoknak a tulajdonságpároknak a halmazát, amelyekre az együttélés lehetséges (3.13. ábra).

- Számításaink a rövid és hosszú távú lappangási idő együttes létezését evolúciósan instabilnak, de epidemiológiailag stabilnak mutatják. (3.16. ábra).

Mint a fentiekhez kapcsolódó matematikai problémát, a következő lineáris skaláris késleltetett differenciálegyenletet vizsgáltuk egy diszkrét késleltetéssel és pozitív, periodikus együtthatókkal:

$$
\dot{x}(t)=-a(t) x(t)+b(t) x(t-1),
$$

ahol $a, b P$-periodikus valós függvények, és $a(t) \geq 0, b(t) \geq 0$. Ezt az egyenletet már számos cikkben vizsgálták, azonban még mindig nem született teljes válasz a nulla egyensúlyi helyzet stabilitását illetően. Ismert, hogy ha a késleltetés a periódus egész számú többszöröse, akkor a stabilitási küszöbszám $r=0$, ahol

$$
r:=\int_{0}^{P}(b(s)-a(s)) \mathrm{d} s .
$$

A 4. fejezetben ezt az elvet általánosítjuk olyan esetekre, amikor a késleltetés és a periódus között nem áll fenn a fenti kapcsolat. Konstruálunk egy példát is, amely megmutatja, hogy $r$ általában nem müködik stabilitási küszöbszámként.

- Beláttuk, hogy $r$ stabilitási küszöbszám, ha $b(u+1)-a(u)$ jeltartó (4.1. Tétel).

- Definiáltunk egy egyenletosztályt, amelyre $r$ nem müködik stabilitási küszöbparaméterként a $b(u+1)-a(u)$ kifejezés jeltartóságára vonatkozó feltevés nélkül (4.3. Tétel, 4.2. ábra, 4.3. ábra).

A disszertáció a szerző következő publikációin alapul:

- K. Nah, G. Röst és Y. Kim. Modelling malaria dynamics in temperate regions with long term incubation period. BIOMAT 2013 - Proc. International Symposium on Mathematical and Computational Biology, 263-285, 2014.

- K. Nah, Y. Nakata és G. Röst. Malaria dynamics with long incubation period in hosts. Computers and Mathematics with Applications, 68(9):915-930, 2014.

- K. Nah és G. Röst, Stability threshold for scalar linear periodic delay differential equations (benyújtva).

- K. Nah, R. Mazzucco, G. Röst, U. Dieckmann, és Å. Brännström. Seasonalitydriven evolution of incubation periods of infectious diseases (kézirat). 


\section{Bibliography}

[1] R. Águas, M. U. Ferreira, and M. G. M. Gomes. Modeling the effects of relapse in the transmission dynamics of malaria parasites. Journal of parasitology research, 2012, 2011.

[2] S. Altizer, A. Dobson, P. Hosseini, P. Hudson, M. Pascual, and P. Rohani. Seasonality and the dynamics of infectious diseases. Ecology letters, 9(4):467-484, 2006.

[3] R. Anderson and R. May. Infectious diseases of humans. Oxford, UK, 1992.

[4] N. Bacaër. A short history of mathematical population dynamics. Springer Science \& Business Media, 2011.

[5] N. Bacaër and S. Guernaoui. The epidemic threshold of vector-borne diseases with seasonality. Journal of mathematical biology, 53(3):421-436, 2006.

[6] K. E. Battle, M. S. Karhunen, S. Bhatt, P. W. Gething, R. E. Howes, N. Golding, T. P. Van Boeckel, J. P. Messina, G. D. Shanks, D. L. Smith, J. K. Baird, and S. I. Hay. Geographical variation in plasmodium vivax relapse. Malar J, 13(144), 2014.

[7] D. J. Bradley. Malaria: old infections, changing epidemiology. Health Transition Review, pages 137-153, 1992.

[8] F. Brauer. Mathematical epidemiology is not an oxymoron. BMC Public Health, 9 (Suppl 1):S2, 2009.

[9] S. Busenberg and K. L. Cooke. Periodic solutions of a periodic nonlinear delay differential equation. SIAM Journal on Applied Mathematics, 35(4):704-721, 1978.

[10] Y. Chen and J. Wu. Threshold dynamics of scalar linear periodic delay-differential equations. In Infinite Dimensional Dynamical Systems, pages 269-278. Springer, 2013.

[11] N. Chitnis, J. M. Cushing, and J. M. Hyman. Bifurcation analysis of a mathematical model for malaria transmission. SIAM Journal on Applied Mathematics, 67(1):2445, 2006. 
[12] G. R. Coatney, W. E. Collins, M. W. Warren, and P. G. Contacos. The primate malarias. US DREW, National Institute of Allergy and Infectious Diseases, Bethesda, 2003.

[13] F. Dercole and S. Rinaldi. Analysis of Evolutionary Processes: The Adaptive Dynamics Approach and Its Applications: The Adaptive Dynamics Approach and Its Applications. Princeton University Press, 2008.

[14] U. Dieckmann, J. A. J. Metz, M. W. Sabelis, and K. Sigmund. Adaptive dynamics of infectious diseases: in pursuit of virulence management, volume 2. Cambridge University Press, 2005.

[15] O. Diekmann, J. A. P. Heesterbeek, and M. G. Roberts. The construction of nextgeneration matrices for compartmental epidemic models. Journal of the Royal Society Interface, 7:873-885, 2010.

[16] K. Dietz. The estimation of the basic reproduction number for infectious diseases. Statistical methods in medical research, 2(1):23-41, 1993.

[17] R. Donnelly, A. Best, A. White, and M. Boots. Seasonality selects for more acutely virulent parasites when virulence is density dependent. Proceedings of the Royal Society B: Biological Sciences, 280, 2013.

[18] D. J. D. Earn. A light introduction to modelling recurrent epidemics. In Mathematical epidemiology, pages 3-17. Springer, 2008.

[19] M. Eisenstein. Drug development: Holding out for reinforcements. Nature, 484 (7395):S16-S18, 2012.

[20] S. A. H. Geritz, É. Kisdi, G. Meszéna, and J. A. J. Metz. Adaptive dynamics of speciation: ecological underpinnings. Adaptive speciation. Cambridge University Press, Cambridge, pages 54-75, 2004.

[21] A. L. Gibbs and F. E. Su. On choosing and bounding probability metrics. International statistical review, 70(3):419-435, 2002.

[22] J. K. Hale. Functional differential equations. Springer, 1971.

[23] J. K. Hale. Introduction to functional differential equations, volume 99. Springer Science \& Business Media, 1993.

[24] H. W. Hethcote. The mathematics of infectious diseases. SIAM review, 42(4): 599-653, 2000.

[25] L. Hulden and L. Hulden. Activation of the hypnozoite: a part of plasmodium vivax life cycle and survival. Malaria Journal, 10:90, 2011. 
[26] L. Huldén, L. Huldén, K. Heliövaara, et al. Natural relapses in vivax malaria induced by anopheles mosquitoes. Malar J, 7(1):64, 2008.

[27] H. C. KIM, S. T. CHONG, P. V. Nunn, and T. A. Klein. Seasonal prevalence of mosquitoes collected from light traps in the republic of korea, 2007. Entomological Research, 40(2):136-144, 2010.

[28] K. Koelle, M. Pascual, and M. Yunus. Pathogen adaptation to seasonal forcing and climate change. Proceedings of the Royal Society B: Biological Sciences, 272(1566): 971-977, 2005.

[29] Korea Centers for Disease Control and Prevention. Mathematical modelling on P. vivax malaria transmission and development of its application program. http:// www.cdc.go.kr/CDC/cms/content/68/12268_view.html, 2009. [Online; accessed 08-Jan-2015].

[30] Korea Meteorological Administration. Monthly data of daily mean temperature of Seoul, South Korea. http://www.kma.go.kr/weather/climate/average_world_ monthly.jsp. [Online; accessed 19-April-2015].

[31] T. Krisztin and G. Vas. Large-amplitude periodic solutions for differential equations with delayed monotone positive feedback. Journal of Dynamics and Differential Equations, 23(4):727-790, 2011.

[32] P. H. Lambert. Malaria: past and present. http://www.nobelprize.org/ educational/medicine/malaria/readmore/history.html, 2005. [Online; accessed 11-May-2015].

[33] H.-W. Lee, H. Nishiura, S.-H. Cho, W.-G. Lee, T.-S. In, S.-U. Moon, G. T. Chung, and T.-S. Kim. Factors affecting delayed diagnosis of plasmodium vivax malaria in the republic of korea. Research Journal of Parasitology, 2(1):72-75, 2007.

[34] J. Li, Y. Zhao, and S. Li. Fast and slow dynamics of malaria model with relapse. Mathematical biosciences, 246(1):94-104, 2013.

[35] Y. Lou and X.-Q. Zhao. Threshold dynamics in a time-delayed periodic sis epidemic model. Discrete Contin. Dyn. Syst. Ser. B, 12:169-186, 2009.

[36] A. A. Lover, X. Zhao, Z. Gao, R. J. Coker, and A. R. Cook. The distribution of incubation and relapse times in experimental human infections with the malaria parasite plasmodium vivax. BMC infectious diseases, 14(1):539, 2014.

[37] G. MacDonald. The Epidemiology and Control of Malaria. Oxford Medical Publications. Oxford University Press, 1957. 
[38] S. Mandal, R. R. Sarkar, and S. Sinha. Mathematical models of malaria-a review. Malaria Journal, 10(202), 2011.

[39] R. J. Maude, W. Pontavornpinyo, S. Saralamba, R. Aguas, S. Yeung, A. M. Dondorp, N. P. J. Day, N. J. White, and L. J. White. The last man standing is the most resistant: eliminating artemisinin-resistant malaria in cambodia. Malaria Journal, $8: 31,2009$.

[40] F. McKenzie. Why model malaria? Parasitology Today, 16(12):511-516, 2000.

[41] I. Mueller, M. R. Galinski, J. K. Baird, J. M. Carlton, D. K. Kochar, P. L. Alonso, and H. A. del Portillo. Key gaps in the knowledge of plasmodium vivax, a neglected human malaria parasite. The Lancet infectious diseases, 9(9):555-566, 2009.

[42] C. C. Murdock, J. Foufopoulos, and C. P. Simon. A transmission model for the ecology of an avian blood parasite in a temperate ecosystem. PloS one, 8(9):e76126, 2013.

[43] K. Nah, I. Choi, and Y. Kim. Estimation of the incubation period of p. vivax malaria in korea from 2006 to 2008. J. Korean Data Inf. Sci. Soc., 21:1237-1242, 2010.

[44] K. Nah, Y. Kim, and J. M. Lee. The dilution effect of the domestic animal population on the transmission of p. vivax malaria. Journal of Theoretical Biology, 266: 299-306, 2010.

[45] G. A. Ngwa and W. S. Shu. A mathematical model for endemic malaria with variable human and mosquito populations. Mathematical and Computer Modelling, 32(7):747-763, 2000.

[46] H. Nishiura, H.-W. Lee, S.-H. Cho, W.-G. Lee, T.-S. In, S.-U. Moon, G. T. Chung, and T.-S. Kim. Estimates of short-and long-term incubation periods of plasmodium vivax malaria in the republic of korea. Transactions of the Royal Society of Tropical Medicine and Hygiene, 101(4):338-343, 2007.

[47] S. S. Oh, M. J. Hur, G. S. Joo, S. T. Kim, J. M. Go, Y. H. Kim, W. G. Lee, and E. H. Shin. Malaria vector surveillance in ganghwa-do, a malaria-endemic area in the republic of korea. The Korean journal of parasitology, 48(1):35-41, 2010.

[48] P. Pongsumpun and I.-M. Tang. Mathematical model for the transmission of plasmodium vivax malaria. International Journal of mathematical models and methods in applied sciences, 3:117-121, 2007. 
[49] R. N. Price, E. Tjitra, C. A. Guerra, S. Yeung, N. J. White, and N. M. Anstey. Vivax malaria: neglected and not benign. The American journal of tropical medicine and hygiene, 77(6 Suppl):79-87, 2007.

[50] M. Prudêncio, A. Rodriguez, and M. M. Mota. The silent path to thousands of merozoites: the plasmodium liver stage. Nature Reviews Microbiology, 4(11):849856,2006 .

[51] R. Qesmi and J. Wu. Periodic systems of delay differential equations, preprint.

[52] B. A. Rahimi, A. Thakkinstian, N. J. White, C. Sirivichayakul, A. M. Dondorp, and W. Chokejindachai. Severe vivax malaria: a systematic review and meta-analysis of clinical studies since 1900. Malaria journal, 13(1):481, 2014.

[53] H. I. Ree. Studies on anopheles sinensis, the vector species of vivax malaria in korea. The Korean Journal of Parasitology, 43:75-92, 2005.

[54] M. Rees. Evolutionary ecology of seed dormancy and seed size. Philosophical Transactions of the Royal Society B: Biological Sciences, 351(1345):1299-1308, 1996.

[55] Roll Back Malaria. The global malaria action plan. Roll Back Malaria partnership, 2008.

[56] R. Ross. Some quantitative studies in epidemiology. Nature, 87:466-467, 1911.

[57] G. Röst. Neimark-Sacker bifurcation for periodic delay differential equations. Nonlinear Analysis: Theory, Methods \& Applications, 60(6):1025-1044, 2005.

[58] G. Röst. Bifurcation of the time-one maps of delay differential equations at points of resonance. Funct. Differ. Eq., 13:585-602, 2006.

[59] G. Röst and Z. Vizi. Backward bifurcation for pulse vaccination. Nonlinear Analysis: Hybrid Systems, 14:99-113, 2014.

[60] S. Ruan, D. Xiao, and J. C. Beier. On the delayed ross-macdonald model for malaria transmission. Bull. Math. Biol., 70:1098-1114, 2008.

[61] K. E. Rudolph, J. Lessler, R. M. Moloney, B. Kmush, and D. A. T. Cummings. Incubation periods of mosquito-borne viral infections: a systematic review. The American journal of tropical medicine and hygiene, 90(5):882-891, 2014.

[62] G. A. Schad, A. B. Chowdhury, C. G. Dean, V. K. Kochar, T. A. Nawalinski, J. Thomas, and J. A. Tonascia. Arrested development in human hookworm infections: an adaptation to a seasonally unfavorable external environment. Science, 180(4085):502-504, 1973. 
[63] F. Sharpe and A. J. Lotka. Contribution to the analysis of malaria epidemiology. iv. incubation lag. In The Golden Age of Theoretical Ecology: 1923-1940, pages 348-368. Springer, 1978.

[64] D. L. Smith, K. E. Battle, S. I. Hay, C. M. Barker, T. W. Scott, and F. E. McKenzie. Ross, macdonald, and a theory for the dynamics and control of mosquitotransmitted pathogens. PLoS pathogens, 8(4):e1002588, 2012.

[65] H. L. Smith. An introduction to delay differential equations with applications to the life sciences. Springer New York, 2011.

[66] H. L. Smith and H. R. Thieme. Dynamical systems and population persistence, volume 118. American Mathematical Soc., 2011.

[67] Z. Szénási, A. Vass, M. Melles, I. Kucsera, J. Danka, A. Csohán, and K. Krisztalovics. Malaria in hungary: origin, current state and principles of prevention. Orvosi hetilap, 144(21):1011-1018, 2003.

[68] N. A. Tiburskaja and O. S. Vrublevskaja. The course of infection caused by the north korean strain of plasmodium vivax. WHO MAL., 895:1-19, 1977.

[69] P. Van den Driessche and J. Watmough. Reproduction numbers and sub-threshold endemic equilibria for compartmental models of disease transmission. Mathematical biosciences, 180(1):29-48, 2002.

[70] W. Wang and X.-Q. Zhao. Threshold dynamics for compartmental epidemic models in periodic environments. Journal of Dynamics and Differential Equations, 20(3): 699-717, 2008.

[71] C. L. Wesley and L. J. Allen. The basic reproduction number in epidemic models with periodic demographics. Journal of biological dynamics, 3(2-3):116-129, 2009.

[72] N. J. White. Determinants of relapse periodicity in plasmodium vivax malaria. Malaria journal, 10(1):297, 2011.

[73] A. W. Woodruff and S. G. Wright. A synopsis of infectious and tropical diseases. Butterworth-Heinemann, 2013.

[74] World Health Organization. World malaria report 2012. 2012.

[75] X. Wu, V. R. Duvvuri, Y. Lou, N. H. Ogden, Y. Pelcat, and J. Wu. Developing a temperature-driven map of the basic reproductive number of the emerging tick vector of lyme disease ixodes scapularis in canada. Journal of theoretical biology, 319:50-61, 2013. 
[76] Y. Xiao and X. Zou. On latencies in malaria infections and their impact on the disease dynamics. Math. Biosci. Eng., 10:463-481, 2013.

[77] D. Xu and X.-Q. Zhao. Dynamics in a periodic competitive model with stage structure. Journal of mathematical analysis and applications, 311(2):417-438, 2005. 